\title{
TOPAZ - The Transient One- Dimensional Pipe Flow Analyzer: Code Validation and Sample Problems
}

W. S. Winters

\section{Prepared by}

Sandia National Laboratories

Albuquerque. New Mexico 87185 and Livermore, California 94550

for the United States Department of Energy

under Contract DE-AC04-76DP00789 


\section{DISCLAIMER}

This report was prepared as an account of work sponsored by an agency of the United States Government. Neither the United States Government nor any agency Thereof, nor any of their employees, makes any warranty, express or implied, or assumes any legal liability or responsibility for the accuracy, completeness, or usefulness of any information, apparatus, product, or process disclosed, or represents that its use would not infringe privately owned rights. Reference herein to any specific commercial product, process, or service by trade name, trademark, manufacturer, or otherwise does not necessarily constitute or imply its endorsement, recommendation, or favoring by the United States Government or any agency thereof. The views and opinions of authors expressed herein do not necessarily state or reflect those of the United States Government or any agency thereof. 


\section{DISCLAIMER}

Portions of this document may be illegible in electronic image products. Images are produced from the best available original document. 

UC-32

SAND85-8236

Unlimited Release

Printed October 1985

\section{TOPAZ - The Transient One-Dimensional Pipe Flow Analyzer: \\ Code Validation and Sample Problems}

\section{W. S. Winters}

Computational Mechanics Division

Sandia National Laboratories, Livermore

Manuscript Completed March 14, 1985
SAND- $-85-8236$

DE86 002143

\section{ABSTRACT}

TOPAZ is a "user friendly" computer code for modeling the one-dimensional-transient physics of multi-species gas transfer in arbitrary arrangements of pipes, valves, vessels, and flow branches. This document presents a series of sample problems designed to aid potential users in creating TOPAZ input files. To the extent possible, sample problems were selected for which analytical solutions currently exist. TOPAZ comparisons with such solutions are intended to provide a measure of code validation.

\section{DISCLAIMER}

This report was prepared as an account of work sponsored by an agency of the United States . employees, makes any warranty, States Government nor any agency thereof, nor any of their bility for the accuracy, completeness, or implied, or assumes any legal liability or responsiprocess disclosed, or represents that its usefulness of any information, apparatus, product, or ence herein to any specific commert its use would not infringe privately owned rights. Refermanufacturer, or otherwise doescial product, process, or service by trade name, trademark, mendation, or favoring by the not necessarily constitute or imply its endorsement, recomand opinions of authors expressed herein Government or any agency thereof. The views United States Government or any agency therof nocessarily state or reflect those of the 



\section{CONTENTS}

I INTRODUCTION

II EXAMPLE 1 - ISENTROPIC TRANSFER BETWEEN TWO VESSELS

III EXAMPLE 2 - ISENTROPIC BLOWDOWN OF A VESSEL

IV EXAMPLE 3 - ISENTROPIC BLOWDOWN OF A VESSEL WITH ACCOUSTIC WAVES

V EXAMPLE 4 - SIMULATION OF A SHOCK TUBE

VI EXAMPLE 5 - SIMULATION OF A STEADY STATE FANNO PIPE FLOW

VII EXAMPLE 6 - SIMPLE PISTON MOTION

VIII EXAMPLE 7 - GAS TRANSFER IN A SYSTEM HAVING A FLOW BRANCH

IX EXAMPLE 8 - PREDICTING PRESSURE TRANSDUCER RESPONSE

X EXAMPLE 9 - CALCULATION WITH A BLADDER AND USER SPECIFIED FORM LOSSES

XI CONCLUDING REMARKS

XII REFERENCES 
,

,

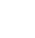
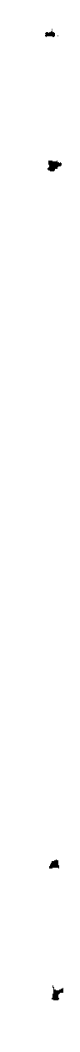

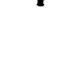

$\therefore$ 


\section{NOMENCLATURE}

\begin{tabular}{ll} 
Symbol & Description \\
$A$ & Area \\
$b_{1}$ & Artificial damping factor in equation 3 \\
$C$ & Sound speed \\
$D$ & Diameter \\
$f$ & Moody or Darcy friction factor \\
$K$ & Form loss coefficient \\
$L$ & Length \\
$\dot{m}$ & Mass flow rate \\
$M$ & Mach number \\
$P$ & Pressure \\
$q$ & Pressure reduction due to artificial viscosity, equation 3 \\
$t$ & Time \\
$\bar{t}$ & Dimensionless time \\
$v$ & Velocity \\
$V$ & Volume \\
\hline & Spacial coordinate \\
\hline
\end{tabular}


Greek Symbols

\section{$\Delta X$}

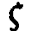

$\gamma$

$\rho$

$\sigma$

$\omega_{n}$

$\boldsymbol{u}$

0

The length of a fluid control volume, spacial discretization for the finite differencing

Damping factor defined by equation 9

Ratio of specific heats

Density

Area ratio defined by equation 1

Natural frequency

Subscripts

Downstream

Upstream

Initial value 


\section{LIST OF TABLES}

$\begin{array}{llr} & & \text { Page } \\ \text { Table 1. } & \text { The CHAMBER Directive and Associated Minor Directives } & 17 \\ \text { Table 2. } & \text { The PIPE Directive and Associated Minor Directives } & 18 \\ \text { Table 3. } & \text { The JOINT Directive and Associated Minor Directives } & 19 \\ \text { Table 4. } & \text { The PISTON Directive and Associated Minor Directives } & 20 \\ \text { Table 5. } & \text { The REGION Directive and Associated Minor Directives } & 21 \\ \text { Table 6. } & \text { The EXECUTION Directive and Associated Minor Directives } & 22 \\ \text { Table 7. } & \text { The EDIT Directive and Associated Minor Directives } \\ \text { Table 8. } & \text { Six Test Cases for Example Problem 1 } & 23 / 24 \\ \text { Table 9. } & \text { Comparison of Unchoking Times for Example Problem } 1 & 27\end{array}$




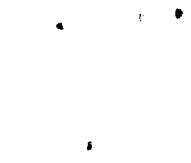




\section{LIST OF FIGURES}

\section{Page}

1a. Schematic for Example 1 26

1b. Mesh generation diagram for Example 1 26

2. TOPAZ input file for Example $1 \quad 28$

3. Pressure histories for varying initial pressure ratios (adiabatic vessels, $V_{2} / V_{1}=1$ )

4. Pressure histories for varying initial pressure ratios (isothermal vessels, $V_{2} / V_{1}=1$ )

5. Pressure histories for varying volume ratios (adiabatic vessels, $P_{2} / P_{1}=.1$ )

6. Pressure histories for varying volume ratios (isothermal vessels, $P_{2} / P_{1}=.1$ )

7a. Schematic for Example 2

7b. Mesh generation diagram for Example 2 37

8. TOPAZ input file for Example $2 \quad 38$

9. Vessel blowdown transient for $\sigma=10 \quad 40$

10. Vessel blowdown transient for $\sigma=4.4968$

11. Vessel blowdown transient for $\sigma=2.0351$

12a. Schematic for Example $3 \quad \mathbf{4 4}$

12b. Mesh generation diagram for Example 3

13. TOPAZ input file for Example 3

14. Comparison of averaged and distributed blowdown pressure transients for $\sigma=10$

15. Comparison of averaged and distributed blowdown pressure transients for $\sigma=\mathbf{4 . 4 9 6 8}$

16. Comparison of averaged and distributed blowdown pressure transients for $\sigma=\mathbf{2 . 0 3 5 1}$

17a. Opened end pressure history for $\sigma=4.4968$

17b. Closed end pressure history for $\sigma=4.4968$ 
18a. Opened end pressure history for $\sigma=2.0351$

18b. Closed end pressure history for $\sigma=2.0351$

19a. Schematic for Example 4

19b. Mesh generation diagram for Example 4

20. TOPAZ input file for Example 4

21a. Shock tube pressure distribution for DAMP $=0 \quad 58$

21b. Shock tube velocity distribution for $D A M P=0$

22a. Shock tube pressure distribution for $\mathrm{DAMP}=2$

$59 / 60$

22b. Shock tube velocity distribution for $\mathrm{DAMP}=2$

23a. Schematic for Example 5

23b. Mesh generation diagram for Example 5

24. TOPAZ input file for Example 5A

25. TOPAZ input file for Example 5B

26. Inlet Mach number vs. dimensionless flow resistance for a steady Fanno flow

27a. Schematic for Example 6

27b. Mesh generation diagram for Example 6

28. TOPAZ input file for Example 6A

29. Underdamped free piston motion $\quad 72$

30. Critically damped free piston motion 73

31. Overdamped free piston motion $\quad 74$

32. The effect of positioning the downstream mechanical stop (XMDN) on underdamped piston motion

33. The effect of Coulomb friction (FCOU) on underdamped piston motion

34. Upstream and downstream pressure histories for critically damped piston motion

35. Influence of gas pressures on underdamped piston motion

36a. Schematic for Example 7

36b. Mesh generation diagram for Example 7

37. TOPAZ input file for Example 7

38. Reservoir and receiver pressure histories

39. Hydrogen, deuterium, and helium inventory in the receiver 
$\begin{array}{lll}\text { - 40a. } & \text { Schematic for Example } 8 & 91\end{array}$

40b. Mesh generation diagram for Example $8 \quad 91$

41. TOPAZ input file for Example $8 \quad 92$

42. Comparison of line pressure and transducer pressure 93

43. Pressure transducer response for various orifice diameters 95/96

44a. Schematic for Example $9 \quad 98$

44b. Mesh generation diagram for Example $9 \quad 98$

45. TOPAZ input file for Example $9 \quad 101$

46. Pressure histories for Example $9 \quad 103$

47. Bladder displacement for Example 9

48. Flow component Mach number vs. time 105

49. Flow component static pressure difference vs. velocity head term

106 



\section{INTRODUCTION}

This report is one in a series of reports documenting the computer code TOPAZ. TOPAZ is an acronym for $(\mathrm{T})$ ransient- $(\mathrm{O})$ ne-dimensional $(\mathrm{P})$ ipe flow $(\mathrm{A})$ naly $(\mathrm{Z})$ er. The code was developed by the present author for the purpose of modeling the physics of onedimensional-transient compressible flow through complex and arbitrary arrangements of pipes, valves, vessels, and flow branches. The code is intended to be "user friendly" so that nearly anyone can make complex gas transfer calculations with little or no knowledge of compressible flow, finite differences, and implicit numerical methods.

The purpose of this document is threefold:

1. To present a series of example problems designed to aid potential users in creating TOPAZ input files.

2. To compare available analytical solutions to TOPAZ predictions thereby providing a measure of code validation.

3. To demonstrate the wide variety of problems that can be analyzed using TOPAZ.

In order to fully benefit from the first objective, it is assumed that the reader is somewhat familiar with TOPAZ modeling discussed in references [1] through [4]. More important, it is assumed the reader is familiar with the TOPAZ Users Manual [5] and thus has some knowledge of how TOPAZ major and minor directives are used to construct the TOPAZ input file. All of the TOPAZ major and minor input directives were summarized in the form of seven Tables in the User's Manual [5]. For the convenience of the reader these same tables are reproduced here as Tables 1 through 7 .

The example problems selected for this report were designed to demonstrate the use of each and every TOPAZ directive including those used to couple gas transfer flow calculations to calculations involving the motion of pistons, diaphragms and bladders. Wherever possible, example problems were selected which have analytical solutions. Unfortunately few analytical solutions exist for the kind of "real" gas transfer situations of interest to most users. Hence, many of the example problems presented here are for highly idealized flows, i.e., adiabatic, isothermal, and isentropic flows of ideal gases.

The "typical" gas transfer problem of interest to most TOPAZ users usually involves predicting time dependent vessel properties for the nearly quasi-steady compressible flow of gases through closed networks. The time scales of interest are generally on the order of the times required to achieve pressure equilibrium in the network. Several of the sample problems presented in this report deal with this kind of gas transfer problem. However, this 
report also includes example problems designed to demonstrate the code's ability to model' events having acoustic time scales (e.g. modeling of shock and rarefaction waves, predicting the response time for pressure transducers, etc.). Example problems are also included to show how one might model a completely steady state compressible flow through a piping network. Finally, several example problems are presented which demonstrate TOPAZ modeling of piston and diaphragm motion.

A few words are appropriate regarding the organization of this report. Each of the subsequent sections deals with a particular example problem having one or more parts. A brief introduction is given followed by the problem statement and a discussion of the problem. A schematic drawing and the corresponding TOPAZ mesh generation diagram for each example problem are also presented. The mesh generation diagram is a simple sketch in which vessels (CHAMBERs) are represent by large open circles, constant diameter flow paths (PIPEs) are represented by lines, and connections between vessels and flow paths (JOINTs) are represented by solid dots (see e.g. reference 5). The assumed directions for positive flow are shown as arrows along the flow paths. Also shown is the component numbering. The mesh generation diagram is a valuable aid in constructing and interpreting the TOPAZ input file.

Each of the following sections also includes a copy of the TOPAZ input file required to solve the example problem. The form of the directives used in each input file are generally longer than the minimum required four letters. In addition, a number of comments are inserted in parenthesis for most directives. The comments and long directive forms are used to aid in the interpretation of the input file. Hence, the following directive used to assign a component number to a CHAMBER:

\section{$\mathrm{CHAM}=3$}

might be represented here in the input file as:

\section{CHAMBER (third supply reservoir) $=3$}

As pointed out in the TOPAZ Users Manual [5] these more descriptive directives do not influence the processing of input data. Each of the TOPAZ input files shown in this report may be used as-is to directly reproduce the solution for the example problems. Total computational time on the CTSS system at SNLL for each example is less than 5 minutes, with most run times being less than 1 minute. Readers are reminded that the input files shown here reflect only one way to solve the problems. Other component numbering schemes are almost always possible.

The TOPAZ-generated output file for each example problem will not be presented here. Instead, the TOPAZ predictions are presented in plotted form for discussion purposes. When appropriate the TOPAZ predictions are compared to the analytical solutions. 
Table 1. The CHAMBER Directive and Associated Minor Directives

\begin{tabular}{|c|c|c|}
\hline DIRECTIVE & DESCR I PTION & DEFAULT \\
\hline CHAM & $\begin{array}{l}\text { Major directive which assigns a unique component } \\
\text { number to a particular CHAMBER. }\end{array}$ & none \\
\hline DIAM & CHAMBER diameter. (m) & none \\
\hline VOLU & $\begin{array}{l}\text { CHAMBER volume. The user may find it more convenient } \\
\text { to substitute this directive in place of the DIAM } \\
\text { directive. The code will then calculate the approp- } \\
\text { riate value of DIAM based on the input value for } \\
\text { VOLU (and if appropriate LENG). Either DIAM or VOLU } \\
\text { must be supplied for each CHAMBER. (m3) }\end{array}$ & none \\
\hline LENG & $\begin{array}{l}\text { CHAMBER length. When } L E N G=0 \text {, the chamber is assumed } \\
\text { to be spherical in shape with a diameter of DIAM. } \\
\text { When a non zero value is used, the chamber takes on } \\
\text { the shape of a cylinder having a length and diameter } \\
\text { of LENG and DIAM respectively. (m) }\end{array}$ & 0 \\
\hline HFLA & $\begin{array}{l}\text { CHAMBER heat transfer coefficient flag used to model } \\
\text { the heat exchange between the chamber walls and the } \\
\text { resident gas mixture. } \\
\text { HFLA }=1 \text { Adiabatic case, } h=0 \text {. } \\
\text { HFLA }=2 \text { Isothermal case, } h=\text { infinite. } \\
\text { HFLA }=3 \text { Pipe flow forced convection, } h=f(R e, P r) \text {. } \\
\text { HFLA }=4 \text { Vessel free convection, } h=f(R a) \text {. }\end{array}$ & 4 \\
\hline GENE & $\begin{array}{l}\text { Mass generation rate within CHAMBER. Mass is gener- } \\
\text { ated only for the time perion between GSTA and GSTO. } \\
(\mathrm{kg} / \mathrm{s})\end{array}$ & 0. \\
\hline GSTA & Time when mass generation (GENE) initiates. (s) & infinite \\
\hline GSTO & Time when mass generation (GENE) terminates. ( $s$ ) & 0 . \\
\hline INIT & $\begin{array}{l}\text { CHAMBER initial conditions flag used to identify the } \\
\text { REGION number in which the CHAMBER resides. }\end{array}$ & none \\
\hline
\end{tabular}


Table 2. The PIPE Directive and Associated Minor Directives

\begin{tabular}{|c|c|c|}
\hline DIRECTIVE & DESCRIPTION & DEFAULT \\
\hline PIPE & $\begin{array}{l}\text { Major directive which assigns a unique component } \\
\text { number to a particular pipe. }\end{array}$ & none \\
\hline DIAM & PIPE diameter. (m) & none \\
\hline LENG & PIPE length. (m) & none \\
\hline HFLA & $\begin{array}{l}\text { PIPE heat transfer coefficient flag used to model } \\
\text { the heat exchange between the pipe walls and the } \\
\text { resident gas mixture. } \\
\text { HFLA=1 Adiabatic case, } h=0 \text {. } \\
\text { HFLA }=2 \text { Isothermal case, } h=\text { infinite. } \\
\text { HFLA }=3 \text { Pipe flow forced convection, } h=f(R e, P r) \text {. }\end{array}$ & 3 \\
\hline FFLA & $\begin{array}{l}\text { PIPE friction factor flag used to model pipe wall } \\
\text { frictional effects on the flowing resident gas mixture. } \\
\text { FFLA=1 User specified constant Darcy friction factor } \\
\text { will be used, f=FDAT. } \\
\text { FFLA=2 Moody friction factor model where Darcy } \\
\text { friction factor is a function of the local } \\
\text { Re and tube wall relative roughness, } \\
\text { f=f(Re,FDAT). }\end{array}$ & 2 \\
\hline FDAT & $\begin{array}{l}\text { PIPE friction data. } \\
\text { FDAT }=\text { User specified constant Darcy f (for FFLA=1). } \\
\text { FDAT = User specified global pipe wall roughness ratio } \\
\text { (roughness height/diameter) used in the Moody } \\
\text { friction factor computation (for FFLA=2). }\end{array}$ & 0 . \\
\hline NUMB & Number of CEs to be used in representing the PIPE. & none \\
\hline INIT & $\begin{array}{l}\text { PIPE initial conditions flag used to identify the } \\
\text { REGION number in which the PIPE resides. }\end{array}$ & none \\
\hline
\end{tabular}


Table 3. The JOINT Directive and Associated minor directives

\begin{tabular}{|c|c|c|}
\hline DIRECTIVE & DESCRIPTION & DEFAULT \\
\hline JOIN & Major directive assigning component number to JOINT. & none \\
\hline UPST & $\begin{array}{l}\text { Flag identifying the number of the component } \\
\text { (i.e. PIPE or CHAMBER) located upstream of the JOINT. } \\
\text { The UPST and DOWN directives establish the sign COn- } \\
\text { vention for positive flow (upstream to downstream). }\end{array}$ & none \\
\hline DOWN & $\begin{array}{l}\text { Flag identifying the number of the component } \\
\text { (i.e. PIPE or CHAMBER) located downstream of JOINT. }\end{array}$ & none \\
\hline DIAM & $\begin{array}{l}\text { Diameter of the JOINT flow path. When this directive } \\
\text { is not used, the upstream or downstream component } \\
\text { diameter will be assumed depending on which is the } \\
\text { smallest (minimum). (m) }\end{array}$ & minimum \\
\hline KFLA & $\begin{array}{l}\text { JOINT form loss flag used to model flow losses. } \\
\text { KFLA=1 User constants for forward/reverse flow. } \\
\text { KFLA }=2 \text { User specified formula. Consult Author. } \\
\text { KFLA=3 Approximates isentropic flow. (no losses) }\end{array}$ & 1 \\
\hline FLOS & $\begin{array}{l}\text { User specified form loss constant for forward flow } \\
\text { (i.e. upstream to downstream). Used when KFLA }=1 \text {. }\end{array}$ & 0 . \\
\hline RLOS & $\begin{array}{l}\text { User specified form loss constant for reverse flow } \\
\text { (i.e. downstream to upstream). Used when KFLA=1. }\end{array}$ & 0 . \\
\hline TOPE & $\begin{array}{l}\text { Time at which JOINT opens. When this directive is } \\
\text { used the JOINT becomes a valve having a time depen- } \\
\text { dent flow area. The valve is closed at time }=0 \text { and } \\
\text { starts to open at time=TOPE. ( } \mathrm{s} \text { ) }\end{array}$ & infinite \\
\hline DTOP & $\begin{array}{l}\text { Time required to open a closed JOINT. The flow area } \\
\text { increase is approximately linear with time. (s) }\end{array}$ & infinite \\
\hline TCLO & $\begin{array}{l}\text { Time at which JOINT closes. When this directive is } \\
\text { used the JOINT becomes a valve having a time depen- } \\
\text { dent flow area. The valve is open at time }=0 \text { and } \\
\text { then begins to close at time }=\text { TCLO. If both the TOPE and } \\
\text { TCLO directives are specified for a JOINT, it becomes } \\
\text { a valve that is closed at time }=0 \text {, starts to open at time= } \\
\text { TOPE, and starts to close at time }=\text { TCLO. When both TOPE an } \\
\text { TCLO are specified, TOPE+DTOP must be iess than TCLO. (s) }\end{array}$ & infinite \\
\hline DTCL & $\begin{array}{l}\text { Time required to close an open JOINT. The flow area } \\
\text { decrease is approximately linear with time. (s) }\end{array}$ & infinite \\
\hline
\end{tabular}


Table 4. The PISTON Directive and Associated Minor Directives.

\begin{tabular}{|c|c|c|}
\hline DIRECTIVE & DESCRIPTION & DEFAULT \\
\hline PIST & $\begin{array}{l}\text { Major directive which assigns a unique component } \\
\text { number to a particular PISTON. }\end{array}$ & none \\
\hline UPST & $\begin{array}{l}\text { Flag identifying the CHAMBER number located on the } \\
\text { assumed high pressure side of the PISTON. The UPST } \\
\text { and DOWN directives establish the sign convention for } \\
\text { piston motion. POsitive displacement and velocities } \\
\text { imply PISTON movement from the upstream direction to } \\
\text { the downstream direction. }\end{array}$ & none \\
\hline DOWN & $\begin{array}{l}\text { Flag identifying the CHAMBER number located on the } \\
\text { assumed downstream side of the PISTON. }\end{array}$ & none \\
\hline XMUP & $\begin{array}{l}\text { The maximum allowable travel distance in the upstream } \\
\text { direction, i.e. position of a mechanical stop. }(\mathrm{m})\end{array}$ & 0. \\
\hline XMDN & $\begin{array}{l}\text { The maximum allowable travel distance in the downstream } \\
\text { direction, i.e. position of a mechanical stop. }(\mathrm{m})\end{array}$ & 0. \\
\hline FBRE & $\begin{array}{l}\text { Breakaway force, i.e. force which must be overcome } \\
\text { prior to the initial piston movement. (N) }\end{array}$ & 0 . \\
\hline XKZE & $\begin{array}{l}\text { The value of } x \text { (PISTON displacement cooridinate) where } \\
\text { the PISTON spring force is zero. }(\mathrm{m})\end{array}$ & 0 . \\
\hline MASS & PISTON mass. $(\mathrm{kg})$ & 0. \\
\hline CVIS & PISTON viscous damping factor. $(\mathrm{N}-\mathrm{s} / \mathrm{m})$ & 0 . \\
\hline KSPR & PISTON spring constant. $(\mathrm{N} / \mathrm{m})$ & 0. \\
\hline AREA & PISTON cross-sectional area. (m2) & 0. \\
\hline AFAC & PISTON cross-sectional area multiplier. & 1. \\
\hline FCOU & PISTON coulomb friction force. (N) & 0. \\
\hline FORC & Applied constant force. (N) & 0. \\
\hline FSTA & Time when constant force (FORC) in applied. (s) & infinite \\
\hline FSTO & Time when constant force (FORC) is removed. (s) & 0 . \\
\hline
\end{tabular}

Note: TOPAZ assigns 0 velocity and 0 position for PISTON initial conditions. 
Table 5. The REGION Directive and Associated Minor Directives.

DIRECTIVE DESCRIPTION
particular REGION.

TEMP Intial temperature for gas occupying the REGION. (K) 295.

TWAL Hall temperature for all components in the REGION. 295. The wall temperature remains constant with time. ( $K$

MIXT Flag that identifies which equation of state and Currently the following options are available:

MIXT=1 Ideal gas (Daiton) model for the five species mixture of $\mathrm{H} 2,02, \mathrm{~T} 2, \mathrm{HE} 3, \mathrm{HE} 4$. Constant ambient temperature transport properties.

MIXT=2 Abel-Nobel real gas model for the five species mixture of $\mathrm{H2}, \mathrm{D2}, \mathrm{T2}, \mathrm{HE3}, \mathrm{HE} 4$. Variable transport properttes.

MIXT=3 Clark-Ashurst model for the five species mixture of $\mathrm{H2}, 02, \mathrm{T2}, \mathrm{HE} 3, \mathrm{HE} 4$. Variable transport properties. Thts model is useful when using TOPAZ to produce "fillup" calculations but is not recommended for time integrations, 1.e. transient modeling.

MIXT=4 Abel-Nobel real gas model for the five spectes mixture of $\mathrm{H} 2,02, \mathrm{~T} 2, \mathrm{HE} 3, \mathrm{HE} 4$. Constant ambient temperature transport properties. This is a good choice for "debugging" runs.

Pressure of gas mixture occupying the REGION. User may choose to specify the mixture molar density instead of the pressure but one of these two minor directives must be present for all REGIONs. If both (or neither) are present, the processing of input data will terminate with an appropriate message. (Pa)

Molar density of all gas occupying the REGION. The user may choose to specify the pressure instead of the molar density but one of these two minor directIves must be present for all REGIONs. If both (or neither) are present, processing of input data will terminate with an appropriate message. (kg-mol/m3)

Inftial mole fraction for first species of gas in mixture (e.g. mole fraction of $H 2$ when $M I X T=1,2,3$,or 4). If this directive is not present the first species will not be included in the computations. The GASI should not appear in the input file when it is known that it is impossible for species 1 to ever occupy any portion of the REGION. Not including a gas species in the calculations results in a substantial decrease in computational time. If the REGION is inttially void of species 1 but it is physfcally possible for this specles to occupy any portion of the REGION at a later time, then the correct form of this directive is GASI=.0

GAS2 Initial mole fraction for the second spectes of gas in the gas mixture. The explanation for the GASI directive aiso appites to this directive.

GAS3 Inttial mole fraction for the third spectes of gas in the gas mixture. The explanation for the GASI directive aiso applies to this directive.

GAS4 Initial mole fraction for the forth species of gas in the gas mixture. The explanation for the GASI directive also applies to this directive. 
Table 6. The EXECUTION Directive and Associated Minor Directives.

DIRECTIVE DESCRIPTION

DEFAULT

EXEC

Major directive which determines the extent of TOPAZ

none

execution.

EXEC $=0$ Read and process data, generate mesh, print mesh generation tables if appropriate, print initial conditions, then terminate without performing time integrations.

EXEC $=1$ Same as EXEC=0 except the time integrations are performed.

LIST Directive which permits printing of special listings 1 in addition to those generated in output from time integrations.

LIST $=0$ No additional listings

LIST $=1$ User/TOPAZ mesh generation information

LIST $=2$ Input Dump+User/TOPAZ mesh in fo

LIST $=3$ TOPAZ Dump+Input Dump+User/TOPAZ Mesh info

Options 2 and 3 are not useful to most users.

TSTO Time when time integrations will stop. (s) 0 .

DTMA Time frequency for producing Major Edits. Major Edits 1.E30 are printouts of variables at each and every $C E, M$ and PISTON element. Pressures are printed at each CE, velocities are printed at each $M$ and piston position is printed at each PISTON element. DTMA should be an integer multiple of DTMI. (s)

DTMI Time frequency for producing Minor Edits. Minor Edits are printouts of up to six variables, the identity of which is determined by the EDIT directives. See Table 6 for a discussion of Minor Edits. (s)

ATOL Absolute integrator error tolorance. See Reference (4). 1.E-3

RTOL Relative integrator error tolorance. See Reference (4). 1.E-3

DAMP Finite difference artificial viscosity factor, useful 0. in resolving steep shocks. See Reference (6). 
Table 7. The EDIT Directive and Associated Minor directives.

to be included in the minor edits. Minor edit variplot post processing file.

EFLA EFLA directives must be supplied if EDIT is non zero none The EFLA directive takes the form "EFLA $i, j$ " where $i$ and $j$ are free format numbers which will be truncated to integers. There must be one EFLA directive for each variable printed during minor edits. The $i$ entry identifies the element (CE, M, or PISTON) to be edited. In some cases the User/TOPAZ mesh generation will be required to determine the numbering of CES and Ms. This is particularly true when EDIT elements are CEs and Ms which lie in PIPEs. For JOINTs, CHAMBERs, and PISTONs the component and the element numbers are identical.

For $C E$ and $M$ elements the $j$ entry identifies which of 15 element variables will be printed during the minor edit:

$j=1$ Temperature, edit symbol $T$

$j=2$ Pressure, edit symbol $P$

$j=3$ Internal energy per unit mass, edit symbol $U$

$j=4$ Mass density, edit symbol $R$

$j=5$ Mass of species 1 , edit symbol M1

$j=6$ Mass of species 2, edit symbol M2

$j=7$ Mass of species 3 , edit symbol M3

$j=8$ Mass of species 4 , edit symbol $M 4$

$j=9$ Mass of species 5 , edit symbol M5

$j=10$ Total mass, edit symbol $M$

$j=11$ Mass flow rate, edit symbol $w$

$j=12$ Velocity, edit symbol $V$

$j=13$ Volume, edit symbol VL

$j=14$ Sonic Velocity, edit symbol VS

$j=15$ Mach number, edit symbol MA

For PISTON elements (or components) the $j$ entry identifies which of three element variables will be printed during the minor edit:

$j=1$ Piston position, edit symbol $x$

$j=2$ Piston velocity, edit symbol $V$

$j=2$ Piston kinetic energy, edit symbol KE 
- 


\section{EXAMPLE 1 - ISENTROPIC TRANSFER BETWEEN TWO VESSELS}

\section{Introduction}

The example TOPAZ problem presented in this section deals with the transfer of an ideal gas from an initially high pressure reservoir to an initially low pressure receiver. Flow through the path connecting the reservoir and receiver is assumed isentropic (i.e., no heat transfer and no pressure losses). The TOPAZ analysis is performed for situations in which both vessels are either adiabatic or isothermal. A range of reservoir and receiver volume ratios and initial pressure ratios are examined.

Calculational results from the TOPAZ analysis are compared to the analytical predictions of Chenoweth [7]. Comparisons of unchoke times and reservoir-receiver pressure histories are included.

\section{Problem Statement}

Use TOPAZ to simulate the transfer of an ideal gas (hydrogen) from an initially high pressure reservoir (chamber 1) to an initially low pressure receiver (chamber 2) via an isentropic flow path. Perform the simulation for the cases $A$ through $F$ listed in Table 8.

\section{Discussion}

A schematic of the plumbing for this problem appears in Figure 1a. A suitable TOPAZ mesh generation diagram for simulating this plumbing appears in Figure 1b. The reservoir is simulated as CHAMBER 1, the receiver as CHAMBER 2, and the interconnecting flow path as PIPE 5. JOINTs 3 and 4 are used to connect the pipe to the CHAMBERs with JOINT 3 acting as a valve which opens at time zero.

For the sake of conciseness, only a copy of the TOPAZ input file required for Case $A$ in Table 8 will be presented and discussed. This input file is shown in Figure 2. The assumed CHAMBER volumes, initial pressure levels and initial temperatures are listed in the file. These values were selected to give the required ratios listed for Case $\mathbf{A}$ in Table 1. At time zero the initially high pressure region (REGION 1 ) is separated from the initially low pressure region (REGION 2) by the valve at JOINT 3. The valve begins opening at time zero and has an opening time of .0001 seconds.

The directives for heat transfer and pressure loss reflect the requirement that the CHAMBERs be adiabatic and the flow path isentropic. Note that only a single continuityenergy element (CE) is used in the PIPE connecting the two CHAMBERs. This is common practice in simulating quasi-steady isentropic flows since there are no spacial variations in 


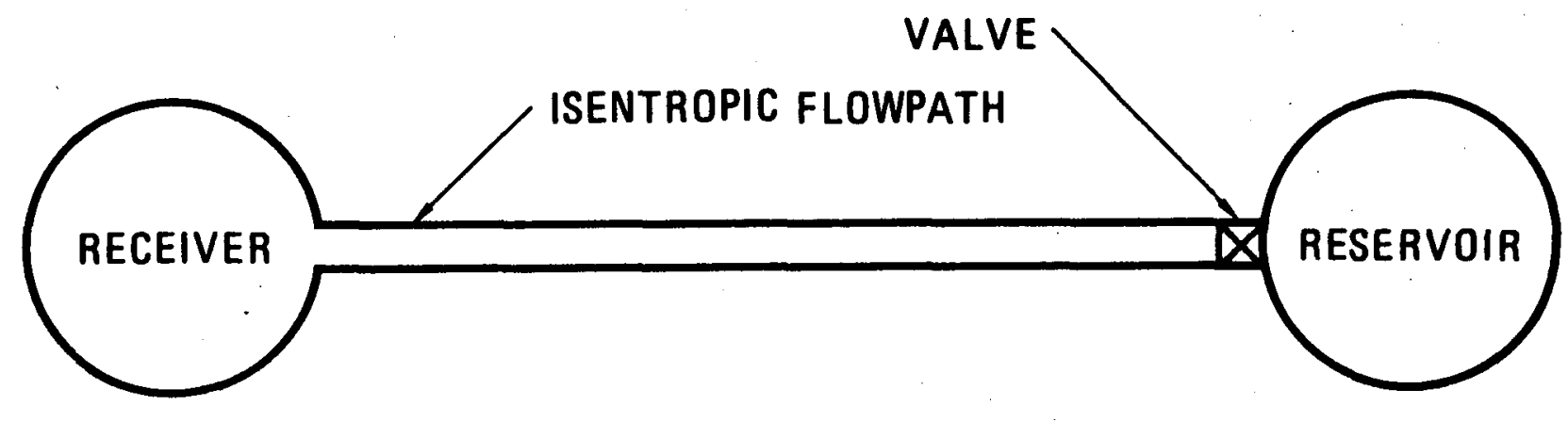

FIGURE 1a. SCHEMATIC FOR EXAMPLE 1

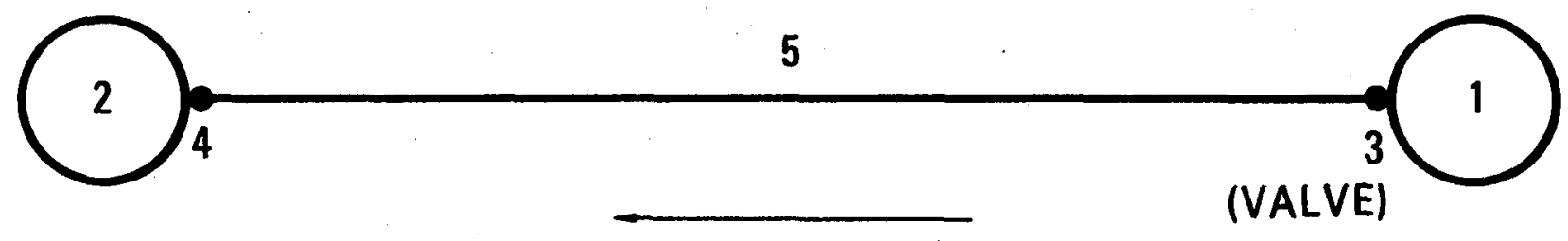

FIGURE 1b. MESH GENERATION DIAGRAM FOR EXAMPLE 1 
Table 8. Six Test Cases for Example Problem 1

\begin{tabular}{llll}
\hline CASE & VESSEL HEAT TRANSFER & V2/V1 & P2(0)/P1(0) \\
\hline A & ADIABATIC & 1.0 & 0.1 \\
B & ISOTHERMAL & 1.0 & 0.1 \\
C & ADIABATIC & 10.0 & 0.1 \\
D & ISOTHERMAL & 10.0 & 0.1 \\
E & ADIABATIC & 1.0 & 0.5 \\
F & ISOTHERMAL & 1.0 & 0.5
\end{tabular}




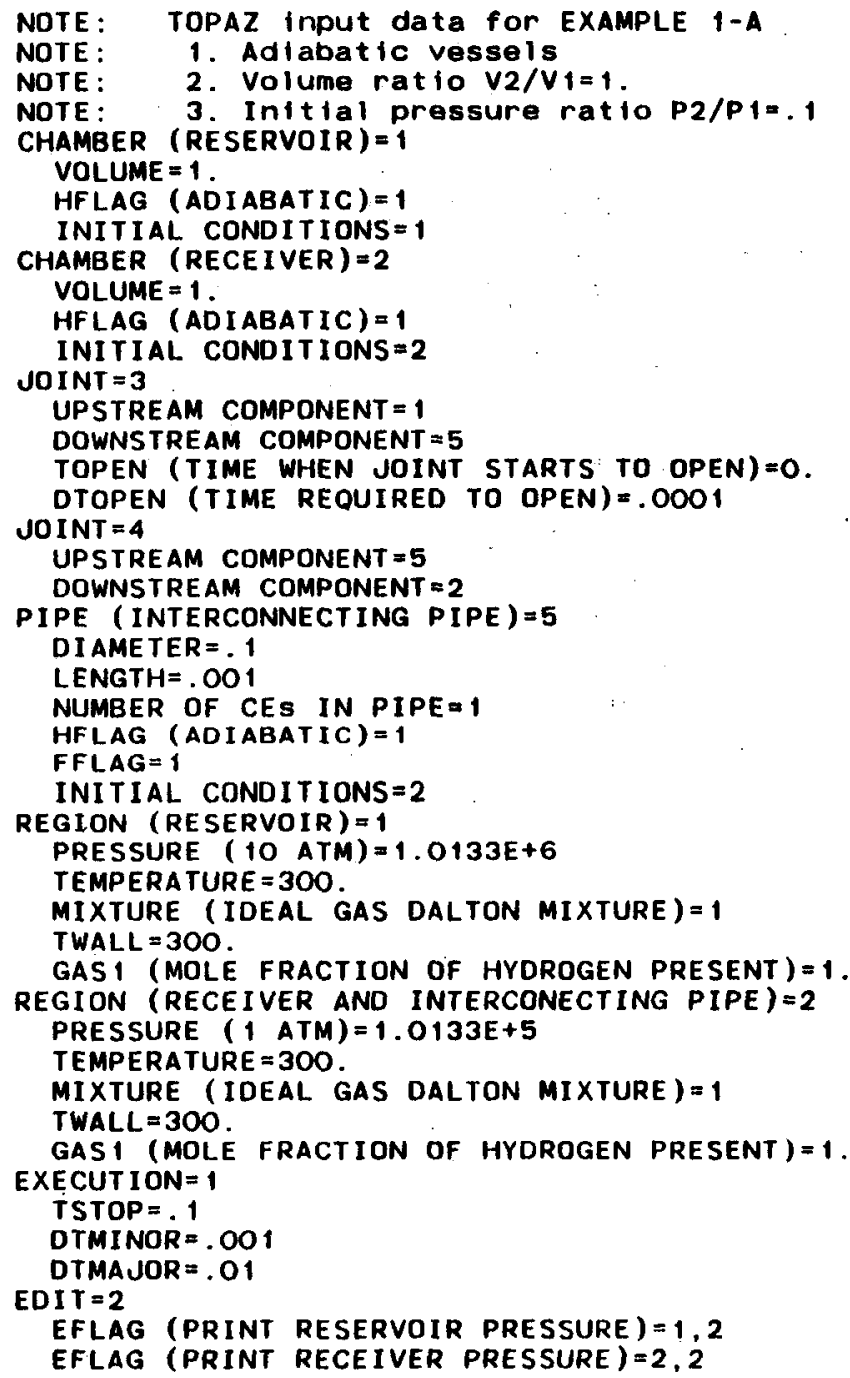

FIGURE 2. TOPAZ INPUT FILE FOR EXAMPLE 1 
gas properties along the flow path. Increasing the spacial discretization along the flow path would not improve the accuracy. Furthermore, for reasons which are not yet completely understood, the use of multiple CEs along such a flow path (i.e. quasi-steady isentropic) often leads to numerical difficulties.

TOPAZ predictions for Cases $A$ through $\mathbf{F}$ are compared to the analytical predictions of Chenoweth [7] in Table 9 and in Figures 3 through 6. The unchoking times which appear in the TOPAZ output files for the six cases are compared with the corresponding analytical values in Table 9. For the most part agreement is within one percent except for the cases in which the transfer times were extremely short. For these short times the finite valve opening time (.0001 seconds) may be influencing the TOPAZ results slightly.

In Figures 3 through 6 the analytical and TOPAZ-predicted normalized pressure ratio $P_{1}(t) / P_{2}(\mathrm{t})$ is plotted against dimensionless time. The dimensionless time is the ratio of the real time, $t$, to the time required to achieve pressure equilibrium in the system, $t_{e q}$. Agreement between the analysis and the TOPAZ predictions is excellent over the full range of volume ratios $\left(V_{2} / V_{1}\right)$ and initial pressure ratios $\left(P_{2} / P_{1}\right)$. The agreement is equally good for adiabatic and isothermal vessels. 
Table 9. Comparison of Unchoking Times for Example 1 .

\begin{tabular}{|c|c|c|c|}
\hline CASE & ANALYTICAL ${ }^{*}$ & TOPAZ & PERCENT DEVIATION ${ }^{\star \star}$ \\
\hline$A$ & .04016 & .03997 & .5 \\
\hline B & .05496 & .05485 & .2 \\
\hline C & .1485 & .1477 & .5 \\
\hline D & .1913 & .1908 & .3 \\
\hline$E$ & .002238 & .02177 & 2.7 \\
\hline$F$ & .003139 & .003042 & 3.1 \\
\hline
\end{tabular}

* From Reference(7)

** Percent deviation of TOPAZ value from the analytical value. 


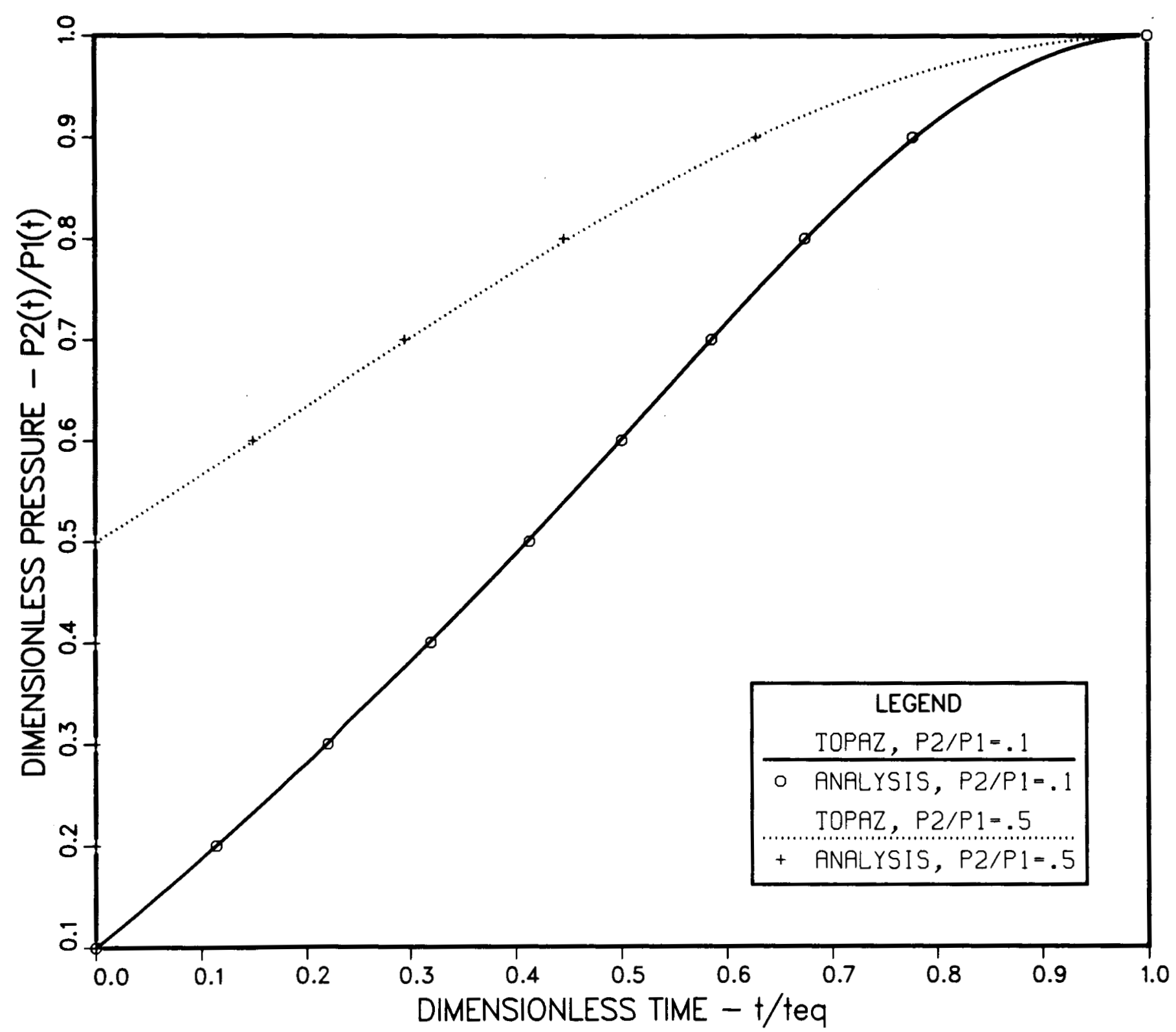

FIGURE 3. PRESSURE HISTORIES FOR VARYING INITIAL PRESSURE RATIOS (ADIABATIC VESSELS, $V_{2} / V_{1}=1$ ) 


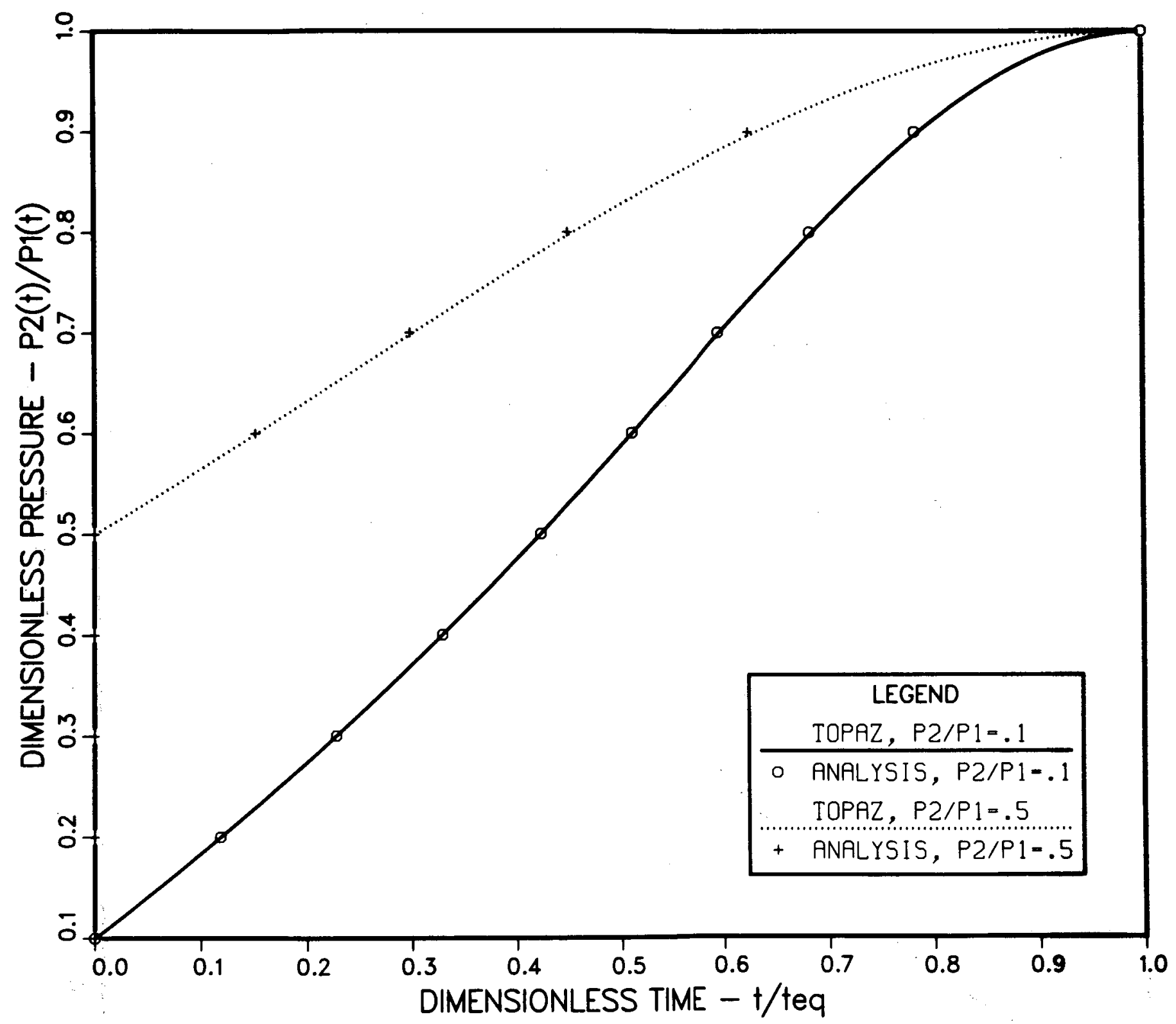

FIGURE 4. PRESSURE HISTORIES FOR VARYING INITIAL PRESSURE RATIOS (ISOTHERMAL VESSELS, $v_{2} / V_{1}=1$ ) 


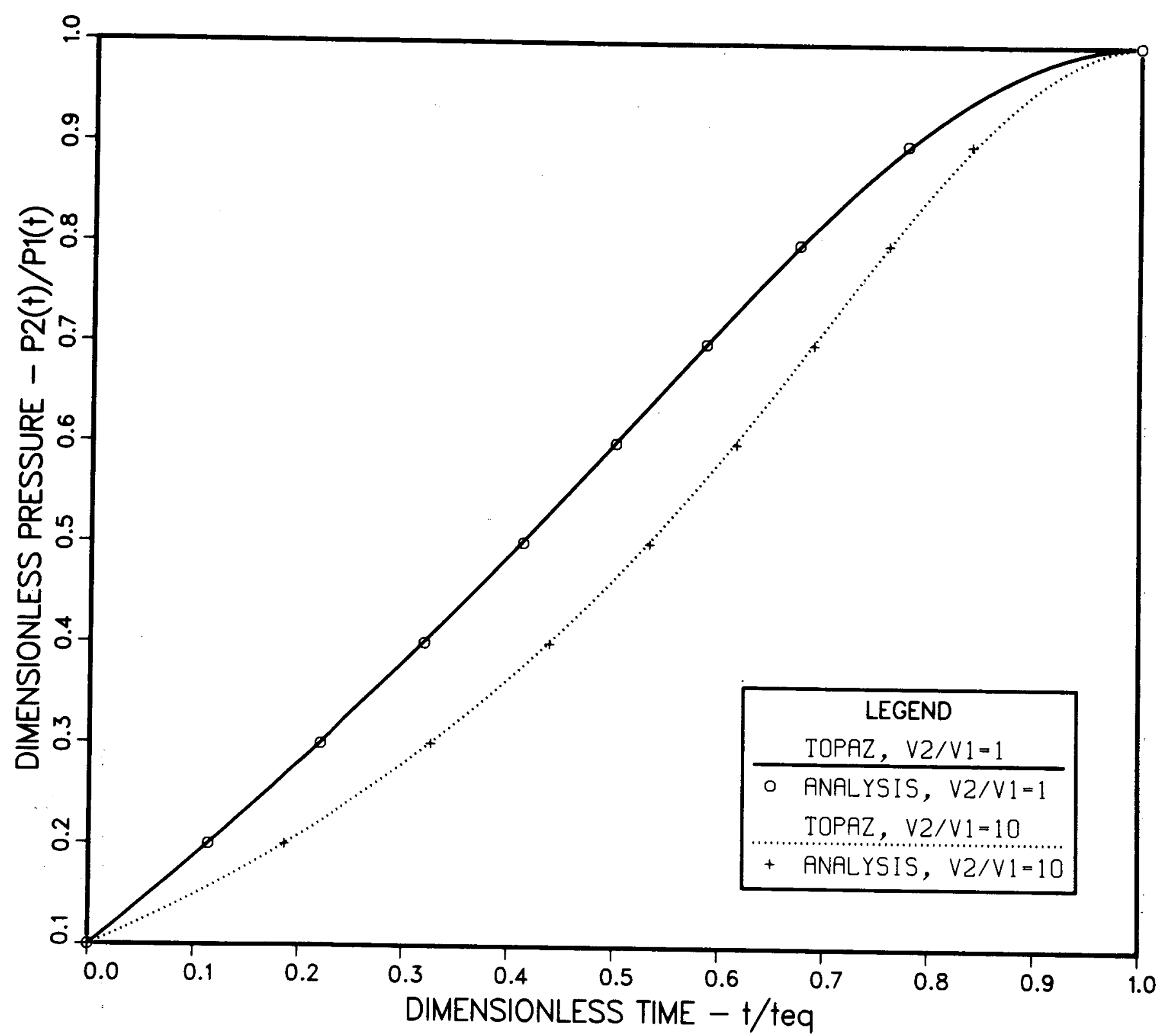

FIGURE 5. PRESSURE HISTORIES FOR VARYING VOLUME RATIOS (ADIABATIC VESSELS, $\mathrm{P}_{2} / \mathrm{P}_{1}=.1$ ) 


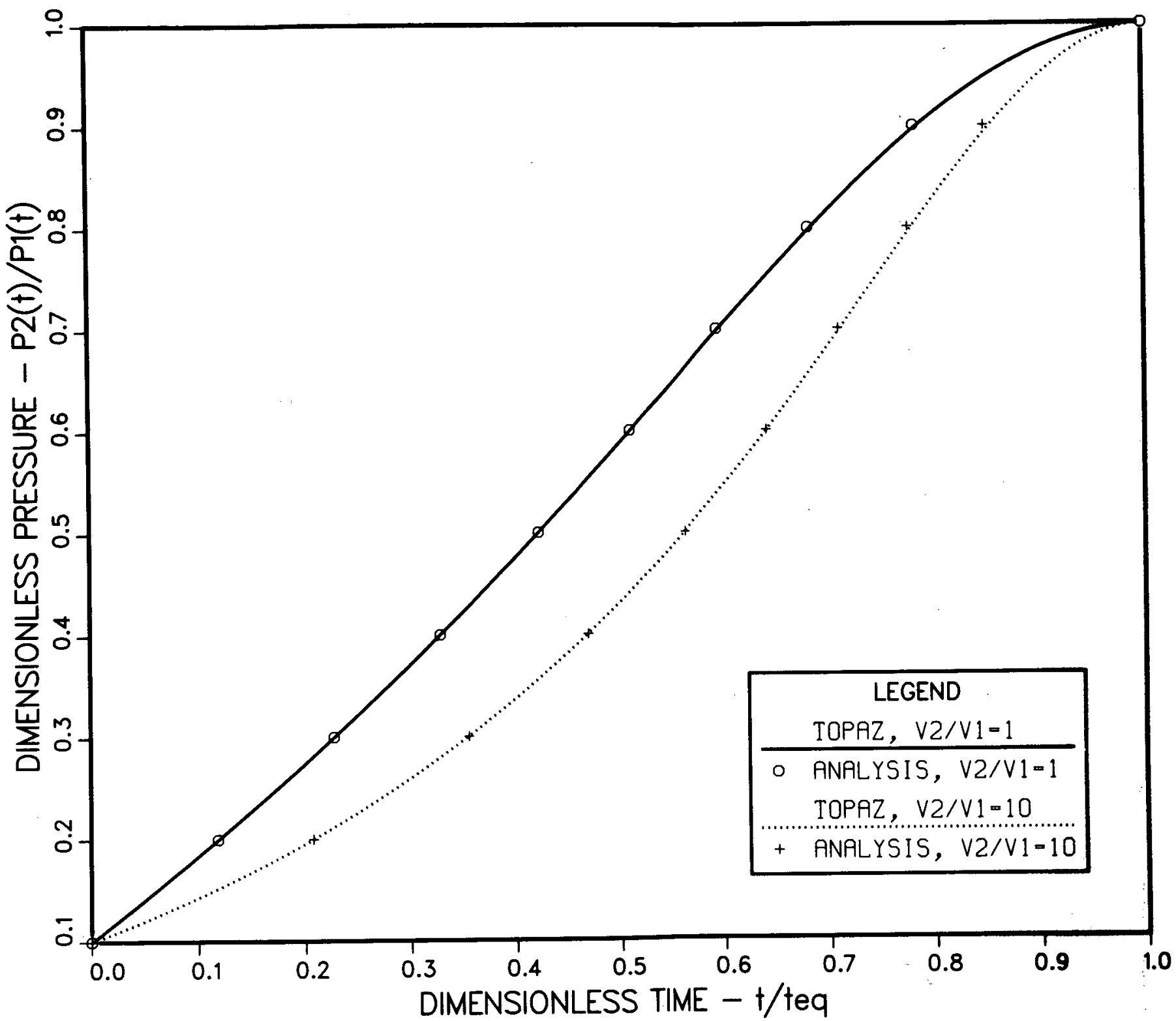

FIGURE 6. PRESSURE HISTORIES FOR VARYING VOLUME RATIOS (ISOTHERMAL VESSELS, $\mathrm{P}_{2} / \mathrm{P}_{1}=.1$ ) 


\section{EXAMPLE 2 - ISENTROPIC BLOWDOWN OF A VESSEL}

\section{Introduction}

In this example problem an isentropic blowdown from a long cylindrical vessel will be simulated. In contrast to the previous problem which delt with the transfer of gas in a closed network, this example illustrates one method for simulating the flow of gas out of the network into the ambient. The objective is to simulate an ambient environment which neither changes temperature or pressure during the simulation. Such an ambient environment serves to provide an outflow boundary condition for gas transfer calculations in open networks.

The method for simulating an outflow to ambient conditions is quite simple. One need only simulate the ambient as a large vessel (several orders of magnitude larger than the network volume). This insures that the ambient pressure will remain relatively constant during the calculations. Constant temperature may be assured by specifing a vessel wall temperature (TWAL directive) equal to the desired ambient temperature and making use of the isothermal heat transfer coefficient flag $($ HFLA $=2)$. In Section VI, this idea will be extended to illustrate how an inflow boundary condition can be simulated.

In this example problem and in the following example problem the dimensionless parameter $\sigma$ will be employed to describe the relative size of the blowdown vessel in relation to the blowdown cross-sectional area. This parameter is defined as follows:

$$
\sigma=\frac{\text { vessel cross-sectional area }}{\text { exit cross-sectional area }}
$$

Hence large values of $\sigma$ imply slow blowdowns of relatively large vessels through small holes. Small values of $\sigma$ imply rapid blowdowns of relatively small vessels through large holes. The lower limit of $\sigma=1.0 \mathrm{implies}$ that one end of the cylindrical vessel is completely open to the ambient.

In the next section (Example 3), it will be shown that accoustic waves play an important part in the vessel blowdowns where $\sigma$ is small (less than 10). In this example problem no attempt will be made to resolve accoustic phenomena in the blowdown vessel. Instead, the vessel will be modeled in the more traditional way, as a single continuity energy element (CE).

Three blowdown cases $(\sigma$ of $10.0,4.4968$, and 2.0351) will be considered in this section. TOPAZ calculations for each of these cases will be compared to the analytical solution for isentropic blowdown of a vessel through an opening where choked flow exists (see e.g. 
references 8 and 9). The analytical expression which describes the time dependent vessel. pressure is given by:

$$
\frac{P}{P_{0}}=\left[1+\frac{\gamma-1}{2 \sigma}\left(\frac{2}{\gamma+1}\right)^{(\gamma+1) / 2(\gamma-1)} \bar{t}\right]^{-2 \gamma /(\gamma-1)}
$$

where $\bar{t}$ is a dimensionless time parameter $t L / C_{0}$.

The analysis leading to equation (2) assumes spacially uniform properties within the vessel during blowdown.

\section{Problem Statement}

Use TOPAZ to simulate the transfer of ideal gas (hydrogen) from a cylindrical vessel (length $=1000 \mathrm{~m}$, diameter $=1 \mathrm{~m}$, initial pressure $=1 \mathrm{~Pa}$ ) to a low pressure ambient (pressure $=1.0 \times 10^{-3} \mathrm{~Pa}$ ) via an isentropic flow path. Assume the initial temperature is 173.127 K). Perform the simulation for the following three cases:
A. $\sigma=10.0$
B. $\sigma=4.4968$
C. $\sigma=2.0351$

\section{Discussion}

Figure $7 \mathrm{a}$ is a schematic drawing for this example problem. The corresponding mesh generation diagram is shown in Figure $7 \mathrm{~b}$. The TOPAZ input file used to simulate the blowdown for case $A(\sigma=10.0)$ is shown in Figure 8. Except for a few changes in the component numbering, sizing, and problem initial conditions, this simulation is nearly identical to that discussed in Section II. In this case, however, the reservoir has become a large plenum (diameter of $1 . \times 10^{10} \mathrm{~m}$ ) which will be maintained at the initial pressure of $1 \times 10^{-3} \mathrm{~Pa}$ and the imposed wall temperature of $173.127 \mathrm{~K}$ throughout the simulation. JOINT 3 which is located between the short exit pipe (PIPE 4) and the ambient (CHAMBER 1) acts as a valve which begins opening at time zero. This JOINT provides the logical separation between initial condition REGIONs 1 and 2. The blowdown vessel is simulated as a single CHAMBER or CE (CHAMBER 4). As was the case in the previous example, all isentropic flow components are simulated without pressure losses and heat transfer. Only the blowdown vessel pressure is printed during the minor edits. 


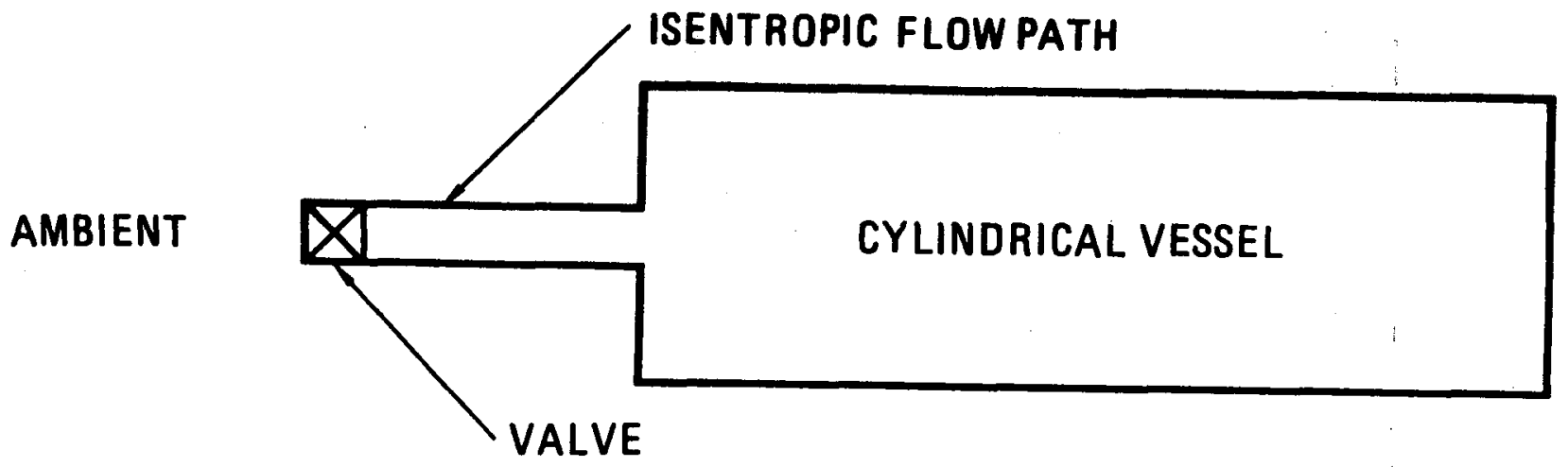

FIGURE 7a. SCHEMATIC FOR EXAMPLE 2

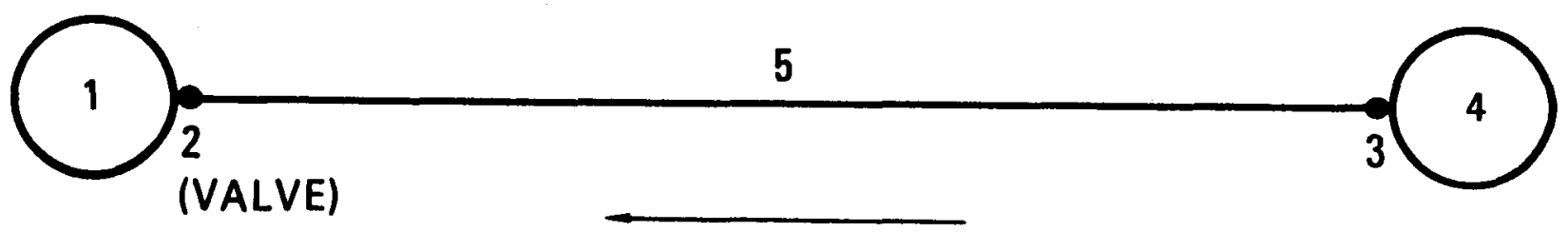

FIGURE 7b. MESH GENERATION DIAGRAM FOR EXAMPLE 2 


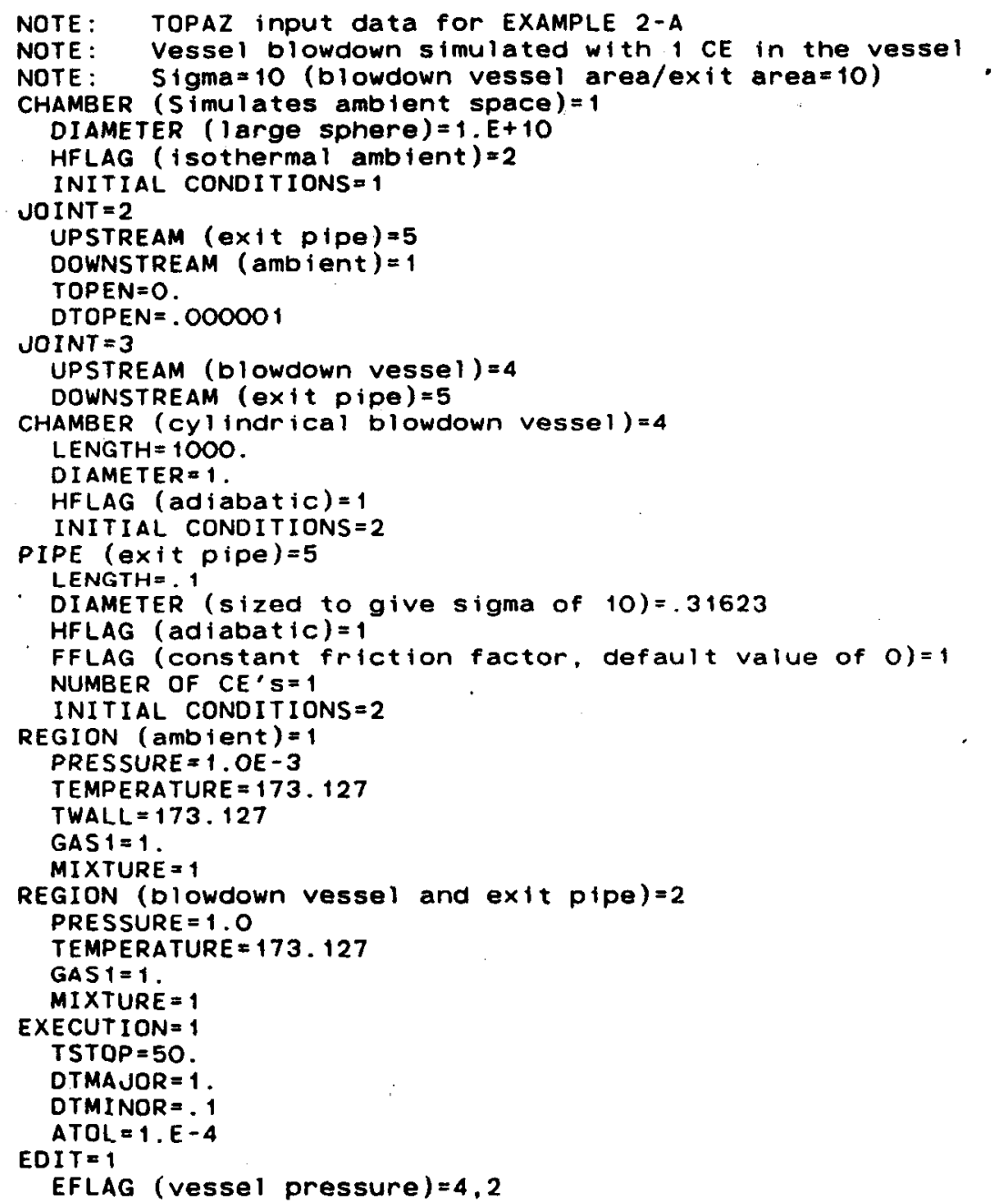

FIGURE 8. TOPAZ INPUT FILE FOR EXAMPLE 2 
. Figures 9 through 11 contain comparisons between the TOPAZ-calculated vessel pres- sure history and the pressure history predicted by the analytical expression, equation (2). Dimensionless pressure $\left(P / P_{0}\right)$ is plotted verses the dimensionless time $\left(t L / C_{0}\right)$ in all three figures. Agreement between the analysis and TOPAZ is excellent in all three cases, particularly for the slowest blowdown $(\sigma=10.0)$ which is the one least affected by the finite valve opening time and unsteady flow effects. (The analytical solution does not account for these effects.) 


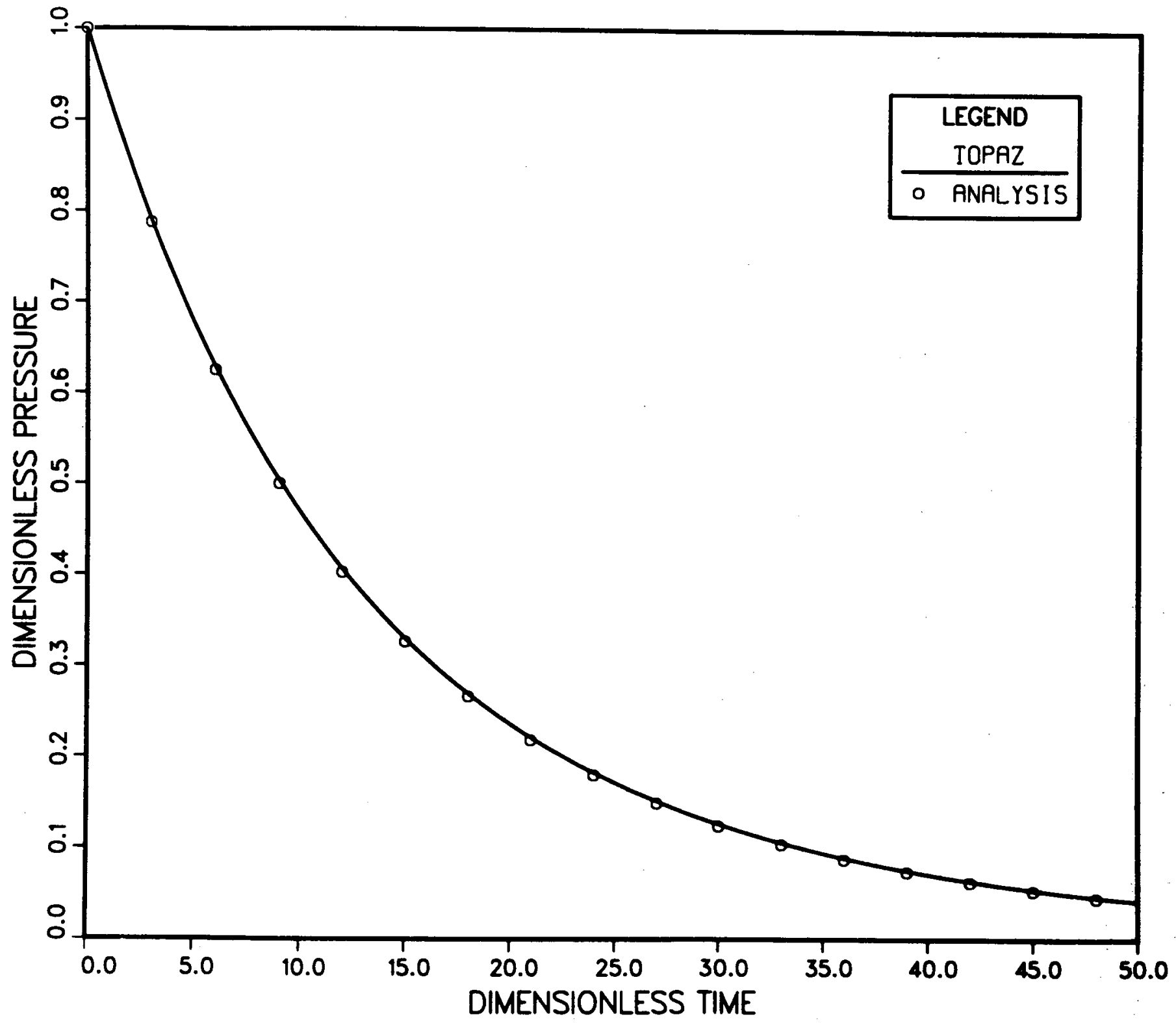

FIGURE 9. VESSEL BLOWDOWN TRANSIENT FOR $\sigma=10$ 


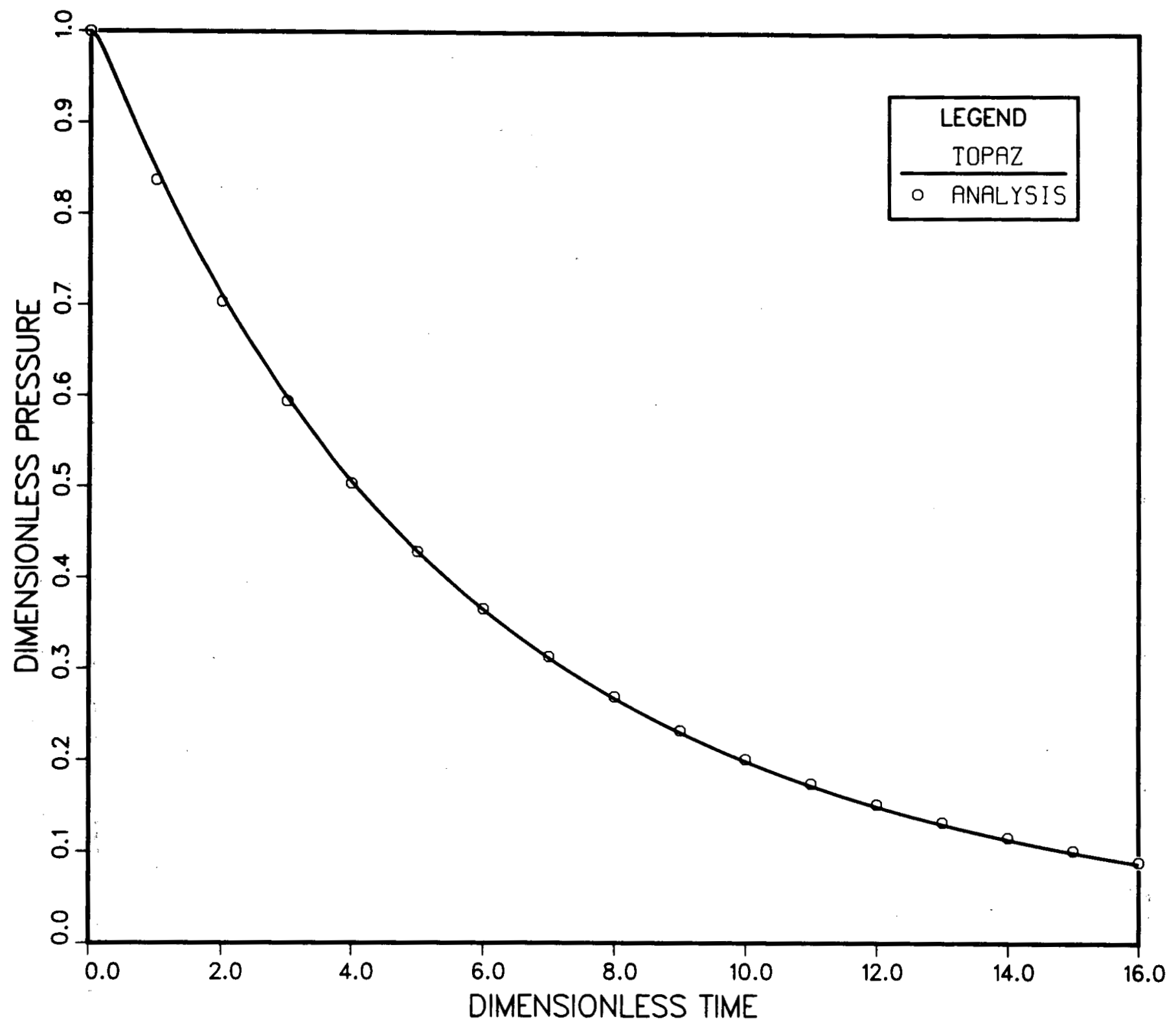

FIGURE 10. VESSEL BLOWDOWN TRANSIENT FOR $\sigma=4.4968$ 


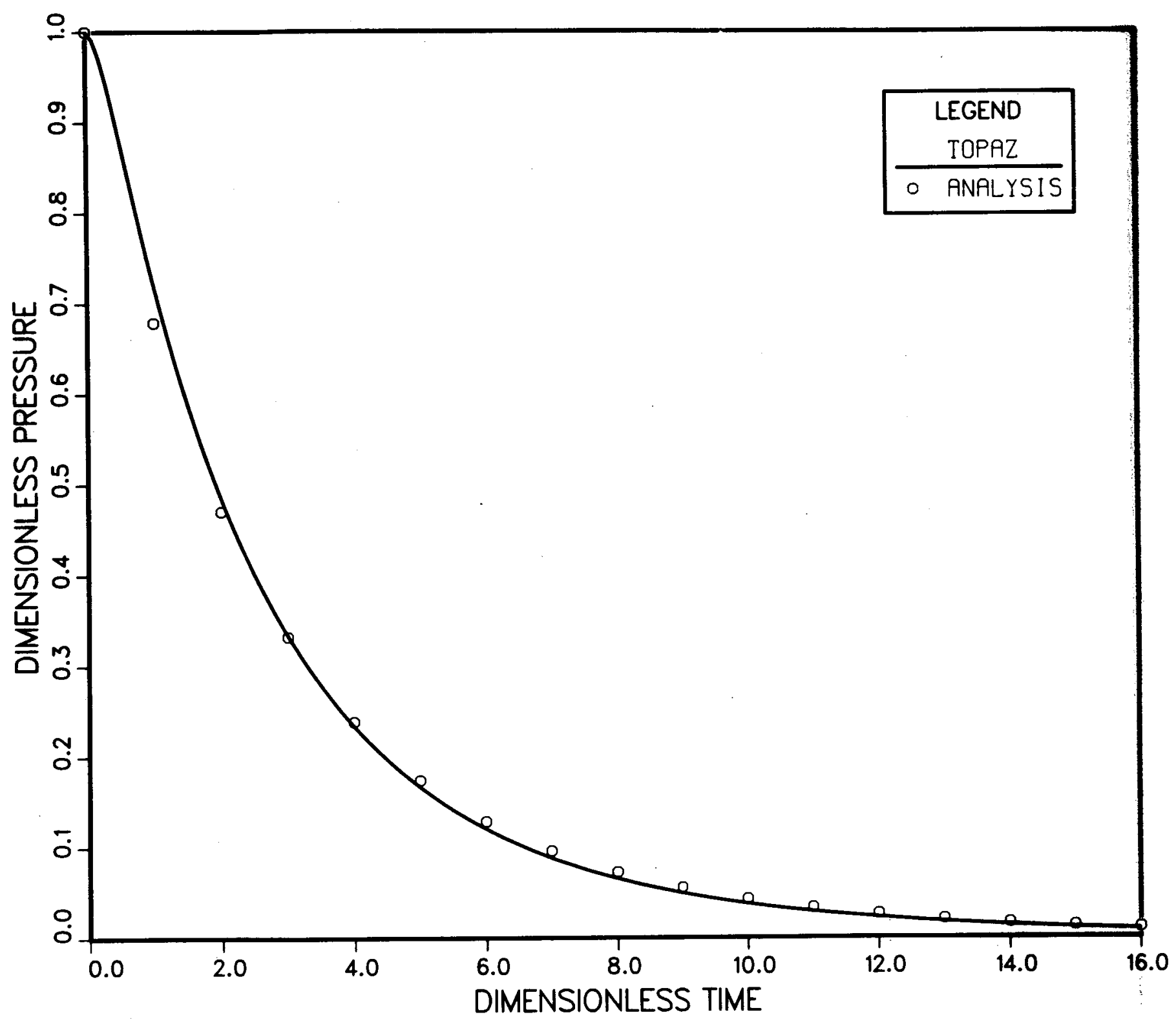

FIGURE 11. VESSEL BLOWDOWN TRANSIENT FOR $\sigma=2.0351$ 


\section{EXAMPLE 3 - ISENTROPIC BLOWDOWN OF A VESSEL WITH ACCOUSTIC WAVES}

\section{Introduction}

The example problem simulated in this section is identical to the vessel blowdown problem presented in the previous section. However, in this section the blowdown vessel will be simulated as a PIPE having $20 \mathrm{CEs}$ rather than as a single CHAMBER. Hence any spacial gradients which might occur inside the vessel during blowdown will be resolved by TOPAZ.

This example problem illustrates the importance of modeling the propagation of pressure waves in vessels. It will be shown that for vessel blowdowns characterized by a $\sigma$ greater than 10 there is seldom a need to use more than a single CE or CHAMBER to simulate the vessel. For those cases in which the propagation of pressure rarefaction waves is important, comparisons with analytical solutions show than TOPAZ is capable of simulating the major one-dimensional-transient features of such waves.

\section{Problem Statement.}

Use TOPAZ to resolve any strong accoustic waves which might occur in the vessel blowdown problem presented in Section III.

\section{Discussion}

The schematic drawing and corresponding mesh generation diagram for this problem is shown in Figure 12. The TOPAZ input file used to simulate case $A(\sigma=10.0)$ is shown in Figure 13. The input file is identical to that used for the problem in the previous section except that the blowdown vessel CHAMBER 4 has been replaced by PIPE 4 having 20 CEs. The pressure nearest the opened end (CE element 42 ) and the pressure nearest the closed end (CE element 4) are printed out during the minor edits. The numbering for the CE elements nearest the opened and closed ends of the vessel are identified in the User-TOPAZ Mesh Generation Table (not shown here).

In order to illustrate the importance of accoustic waves, the TOPAZ-predicted pressure transients at the opened and closed end of the vessel are compared with the "averaged" blowdown transients calculated in the previous section. These comparisons appear in Figures 14, 15, and 16 for the blowdown cases in which $\sigma$ is 10.0, 4.4968, and 2.0351 respectively. These figures are plots of dimensionless pressure $\left(P / P_{0}\right)$ versus dimensionless time $\left(t L / C_{0}\right)$. In all three comparisons, the pressure transients from single $C E$ simulations appear to lie between the opened and closed end transients. Simulating the blowdown 


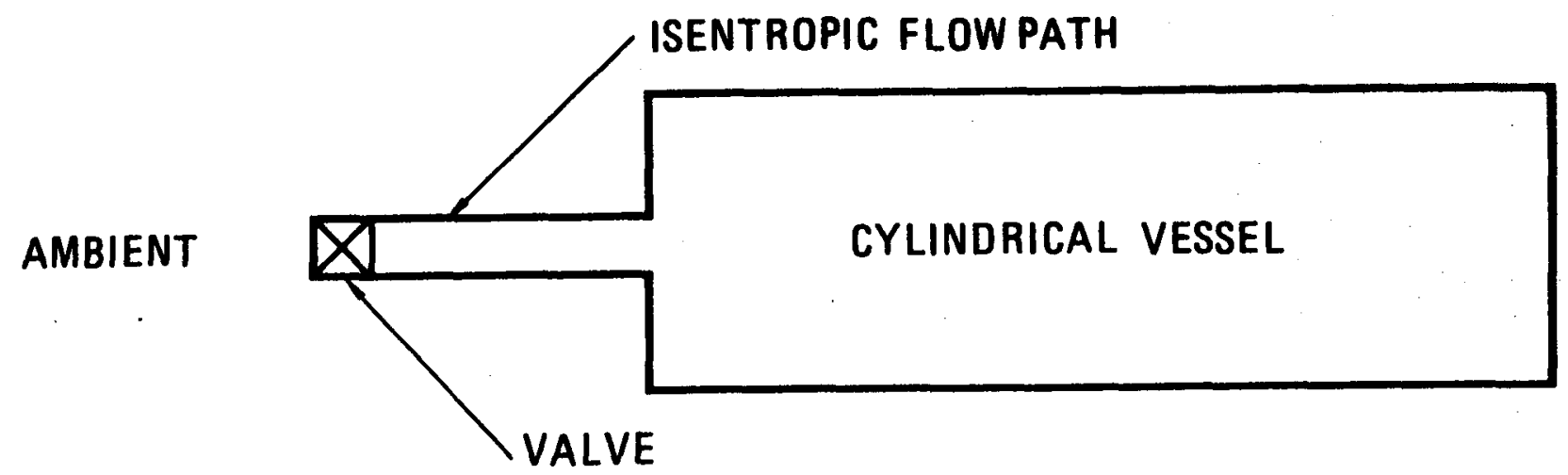

FIGURE 12a. SCHEMATIC FOR EXAMPLE 3

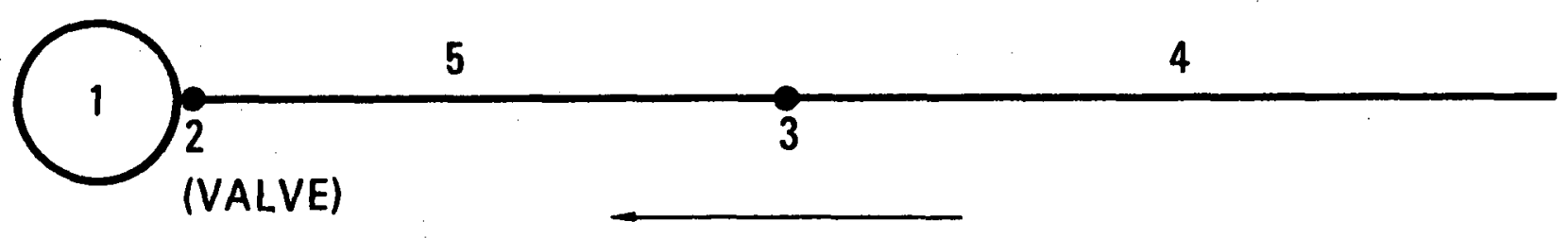

FIGURE 12b. MESH GENERATION DIAGRAM FOR EXAMPLE 3 


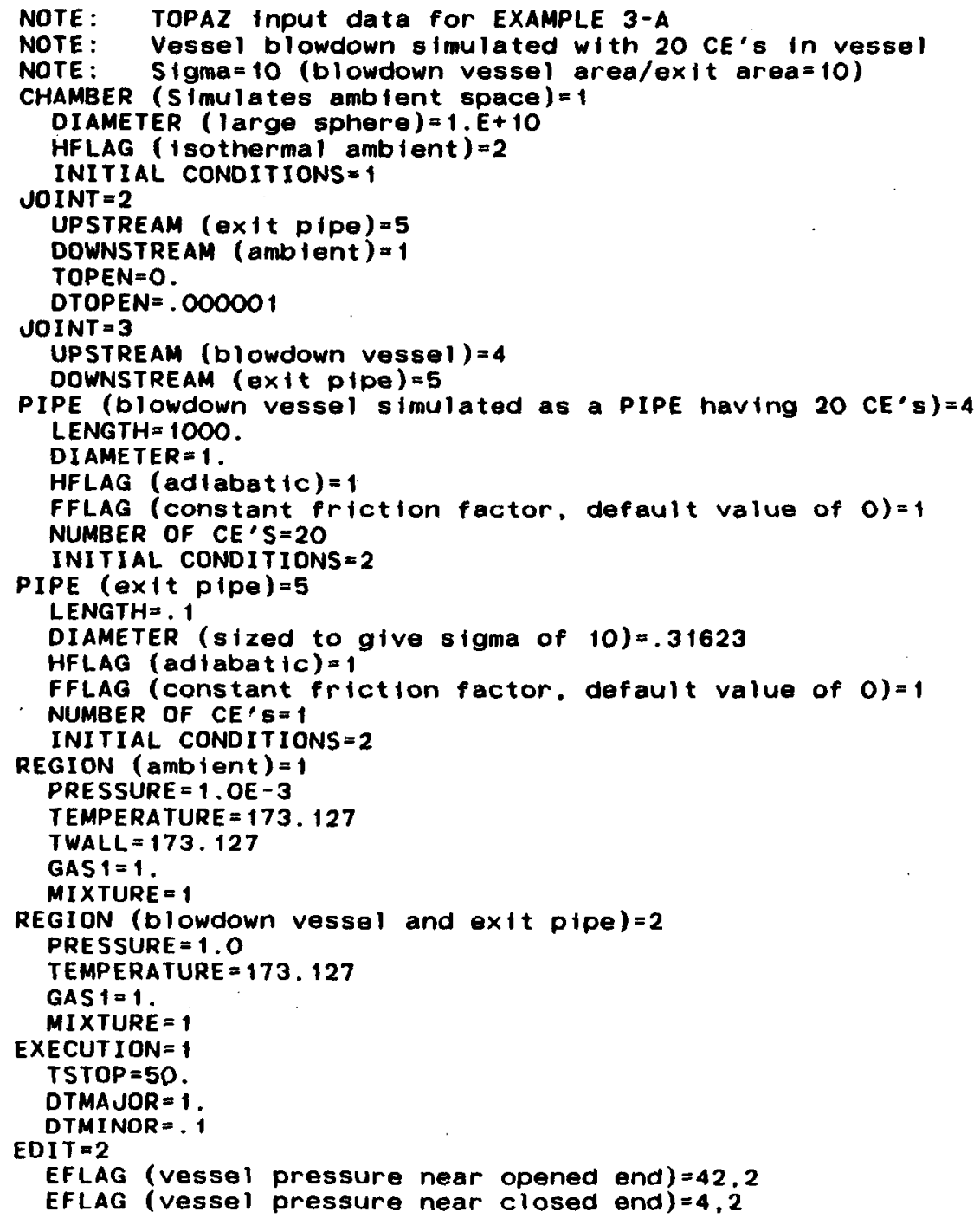

FIGURE 13. TOPAZ INPUT FILE FOR EXAMPLE 3 


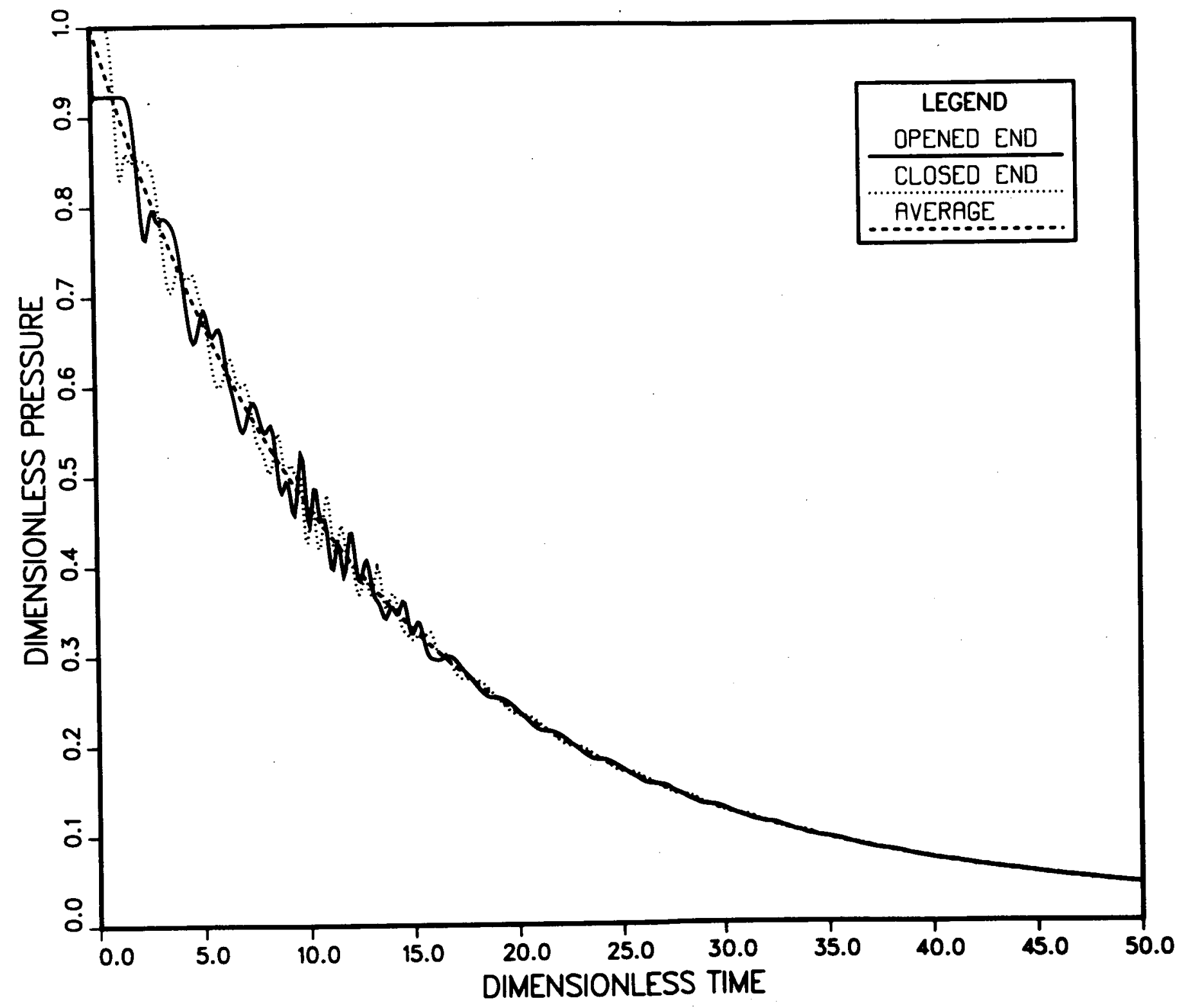

FIGURE 14. COMPARISON OF AVERAGED AND DISTRIBUTED BLOWDOWN PRESSURE TRANSIENTS FOR $\sigma=10$ 


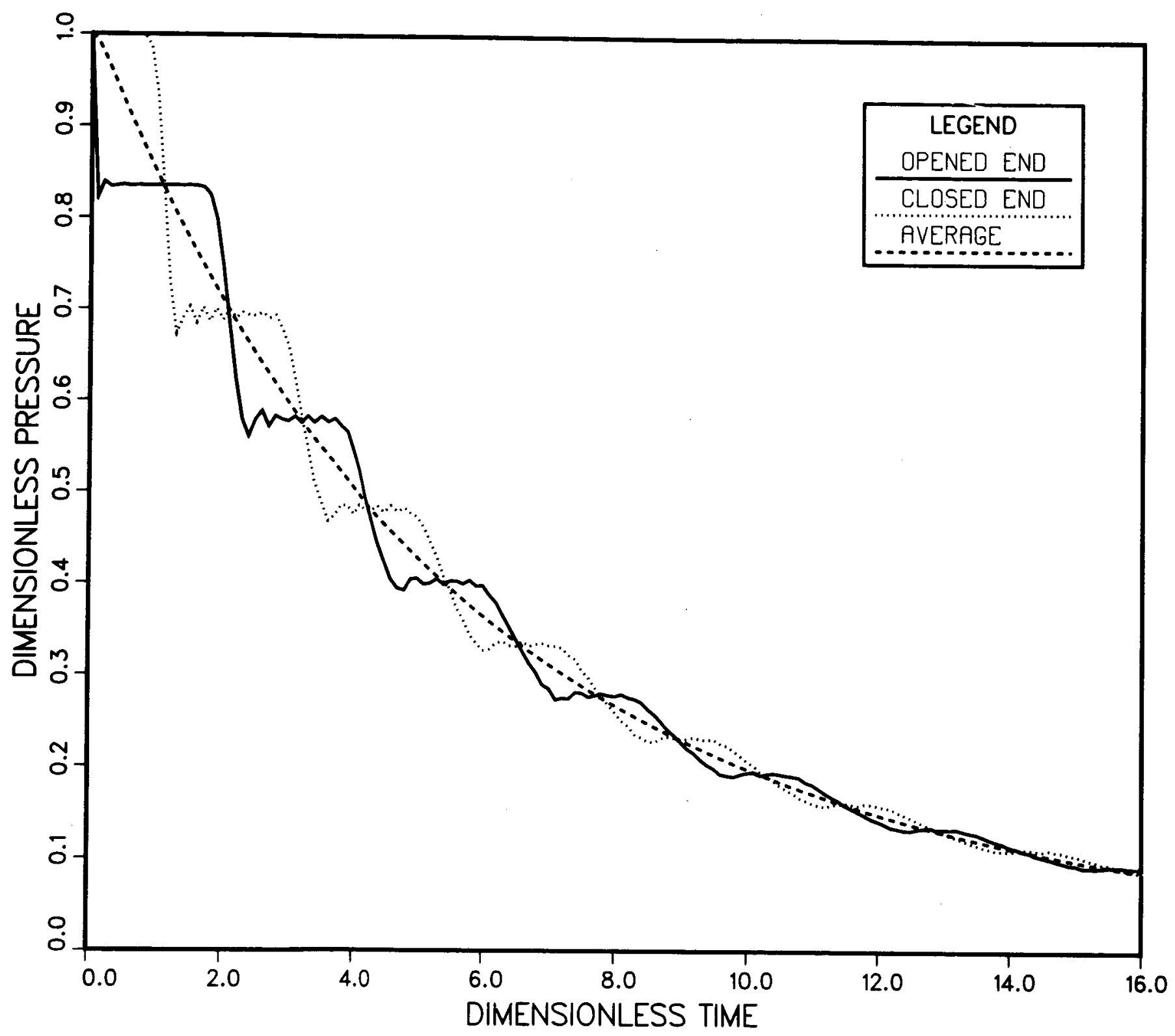




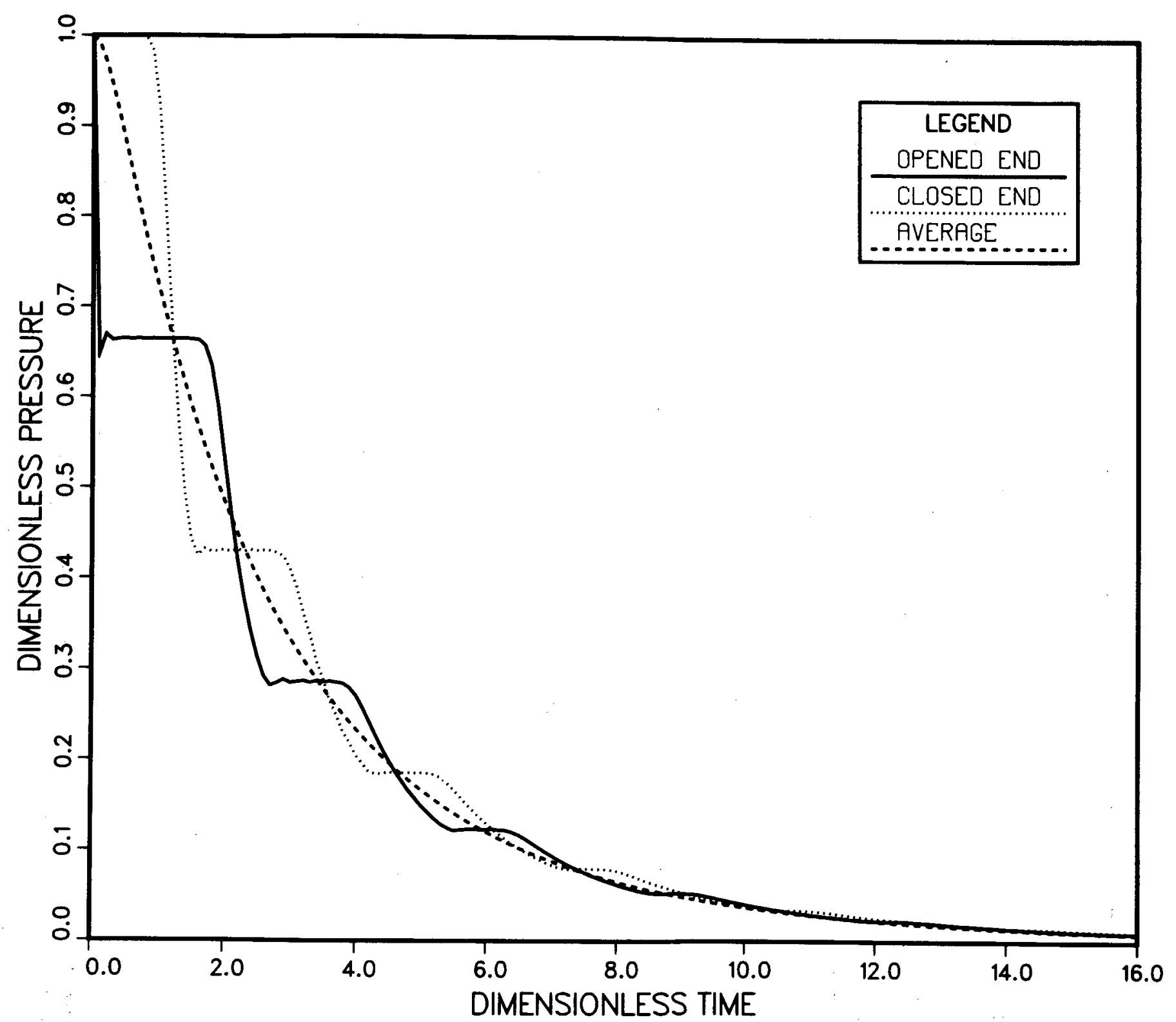

FIGURE 16. COMPARISON OF AVERAGED AND DISTRIBUTED BLOWDOWN PRESSURE TRANSIENTS FOR $\sigma=2.0351$ 
with a single $\mathrm{CE}$ has the effect of "averaging" the pressure over the entire length of the vessel. For slower blowdowns such as that shown for $\sigma=10.0$ in Figure 14, such averaging seems justified since the rarefaction waves generated during blowdown are relatively weak. However, for lower values of $\sigma$ there are substantial differences between the pressures at the opened and closed ends. (See Figures 15 and 16.) It is interesting to note that regardless of the value of $\sigma$, the number of CEs used to simulate the vessel has little or no effect on the time calculated to empty the vessel.

Paolucci [8] employed the method of characteristics and various approximations to construct an analytical solution to describe the pressure transients at the opened and closed ends of a cylindrical blowdown vessel. In particular, he predicted the transients for blowdowns having $\sigma$ values of 4.4968 and 2.0351 . These analytical solutions are compared to the corresponding TOPAZ predictions in Figures 17 and 18. In all cases the major features of the rarefaction wave propagation and reflection appear to have been well replicated by TOPAZ. Both the magnitude and duration of the code calculated pressure plateaus are in agreement with the analysis. The "rounding off" of the TOPAZ calculated pressure transients and the appearance of "wiggles" in the calculations are not, however, a true part of the solution. These are numerical dispersion errors, a consequence of the finite differencing scheme employed in TOPAZ spacial discretization. Such dispersion errors nearly always occur in the numerical simulation of strong accoustic phenomena (propagation of shocks and rarefaction waves). Higher order differencing techniques, adaptive griding, and the addition of artificial viscosity are often employed to minimize these effects (e.g. references $6,10,11)$. Higher order differencing and adaptive griding are difficult to implement in a generalized code such as TOPAZ. However, there is a provision for including artificial viscosity into the calculations. This feature will be examined in the next section. 


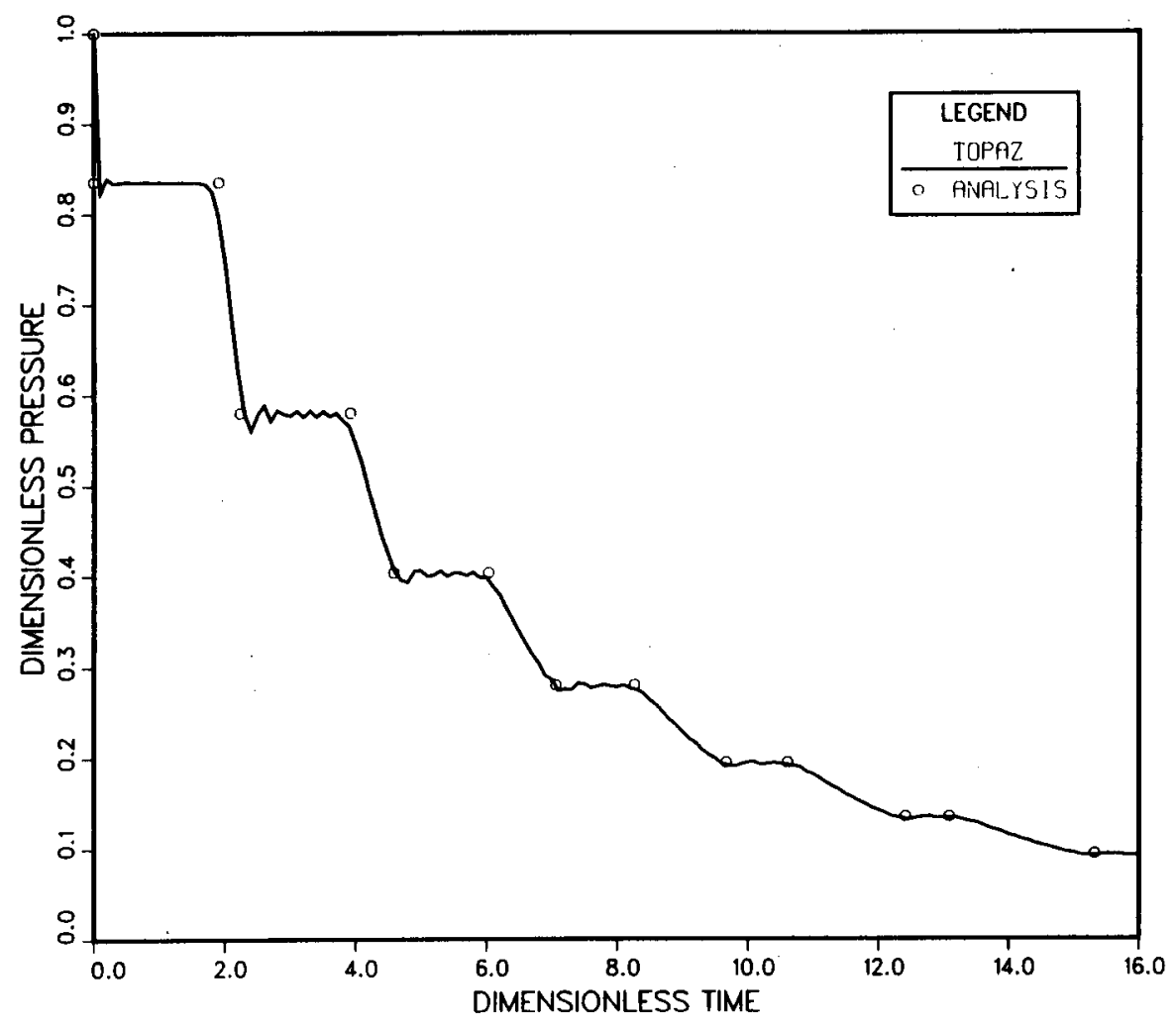

FIGURE 17a. OPENED END PRESSURE HISTORY FOR $\sigma=4.4968$

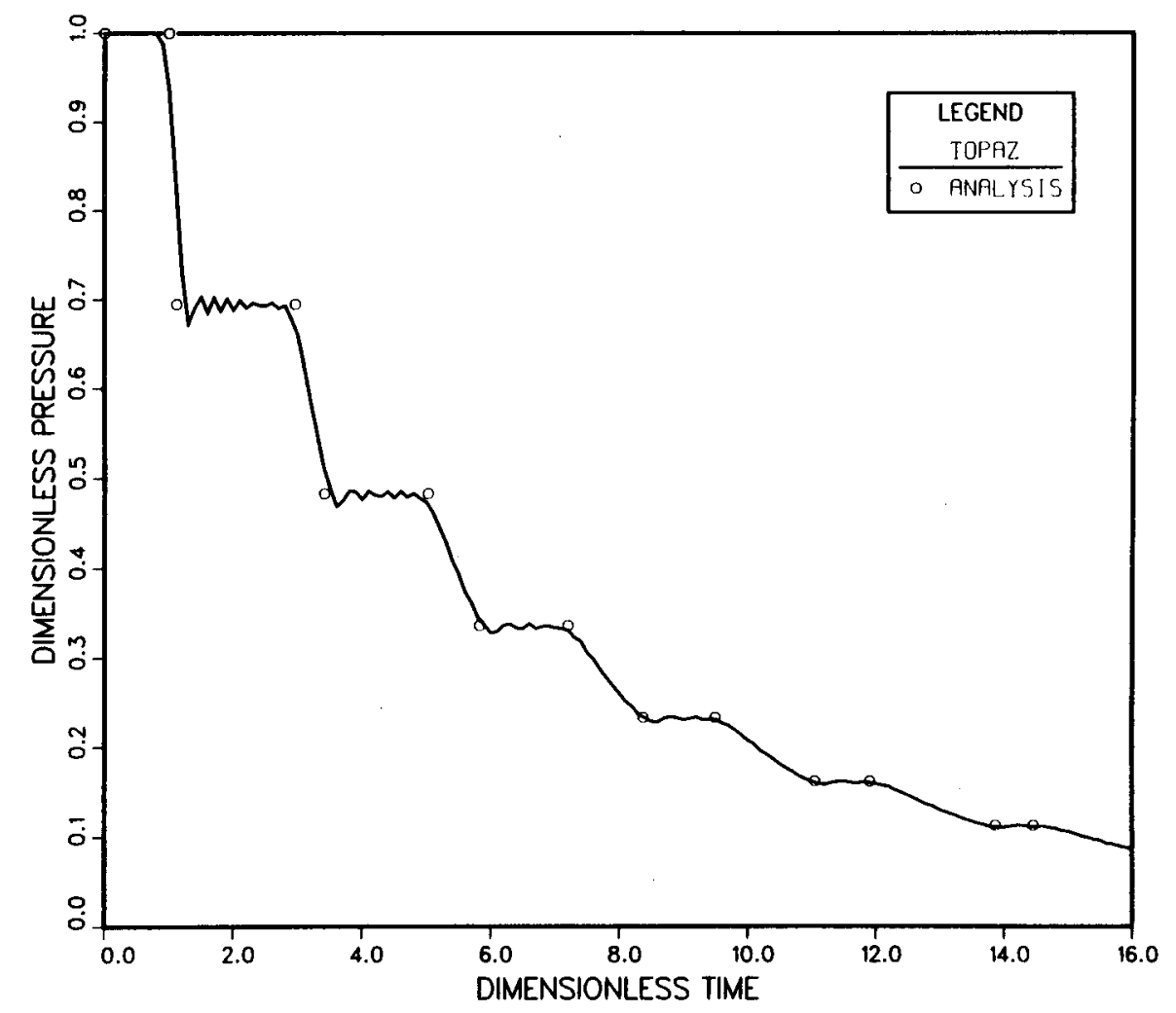

FIGURE 17b. CLOSED END PRESSURE HISTORY FOR $\sigma=4.4968$ 


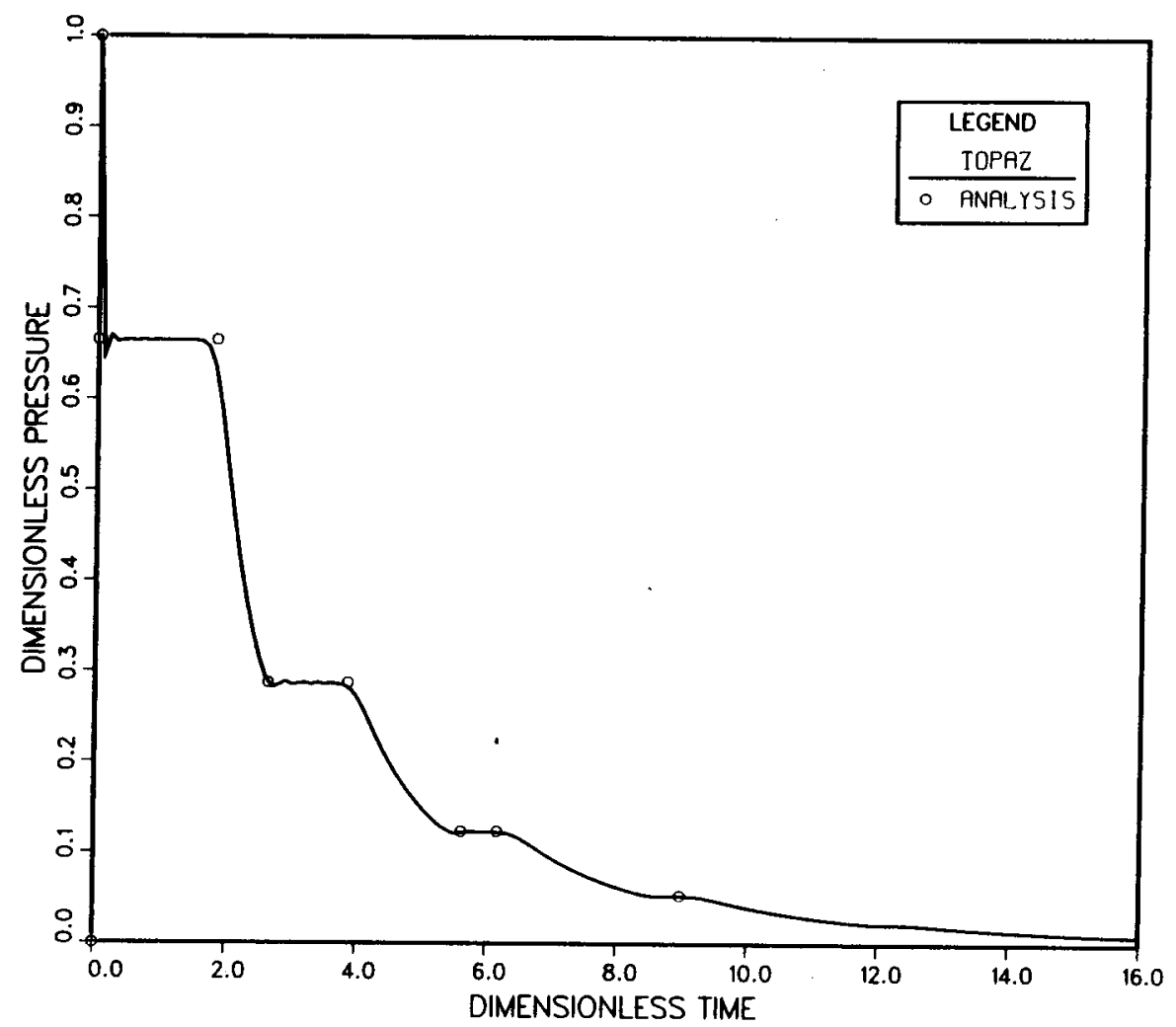

FIGURE 18a. OPENED END PRESSURE HISTORY FOR $\sigma=2.0351$

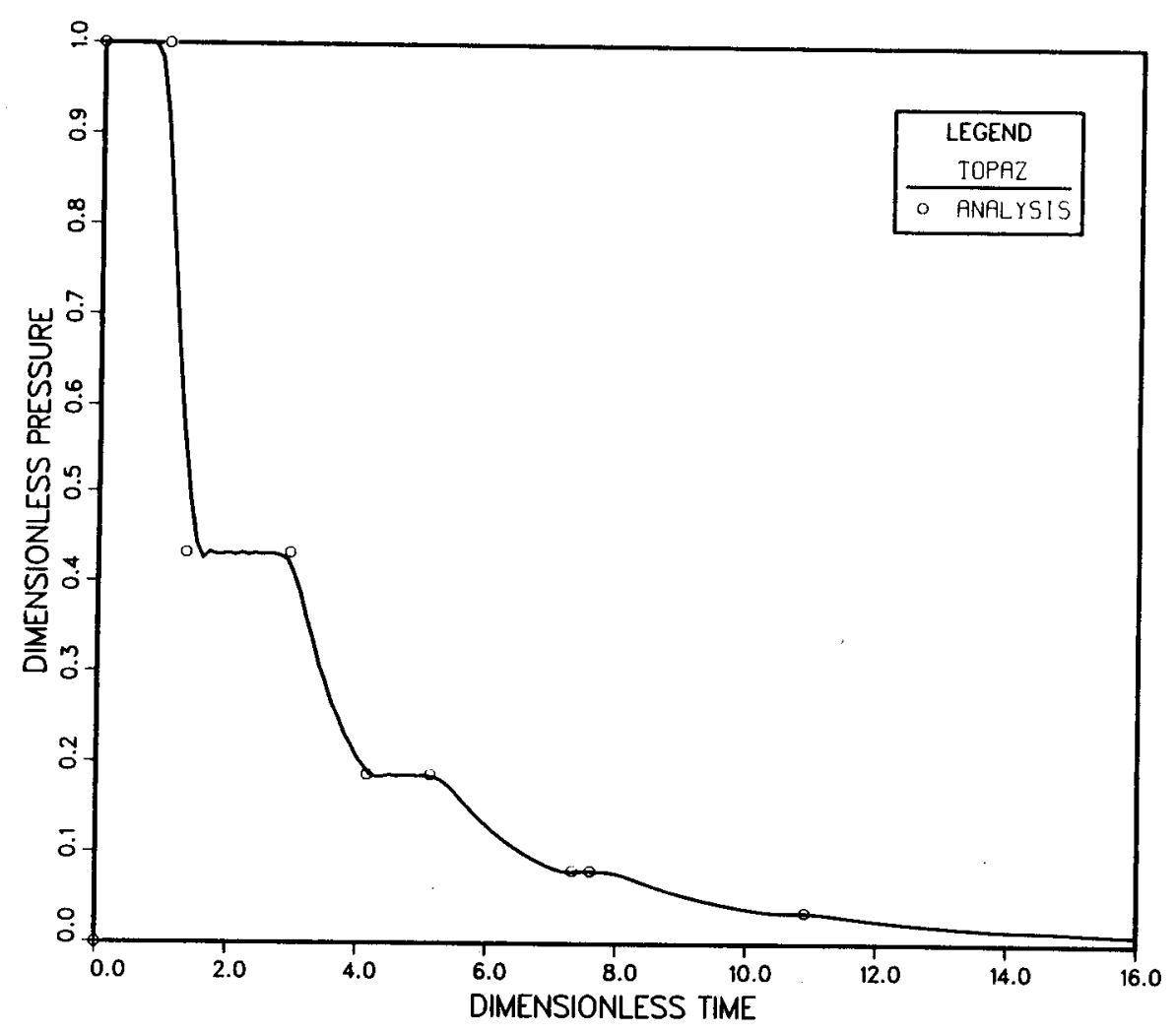

FIGURE 18b. CLOSED END PRESSURE HISTORY FOR $\sigma=2.0351$ 


\section{EXAMPLE 4 - SIMULATION OF A SHOCK TUBE}

\section{Introduction}

The example problem presented in this section is designed to illustrate how TOPAZ can be used to model shock tube phenomena. The one-dimensional ideal gas inviscid shock tube problem has become a standard by which to evaluate various finite difference techniques (e.g. references $6,10,11$ ). The steep fronts (pressure discontinuities) of propagating shocks are among the most difficult phenomena to replicate with a continuous finite difference mesh, i.e., a uniformly spaced mesh to resolve the shock discontinuity. Attempts to resolve shock tube physics inevitably lead to some measure of shock smearing and calculational dispersion errors (errors similar to the "wiggles" discussed in the previous problem).

Many highly specialized finite differencing techniques have been proposed expressly for the purpose of modeling shocks and related phenomena. These techniques generally employ some or all of the following: high order spacial differencing (e.g. second, third, or fourth order spacial differencing), non uniform and adaptive griding, artificial viscosity, or direct application of the Rankine-Hugoniot jump conditions across the shock. TOPAZ was designed to serve as a general tool for modeling gas transfer in arbitrary piping networks and was not intended to serve as a specialized "shock tube" code. Nevertheless, users may obtain surprisingly good results when modeling shock tube physics, especially when the available option for including artificial viscosity is employed.

TOPAZ employs a method previously described by Roach [6] for inducing artificial viscosity into the calculations. The method is equivalent to artificially reducing the pressure in the momentum equation by an amount $q$, where $q$ is given by

$$
q=-\rho\left(b_{1} \Delta x\right)^{2} \frac{\partial v}{\partial x}\left|\frac{\partial v}{\partial x}\right|
$$

and the constant $b_{1}$ is of order unity. Including $q$ in the calculations has the effect of causing an artificial dissipation to occur in the vicinity of steep gradients. This dissipation tends to "smear" steep gradients such as shocks over several mesh points, thereby significantly reducing dispersion errors. Generally when artifical viscosity is employed in TOPAZ shock calculations, the user trades off shock steepness for reduction in dispersion errors.

Since there is seldom a need to smear out the less steep rarefaction waves, equation (3) is only applied locally when the following condition is met:

$$
v \frac{\partial v}{\partial x}<0
$$


This condition insures that the dissipation will only occur at shocks.

Users may induce artificial viscosity into TOPAZ calculations by invoking the DAMP directive (an EXECUTION minor directive). The directive should appear in the input file as

$$
\mathrm{DAMP}=b_{1}
$$

where the constant $b_{1}$ is identical to the constant appearing in equation (3). Recomended values for $b_{1}$ lie between 0 (default value) and 2 . Introducing artificial viscosity into calculations where the time scales of interest are several orders of magnitude greater than the accoustic time scale $\left(L / C_{0}\right)$ is seldom necessary and generally not recomended.

In the remaining part of this section, the inviscid shock tube problem will be modeled with and without artificial viscosity. The resulting calculations will be compared to the analytical solution outlined in reference [12].

\section{Problem Statement}

A diaphragm located at the midpoint of a $1 \mathrm{~m}$ long, $.01 \mathrm{~m}$ diameter shock tube separates high pressure hydrogen $\left(5 \times 10^{5} \mathrm{~Pa}\right)$ from low pressure hydrogen $\left(1 \times 10^{1} \mathrm{~Pa}\right)$. Assume that the hydrogen is an ideal gas with an initial uniform temperature of $300 \mathrm{~K}$. Neglect flow losses and wall heat transfer and computé the pressure and velocity distribution in the shock tube .25 milliseconds after the diaphragm ruptures. Perform the calculation for the following two cases:
A. Damping factor DAMP $=0$ (default)
B. Damping factor $\mathrm{DAMP}=2$

\section{Discussion}

A schematic of the shock tube geometry prior to diaphragm rupture is shown in Figure 19a, and the corresponding mesh generation diagram is shown in Figure 19b. The TOPAZ input file for case $A$ of the shock tube problem is given in Figure 20. The input file for case $B$ is identical except the directive DAMP $=2$ is included as an EXECUTION minor directive.

Only three components are required to simulate the shock tube geometry. The driver section is represented by PIPE 2 and the driven section by PIPE 3. The shock tube diaphragm is simulated as JOINT 1 , an extremely fast opening valve. The opening time of $1 \times 10^{-10} \mathrm{~s}$ is sufficiently fast enough to represent an instantaneous diaphragm rupture. As in most TOPAZ simulations, this initially closed valve provides the most logical boundary for the two initial condition REGIONs. REGION 1 represents the driver gas while REGION 2 represents the driven gas. TSTOP is set for the required .00025 seconds with major edits every .00005 seconds. The final major edit contains the information of interest, 


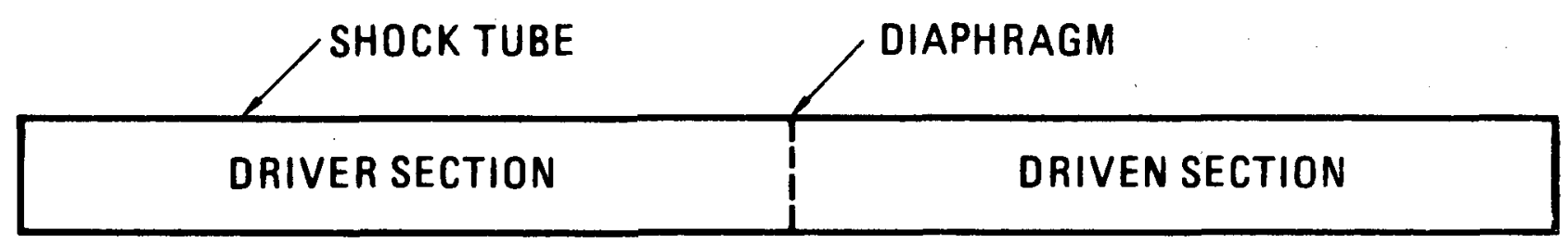

FIGURE 19a. SCHEMATIC FOR EXAMPLE 4

2

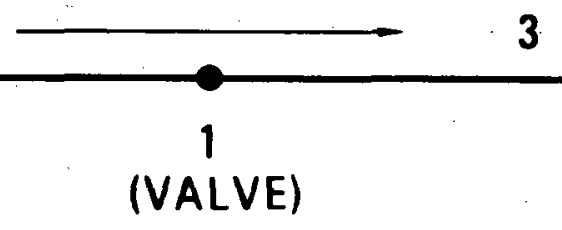

FIGURE 19b. MESH GENERATION DIAGRAM FOR EXAMPLE 4 


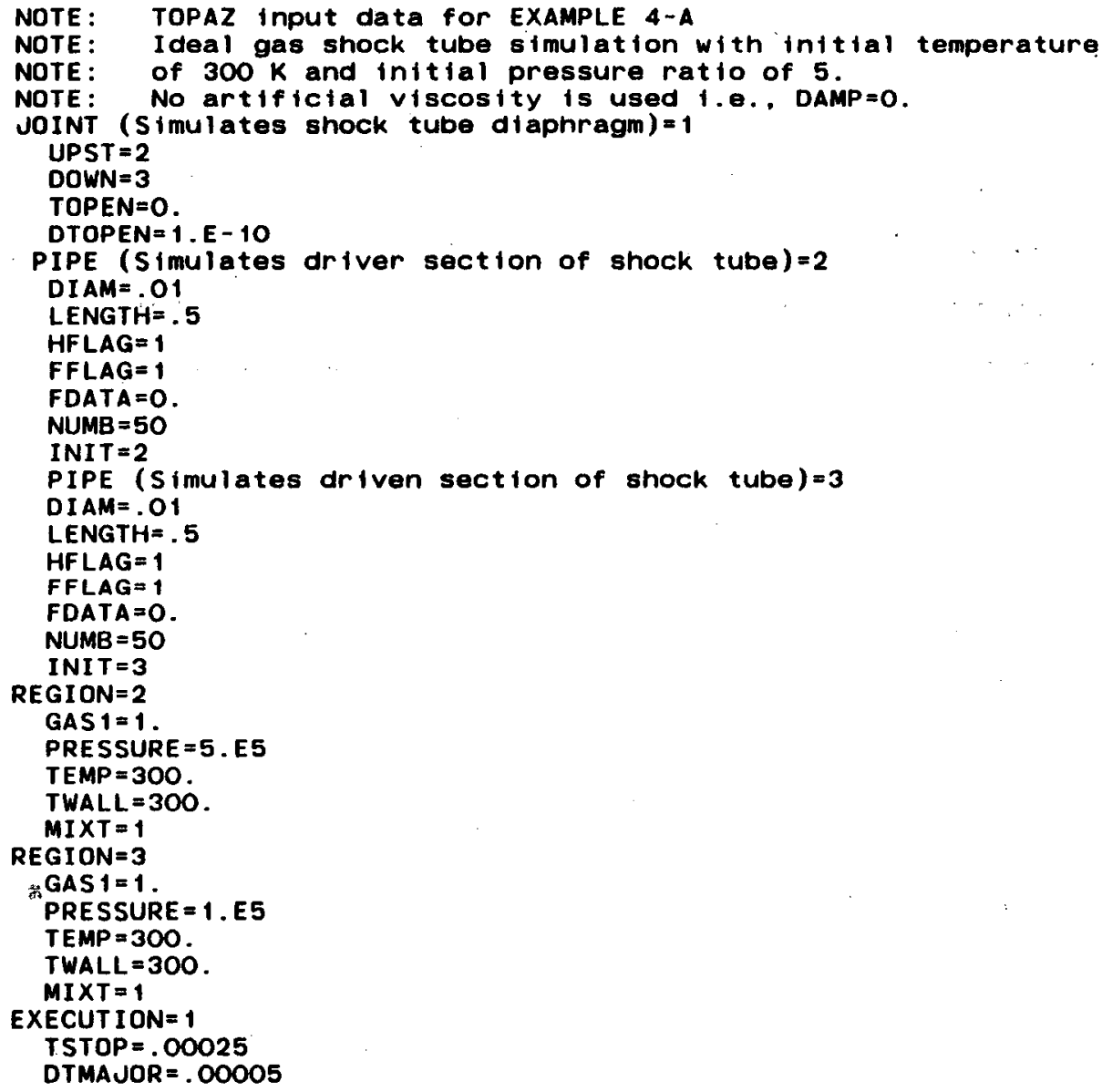

FIGURE 20. TOPAZ INPUT FILE FOR EXAMPLE 4 
an instantaneous "snap shot" of the pressure and velocity distribution in the shock tube at .25 milliseconds.

The pressure and velocity spacial distributions obtained from the final major edit were transcribed and plotted for presentation here in Figures 21 and 22. Since each PIPE was assigned $50 \mathrm{CEs}$, the information presented represents the finite difference shock tube solution for 100 evenly spaced grid points. The TOPAZ solution is represented by the solid line in the figures while the exact analytical solution, obtained from the method of characteristics [12], is shown with the dashed line. The solutions correspond to a time just prior to reflection of the shock at the right end of the shock tube. The initial pressure ratio of 5 was selected in order to produce a strong shock.

Figure 21 represents the solution for case $A$ in which no artificial viscosity is used in the computations, i.e. the default option in which $\mathrm{DAMP}=0$. The 100 mesh points accurately represented the propagation of the rarefaction wave to the left and the propagation of the strong shock to the right. Both the pressure and velocity distributions show dispersion errors, i.e. "wiggles" just behind the shock. Although the frequency and distribution of the dispersion errors can be altered with the addition of mesh points, they can never be eliminated entirely with TOPAZ's (or any other) first order, fixed, uniform grid, finite differencing. Reduction of the dispersion errors can, however, occur if artificial viscosity is induced into the calculations.

Figure 22 represents the solution for case $B$ in which an artificial viscosity damping factor of 2 was used in the computations. The computed solution is identical to case $\mathbf{A}$ except in the region near the shock where the addition of artificial viscosity has substantially reduced the amplitude of the dispersion errors. As discussed earlier, the addition of such damping also has the effect of smearing the shock over additional mesh points thereby reducing its steepness. 


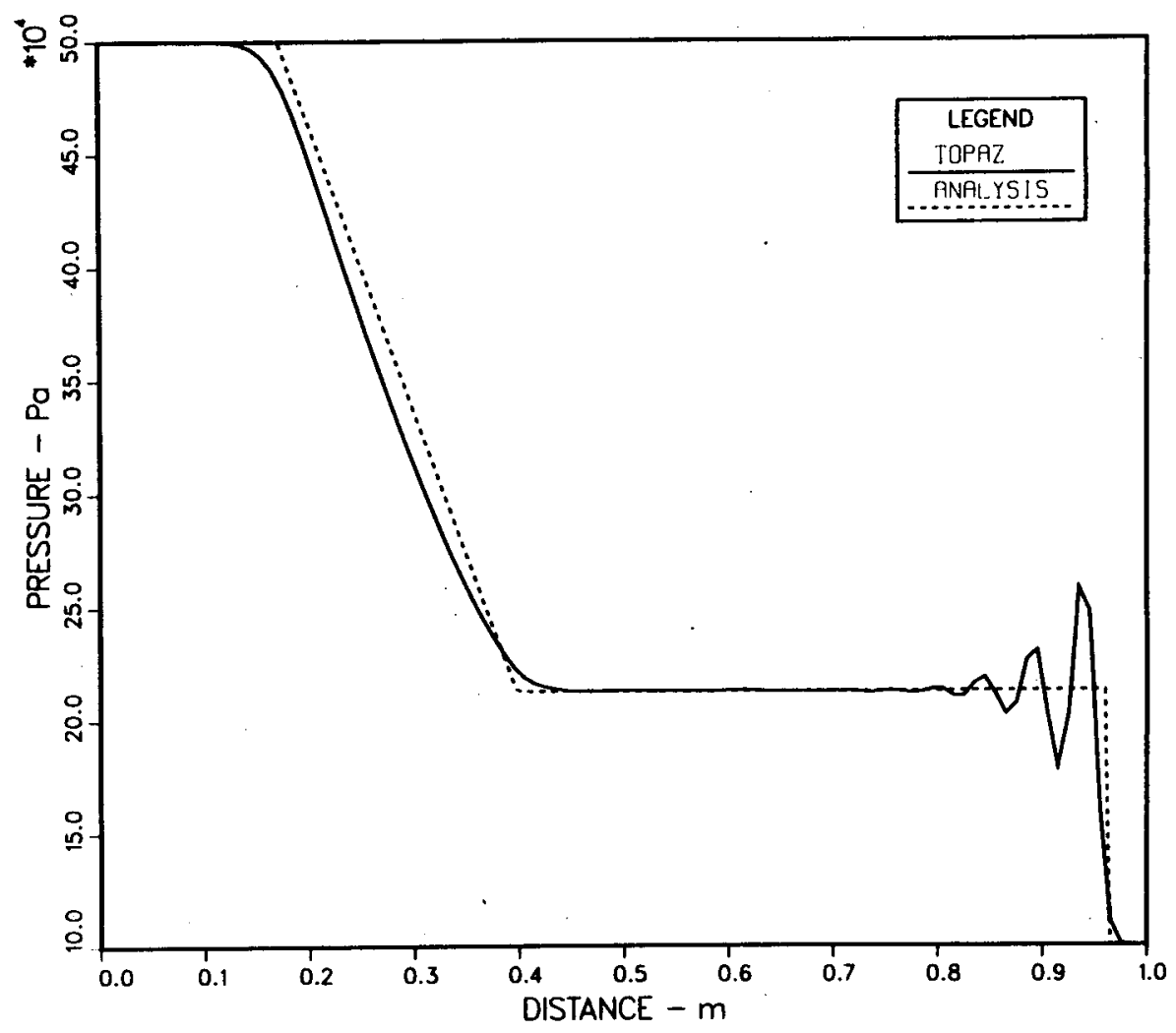

FIGURE 21a. SHOCK TUBE PRESSURE DISTRIBUTION FOR DAMP $=0$

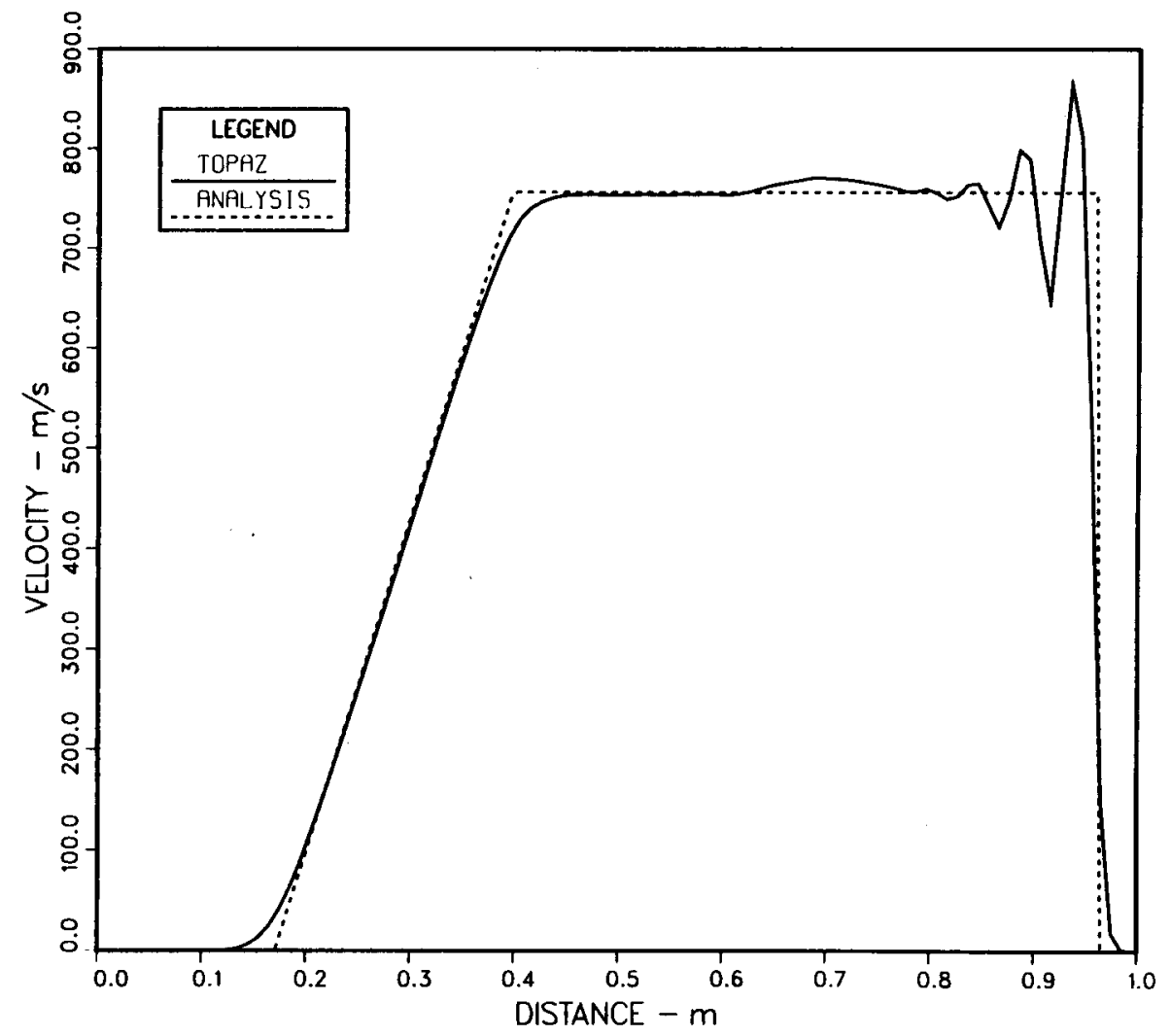

FIGURE 21b. SHOCK TUBE VELOCITY DISTRIBUTION FOR DAMP=0 


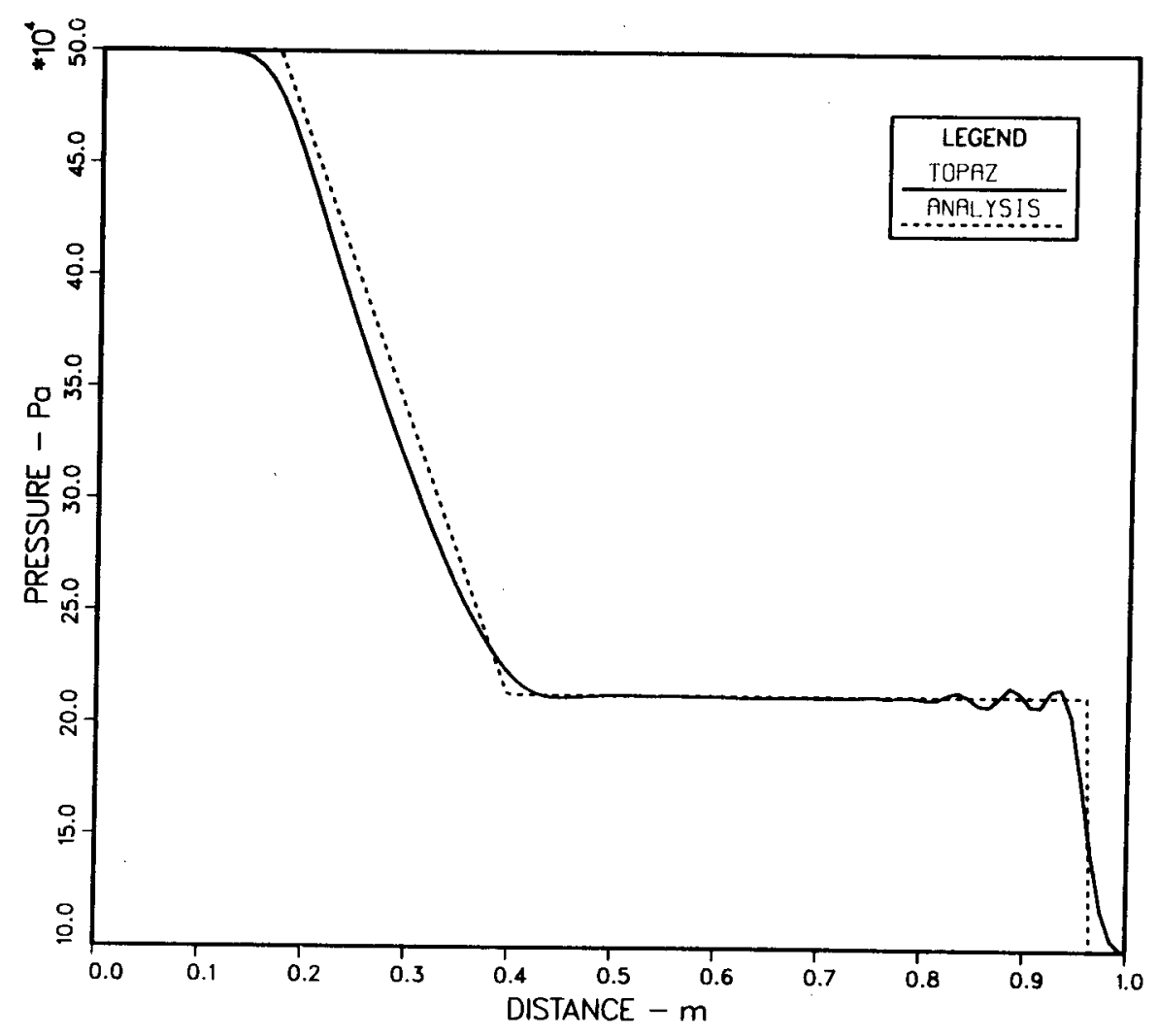

FIGURE 22a. SHOCK TUBE PRESSURE DISTRIBUTION FOR DAMP $=2$

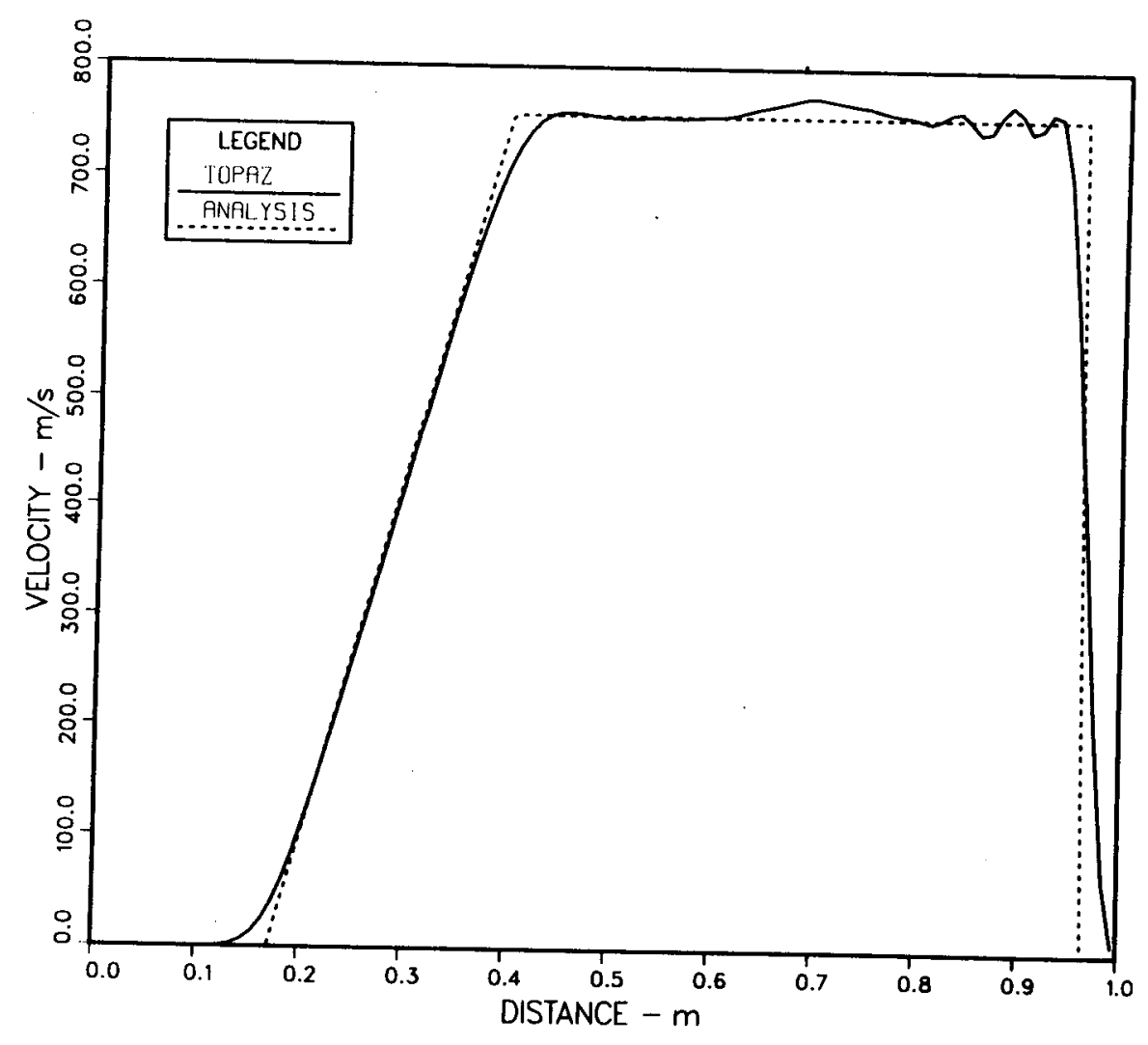

FIGURE 22b. SHOCK TUBE VELOCITY DISTRIBUTION FOR DAMP=2 


.




\section{EXAMPLE 5 - SIMULATION OF A STEADY STATE FANNO PIPE FLOW}

\section{Introduction}

In the previous two sections TOPAZ's ability to model small time scale events (accoustic time scales) was evaluated. In this section TOPAZ will be used to model a steady compressible flow through a pipe, i.e., a problem with an infinite time scale.

The problem simulated here is a simple Fanno line pipe flow, for which Shapiro [12] has outlined an analytical solution. An ideal gas flows through a constant diameter pipe having a uniform and constant friction factor. The pressure difference across the pipe is such that the flow is choked at the exit. The pipe flow is adiabatic. Shipiro's analysis leads to the following solution in terms of the inlet Mach number, $M$, the ratio of specific heats for the gas, $\gamma$, and the dimensionless flow resistance, $f L / d$ :

$$
\frac{4 f L}{D}=\frac{1-M^{2}}{\gamma M^{2}}+\frac{\gamma+1}{2 \gamma} \ln \left[\frac{(\gamma+1) M^{2}}{2\left(1+\frac{\gamma-1}{2} M^{2}\right)}\right]
$$

In this section TOPAZ is used to calculate the pipe inlet Mach number, for a range of flow resistances. These results are compared directly to the analytical solution given by equation (6).

In order to demonstrate the flexibility in assigning steady pipe flow boundary conditions, this problem is solved in two ways, each of which involves starting the calculations with the gas at rest. In the first method flow boundaries are simulated using large plenums which act as pressure sources and sinks. At time zero a valve at the downsteam end of the pipe is opened allowing gas to flow out of the high pressure source plenum, through the pipe, and into the low pressure sink plenum. After a short period of time, the startup transients die out leaving the desired steady state solution.

In the second method, the pressure source and sink plenums are replaced by smaller mass source and sink chambers. No valve is used in the simulation. Instead the gas in the system initially exists at a uniform state and the GENE, GSTA, GSTO directives are used to generate mass in the upstream chamber and remove mass in the downstream chamber. The two methods produce the same results.

\section{Problem Statement}

Simulate the steady flow of ideal gas hydrogen through an adiabatic constant diameter $(.01 \mathrm{~m})$ pipe $14.53 \mathrm{~m}$ in length. Assume a constant friction factor of 0.01 over the entire 
pipe length. Simulate the inlet and outlet flow boundary conditions in the each of the following ways:

A. Use large CHAMBERs to represent pressure source and sink plenums having a pressure ratio of 10 to 1 (e.g., assign initial pressures to the upstream and downstream CHAMBERs of 10 and $1 \mathrm{~Pa}$ respectively).

B. Repeat the calculation by replacing the pressure sources with mass sources. Use the calculated steady state mass flow rate from part $A$ to calculate the required input values for the GENE minor CHAMBER directives.

Adjust the pipe length and repeat the calculations for dimensionless resistances $(f L / D)$ ranging from .003278 to 62.92 .

\section{Discussion}

The problem schematic and corresponding mesh generation diagram appear in Figures $23 \mathrm{a}$ and $23 \mathrm{~b}$ respectively. The TOPAZ input file for simulating part $\mathrm{A}$ of the problem is shown in Figure 24. The valve (JOINT 4) at the end of the pipe (PIPE 5) is used to separate the two initial condition regions (REGIONs 1 and 2). The valve is assigned an opening time (DTOPEN) of .01 s and begins opening at time zero. The minor edit variables for this problem are the mass flow rate and Mach number for the CE at the upstream end of the PIPE. Ten CE's are used to divide the PIPE. The assigned value of TSTOP $=.5 \mathrm{~s}$ was sufficient to achieve a steady flow. The calculated mass flow rate and inlet Mach number was $1.618 \times 10^{-7} \mathrm{Kg} / \mathrm{s}$ and .2 respectively.

The input file for part $B$ is shown in Figure 25. The calculated mass flow rate from part $A$ was used to specify the directive $\mathrm{GENE}=1.618 \mathrm{E}-7$ for the upstream mass source and the directive GENE=-1.618E-7 for the downstream mass sink. At steady state the calculated mass flow and inlet Mach 'number were again $1.618 \times 10^{-7} \mathrm{Kg} / \mathrm{s}$ and .2 respectively.

TOPAZ was used to calculate inlet Mach numbers for the full range of dimensionless flow resistances. The calculated values are compared to the analytical solution of equation (6) in Figure 26. Subdividing the PIPE into $10 \mathrm{CE}$ 's was sufficient to produce excellent results over the entire range of flow resistances. 


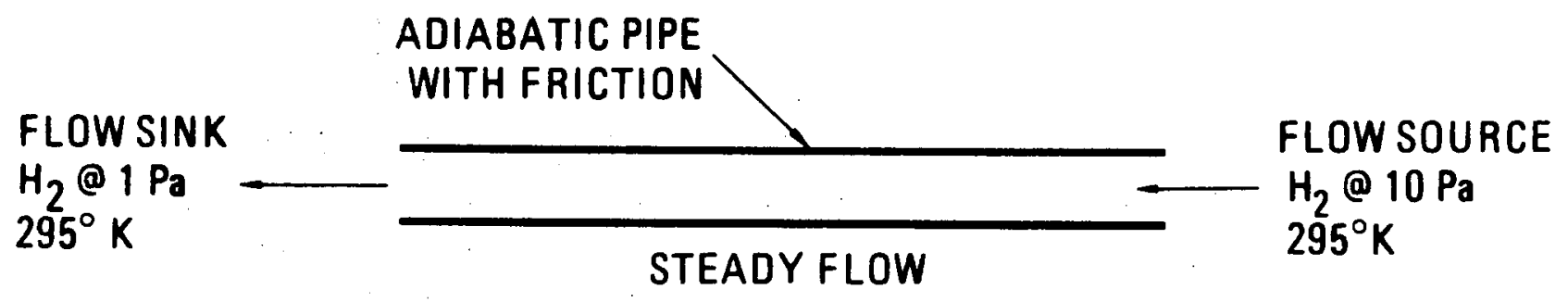

FIGURE 23a. SCHEMATIC FOR EXAMPLE 5

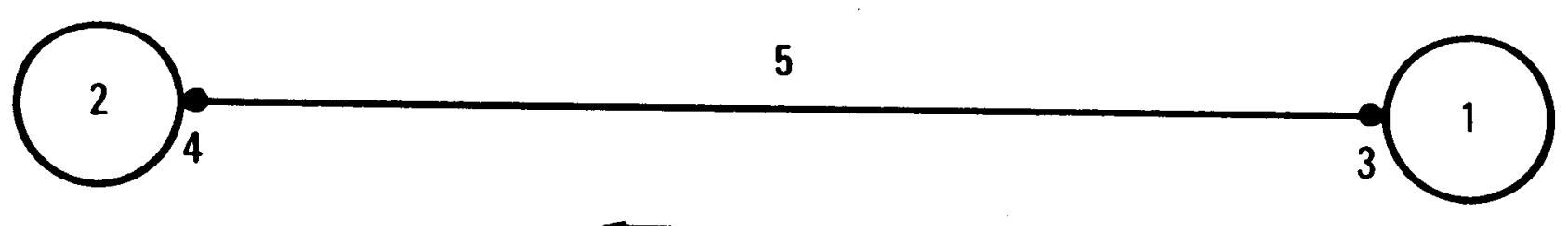

FIGURE 23b. MESH GENERATION DIAGRAM FOR EXAMPLE 5 


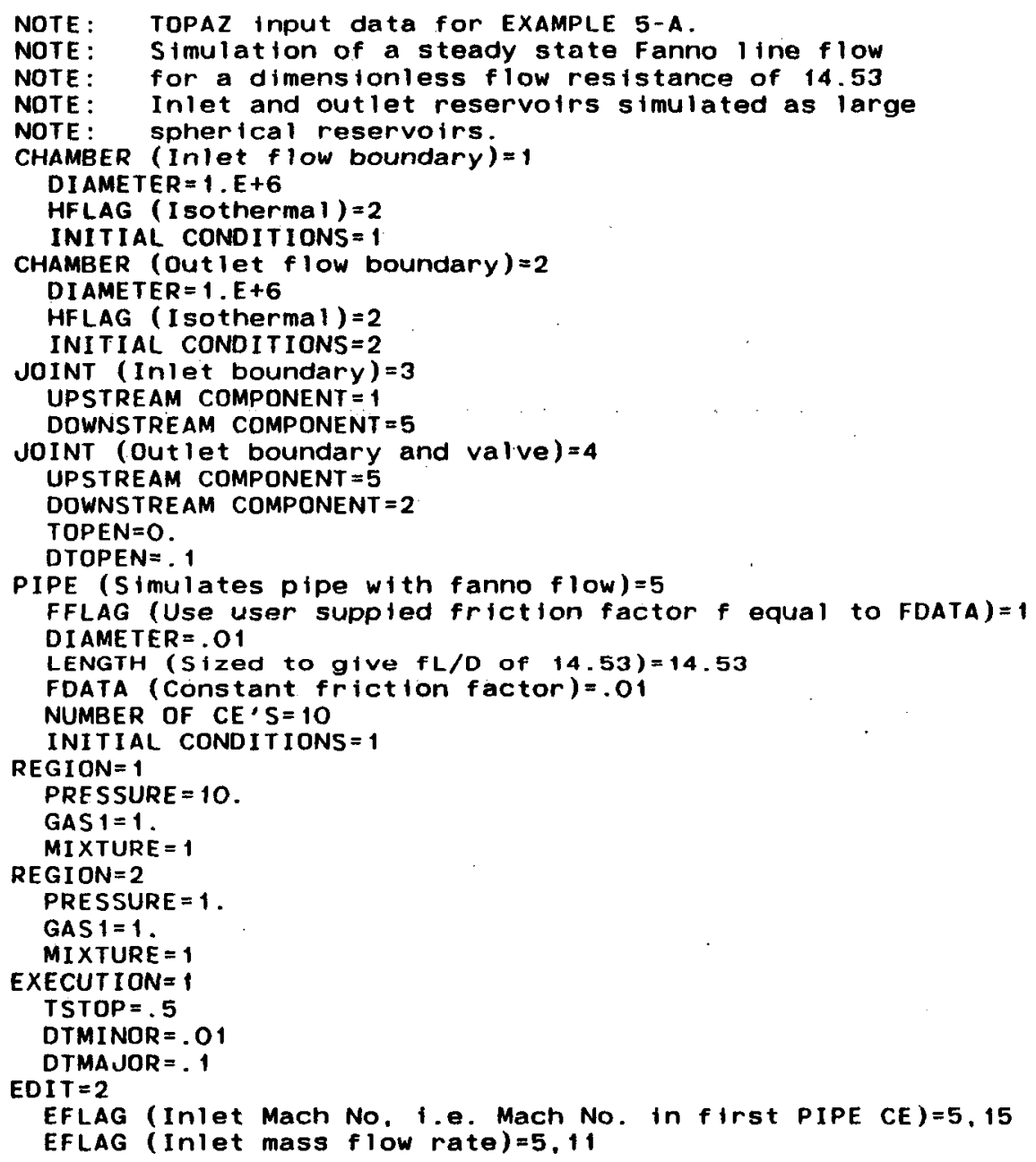

FIGURE 24. TOPAZ INPUT FILE FOR EXAMPLE 5A 


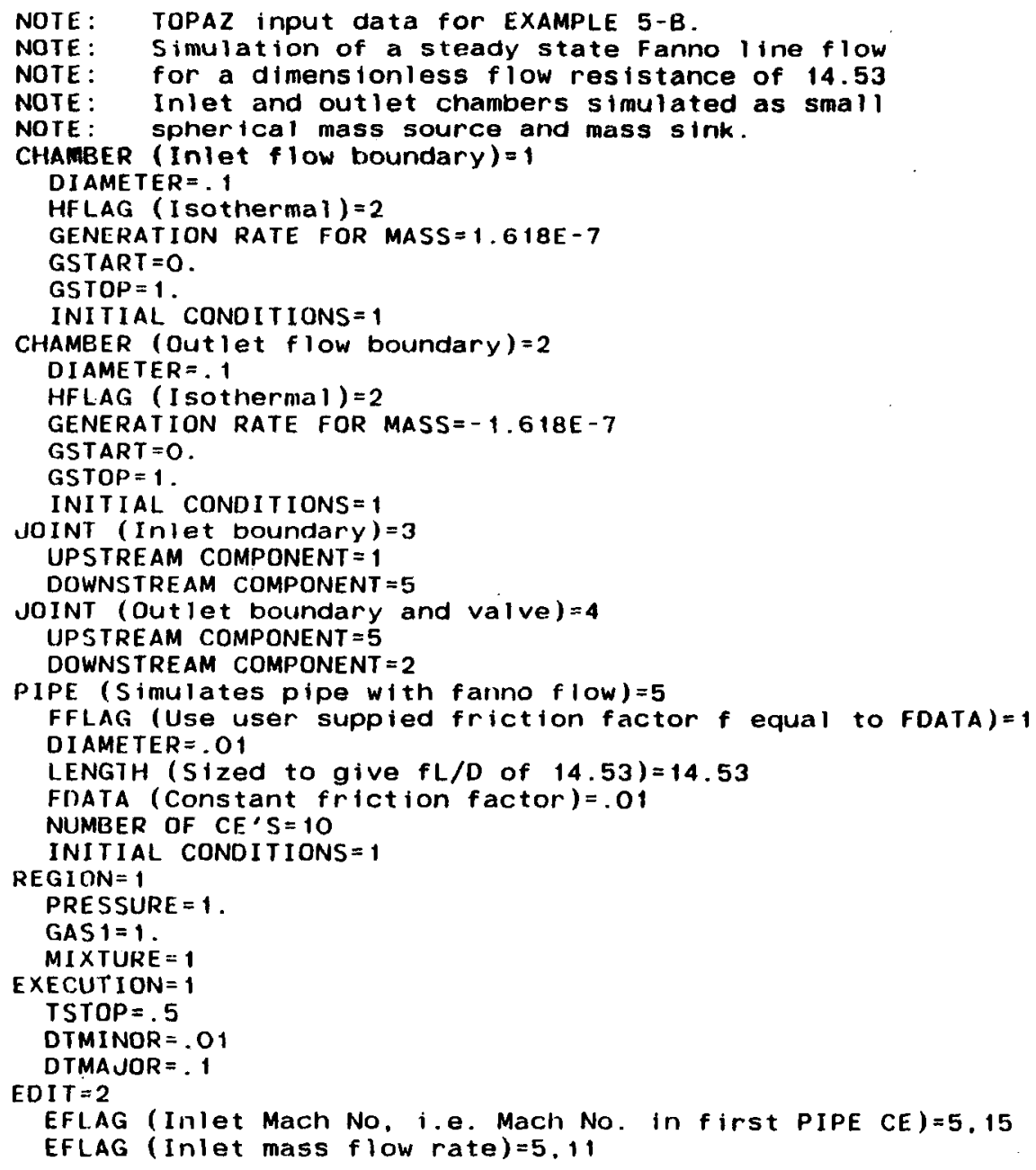

FIGURE 25. TOPAZ INPUT FILE FOR EXAMPLE 5B 


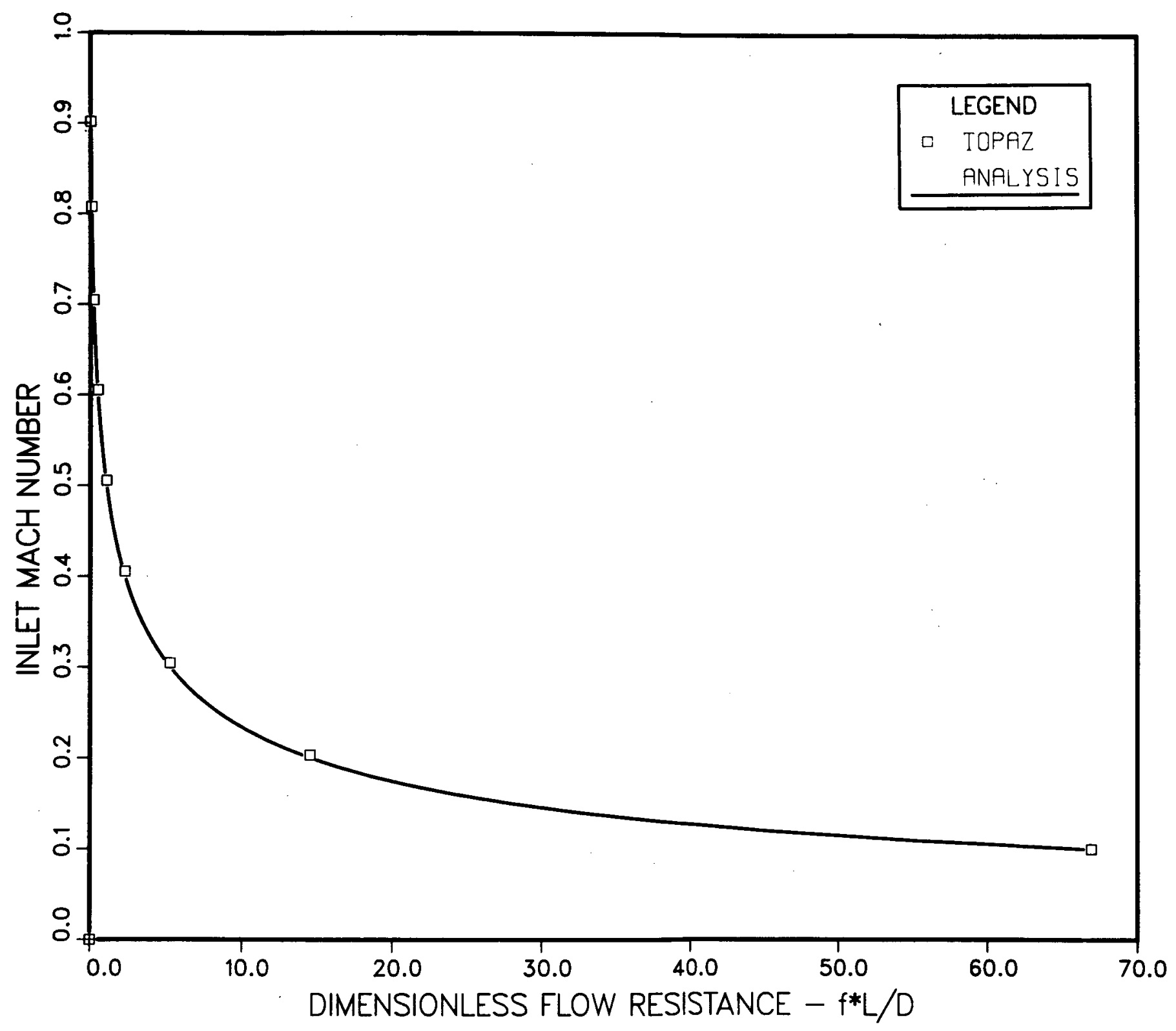

FIGURE 26. INLET MACH NUMBER VS. DIMENSIONLESS FLOW RESISTANCE FOR A STEADY FANNO FLOW 


\section{EXAMPLE 6 - SIMPLE PISTON MOTION}

\section{Introduction}

This example problem illustrates how to utilize the PISTON directives to simulate the motion of pistons, diaphragms, and bladders. In particular, a simple mass-spring-damper system acted upon by a constant force will be simulated. The overdamped, critically damped, and underdamped solutions will be calculated and compared to the analytical solutions. Piston calculations with simulated mechanical stops and Coulomb friction will also be illustrated.

The second order differential equation used in TOPAZ to describe piston, diaphragm, and bladder motion is given by:

$$
\begin{array}{r}
(\mathrm{MASS}) \ddot{\mathrm{X}}+(\mathrm{CVIS}) \dot{\mathrm{X}}+\mathrm{KSPR}(\mathrm{X}-\mathrm{XKZE})=(\mathrm{AFAC})(\mathrm{AREA})\left(P_{u}-P_{d}\right) \\
-\mathrm{FCOU}+\mathrm{FORC}
\end{array}
$$

where $\mathrm{X}$ is the piston dispacement and $\left(P_{u}-P_{d}\right)$ is the pressure difference across the piston. The remaining nomenclature in the equation is identical to the PISTON minor directive nomenclature given in Table 4 . The classical mass-spring-damper problem may be simultated by first eliminating the influence of the piston pressure pressure difference $P_{u}-P_{d}$, i.e. let $\mathrm{AFAC}=0$, and then setting XKZE and FCOU to zero (defaults). At time zero a constant force, FORC, is applied to the piston and the objective is to compute the piston position as a function of time.

The applicable piston parameters may be related to the piston natural frequency, $\omega_{\eta}$, and the damping factor, $\zeta$, by the following expressions:

$$
\begin{gathered}
\omega_{\eta}^{2}=\frac{\mathrm{KSPR}}{\mathrm{MASS}} \\
2 \zeta \omega_{\eta}=\frac{\mathrm{CVIS}}{\text { MASS }}
\end{gathered}
$$

Numerous references including reference [13] present the analytical solutions for the sample mass-spring-damper problem. Three distinct solutions exist depending on the value 
of $\zeta$ selected:

Underdamped Solution $\varsigma<1$

Criticially Damped Solution $\varsigma=1$

Overdamped Solution $\varsigma>1$

In this section, TOPAZ calculations for the mass-spring-damper problem will be compared to the three analytical solutions from reference [13]. These calculations simulate an unrestrained piston. The underdamped case will also be simulated for a restrained situation in which a mechanical stop prevents the piston from making its full excursion. Finally, the simulation of Coulomb friction will be demonstrated and the influence of pressure forces on piston motion will be examined.

\section{Problem Statement}

A piston is placed in its equilibrium position at the midpoint of a cylinder which is 1 $\mathrm{m}$ in diameter and $4 \mathrm{~m}$ long. The piston has a mass of $1 \mathrm{~kg}$, and a spring constant of 9 $\mathrm{N} / \mathrm{m}$. At time zero a force of $9 \mathrm{~N}$ is applied to the piston. Assume that hydrogen initially at $1 \mathrm{~Pa}$ is trapped in the upstream and downstream sides of the cylinder. During the piston excursions, this gas is expanded and compressed isothermally. Neglect the effect of pressure changes on the piston motion (i.e. $\mathrm{AFAC}=0$ ) and compute the piston motion as a function of time for the following five cases:
A. Underdamped case $(\zeta=.3), \dot{C}$ CIS $=1.8 \mathrm{~N}-\mathrm{s} / \mathrm{m}$.
B. Critically damped case $(\varsigma=1),. \mathrm{CVIS}=6.0 \mathrm{~N}-\mathrm{s} / \mathrm{m}$.
C. Overdamped case $(\varsigma=2)$, CVIS $=12.0 \mathrm{~N}-\mathrm{s} / \mathrm{m}$.
D. Repeat case $A$ with a mechanical stop at $X=1.2 \mathrm{~m}$.
E. Repeat case A with Coulomb friction of $1 \mathrm{~N}$.

Finally, include the effect of pressure changes (i.e. $\mathrm{AFAC}=1$, the default) for the following case:

F. Underdamped case $(\zeta=.3)$, CVIS $=1.8 \mathrm{~N}-\mathrm{s} / \mathrm{m}$. 


\section{Discussion}

Schematic and mesh generation diagrams for this problem are shown in Figures 27a and $27 \mathrm{~b}$ respectively. The TOPAZ input file required to solve case $A$ is given in Figure 28. The piston mechanical stop parameters XLDN and XLUP were set near the ends of the cylinder so that they do not interfere with piston motion. CHAMBER 1, the upstream chamber, contains the gas which will be expanded and CHAMBER 2, the downstream chamber, contains the gas which will be compressed. Minor edits for piston position and the upstream and downstream pressures have been provided for in the input file.

The TOPAZ calculations for the underdamped, critically damped, and overdamped piston are compared to the analytical solutions of reference [13] in Figures 29, 30, and 31 respectively. In all cases the agreement is excellent.

Figure 32 shows the effect on underdamped piston motion of moving the downstream mechanical stop from near the end of the cylinder (XMDN=1.999) to $\mathrm{X}=1.2 \mathrm{~m}(\mathrm{XMDN}=1.2)$. The unrestrained (case A) as well as the restrained (case D) piston motions are plotted for comparison purposes. The two solutions are identical up to the point where the stop is encountered. Since the stop was located downstream of the new piston equilibrium position $(x=1.0)$, there is sufficient spring force to pull the piston back off the stop. Both the restrained and unrestrained pistons vibrate to equilibrium at the undamped natural frequency, $\omega_{\eta}=1.2$ cycles per second, although phase and amplitude changes are apparent because of the mechanical stop.

Figure 33 compares the underdamped piston motions with and without the $1 \mathrm{~N}$ Coulomb friction force. The friction force $(\mathrm{FCOU}=1$.) causes the piston to move more slowly during the early time. As the piston approaches the $\mathrm{X}=1.0$ position the sum of the forces (inertia, viscous damping, spring, and FORC) acting on the piston becomes less than the Coulomb friction force. This causes the piston to come abruptly to rest short of the equilibrium point for case $A$.

Thus far little has been said regarding the gas calculations in CHAMBERs 1 and 2. Although changes in pressure do not affect the piston motion (since $A F A C=0$ ), the piston motion does affect the calculation of the chamber pressures. Consider, for example, case $B$ in which the final piston position is $X=1.0$. This corresponds to a 33 percent increase in the upstream (CHAMBER 1) volume and a 50 percent decrease in the downstream (CHAMBER 2) volume. For the isothermal expansion and compression the final upstream and downstream chamber pressures should be $0.667 \mathrm{~Pa}$ and $2.0 \mathrm{~Pa}$ respectively. This is confirmed by the calculated pressure transients for case B which are shown in Figure 34 .

In cases $A$ through $E$, the influence of the upstream and downstream gas pressures on the piston motion was deliberately decoupled using the directive "AFAC $=0$ ". Most applications require that the motion of pistons, diaphragms, and bladders be fully coupled to the time dependent upstream and downstream pressures. Hence, the default value for AFAC in TOPAZ is 1 . Figure 35 shows the motion of the underdamped piston when acted upon by the gas pressure forces as well as the forcing function FORC (Curve labeled CASE F). For comparison purposes the response from case $A$ is also shown in the figure. 


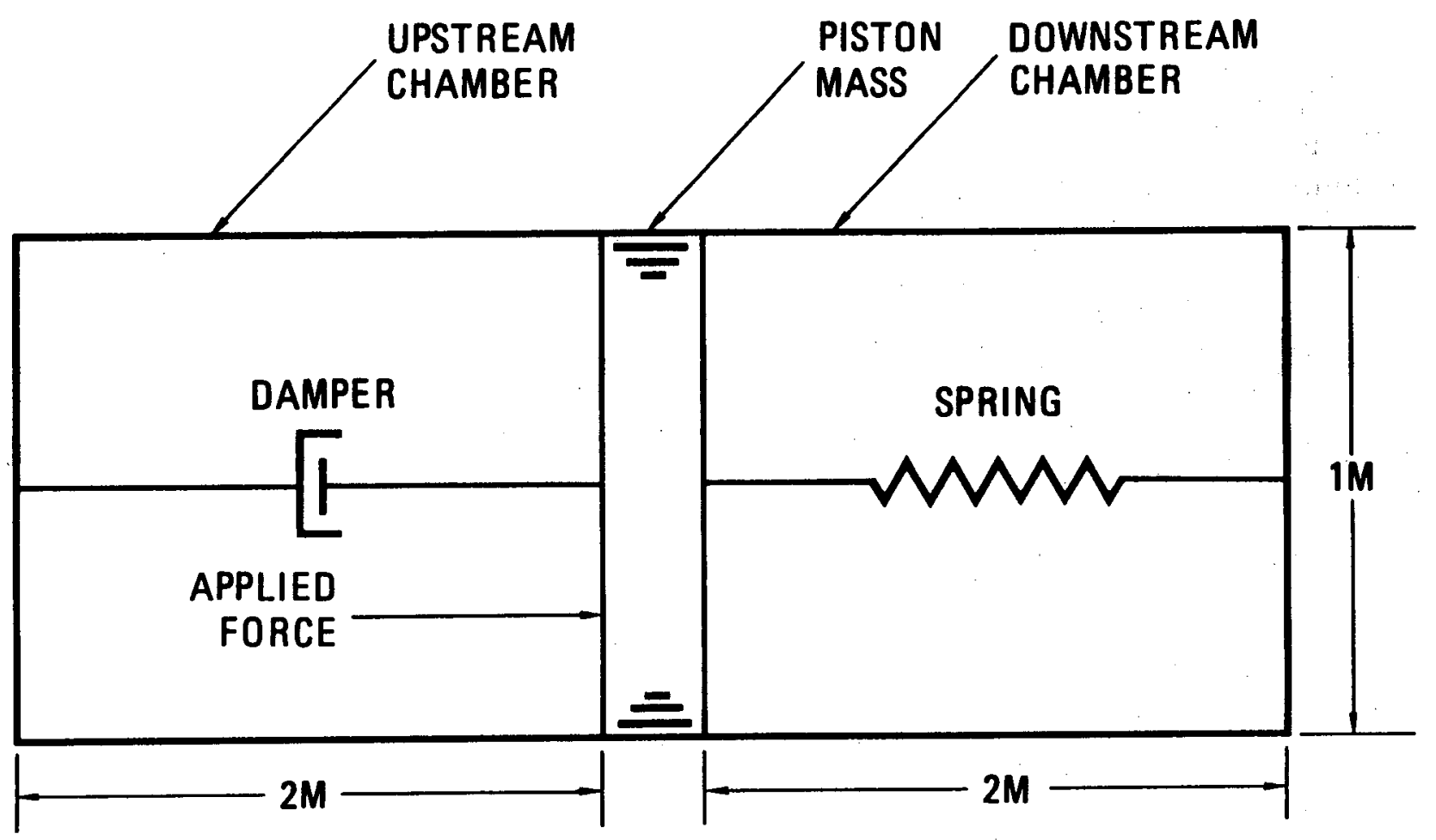

FIGURE 27a. SCHEMATIC FOR EXAMPLE 6

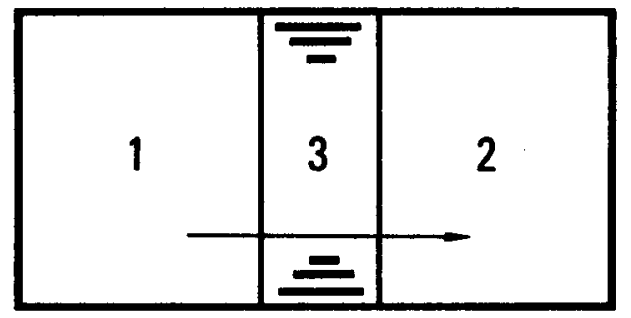

FIGURE 27b. MESH GENERATION DIAGRAM FOR EXAMPLE 6 


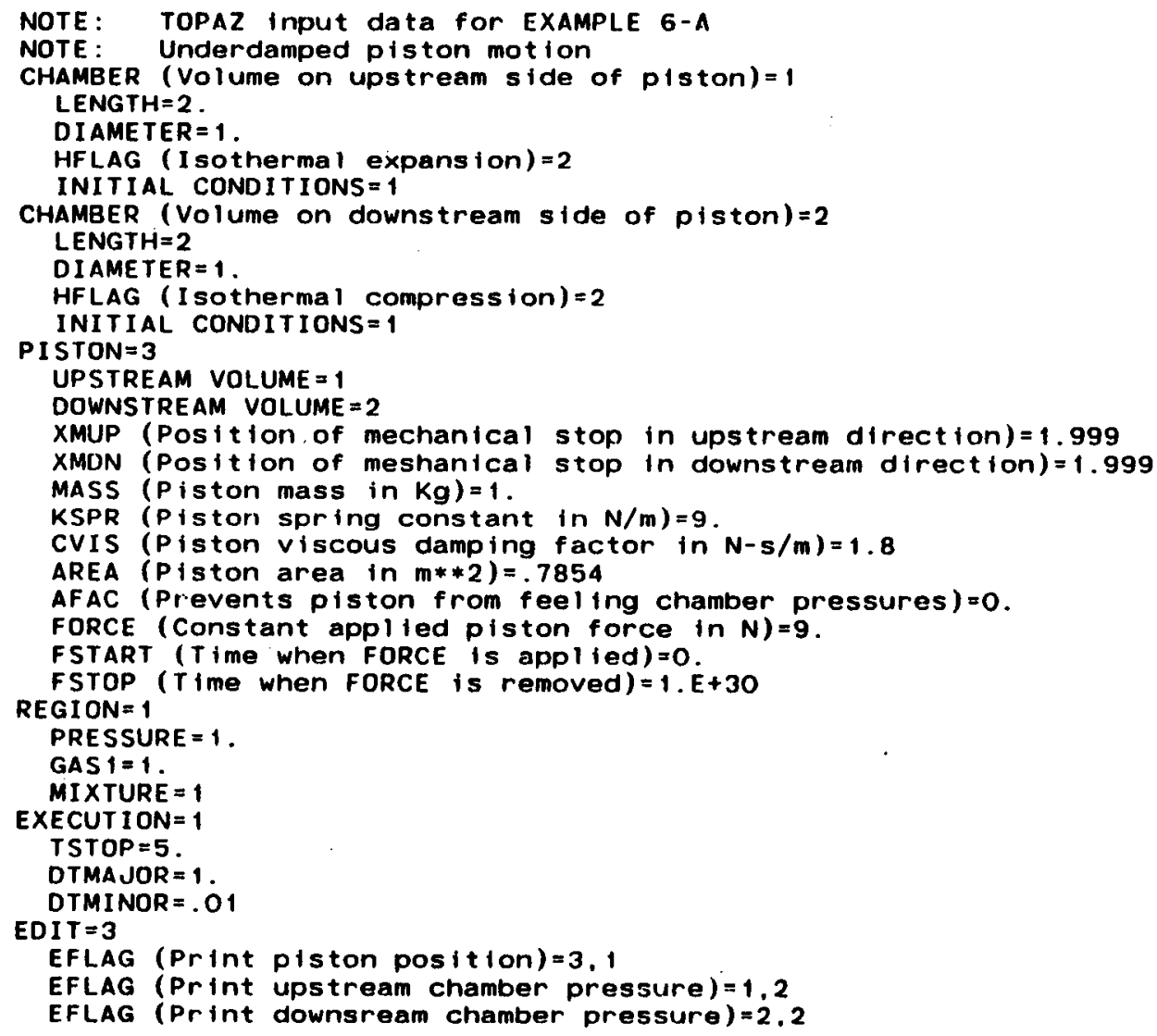

FIGURE 28. TOPAZ INPUT FILE FOR EXAMPLE 6A 


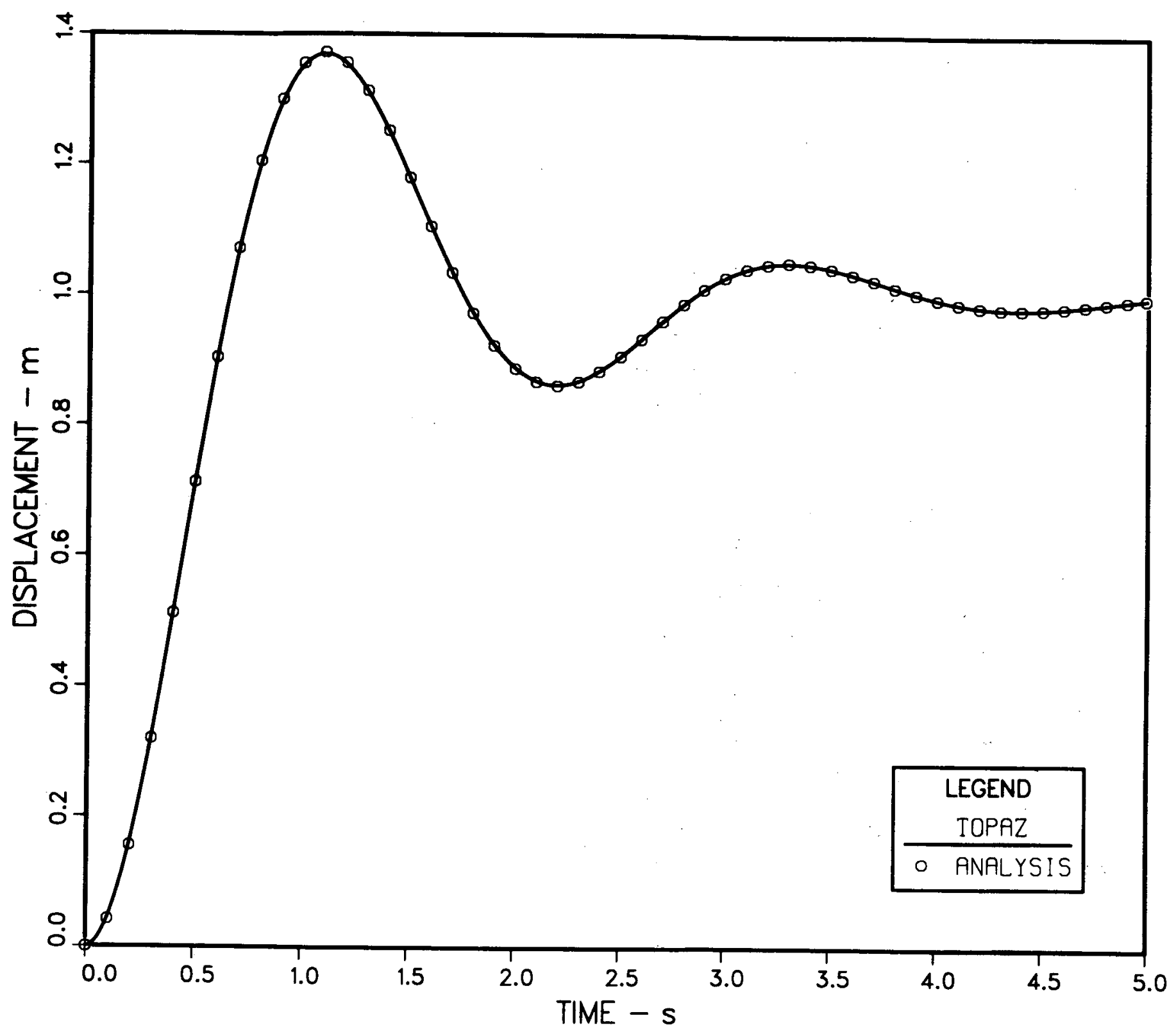

FIGURE 29. UNDERDAMPED FREE PISTON MOTION 


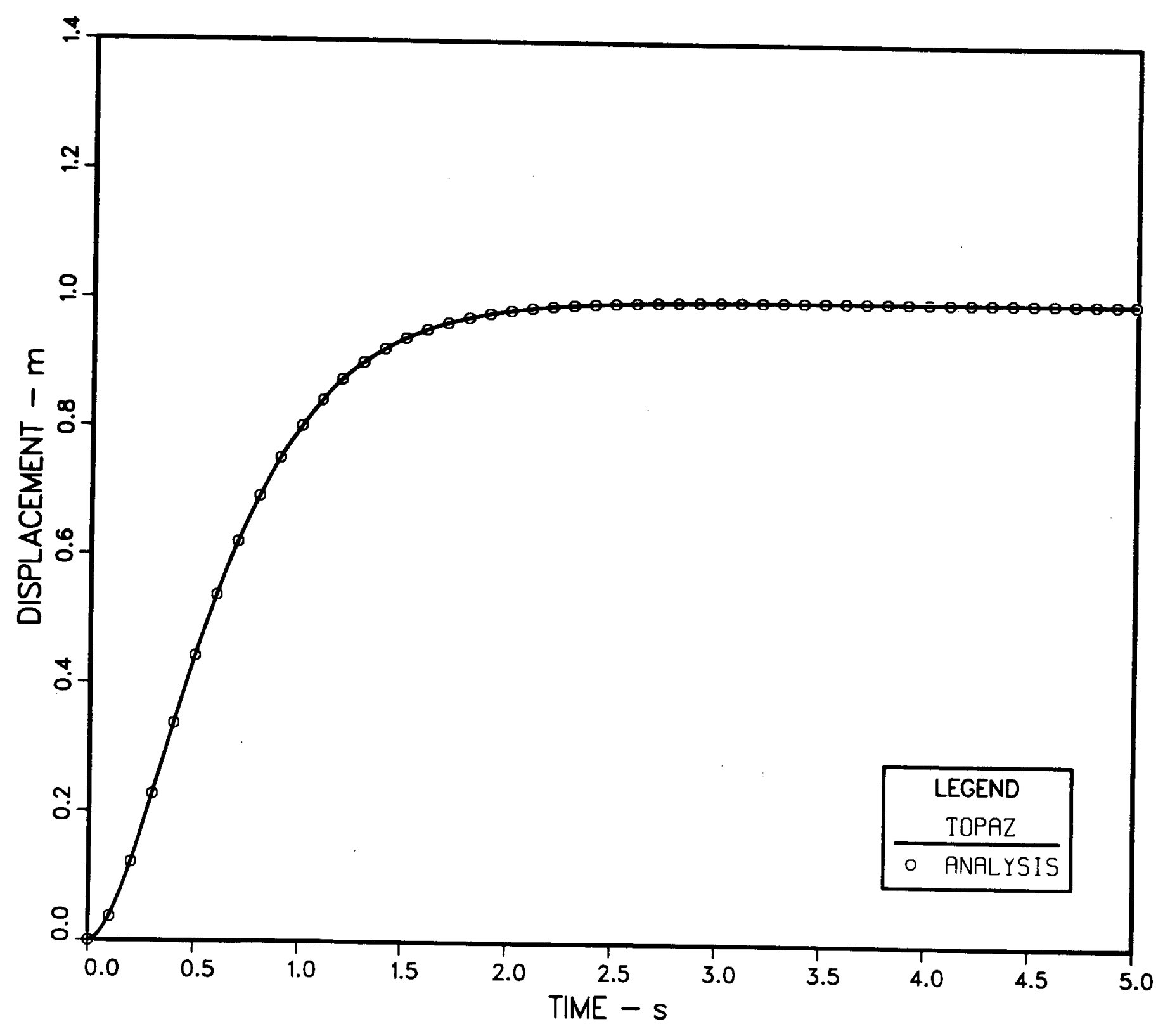

FIGURE 30. CRITICALLY DAMPED FREE PISTON MOTION 


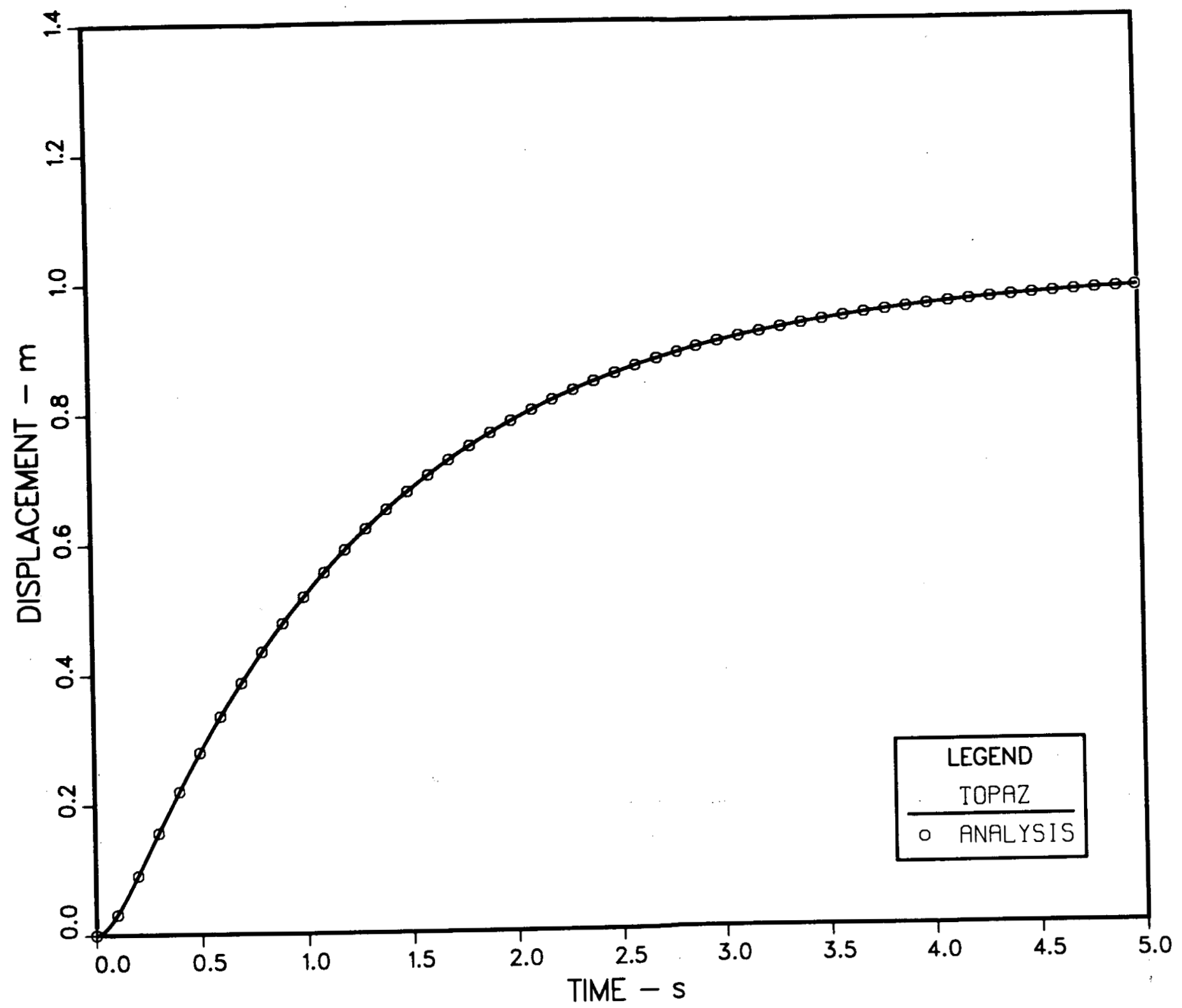

FIGURE 31. OVERDAMPED FREE PISTON MOTION 


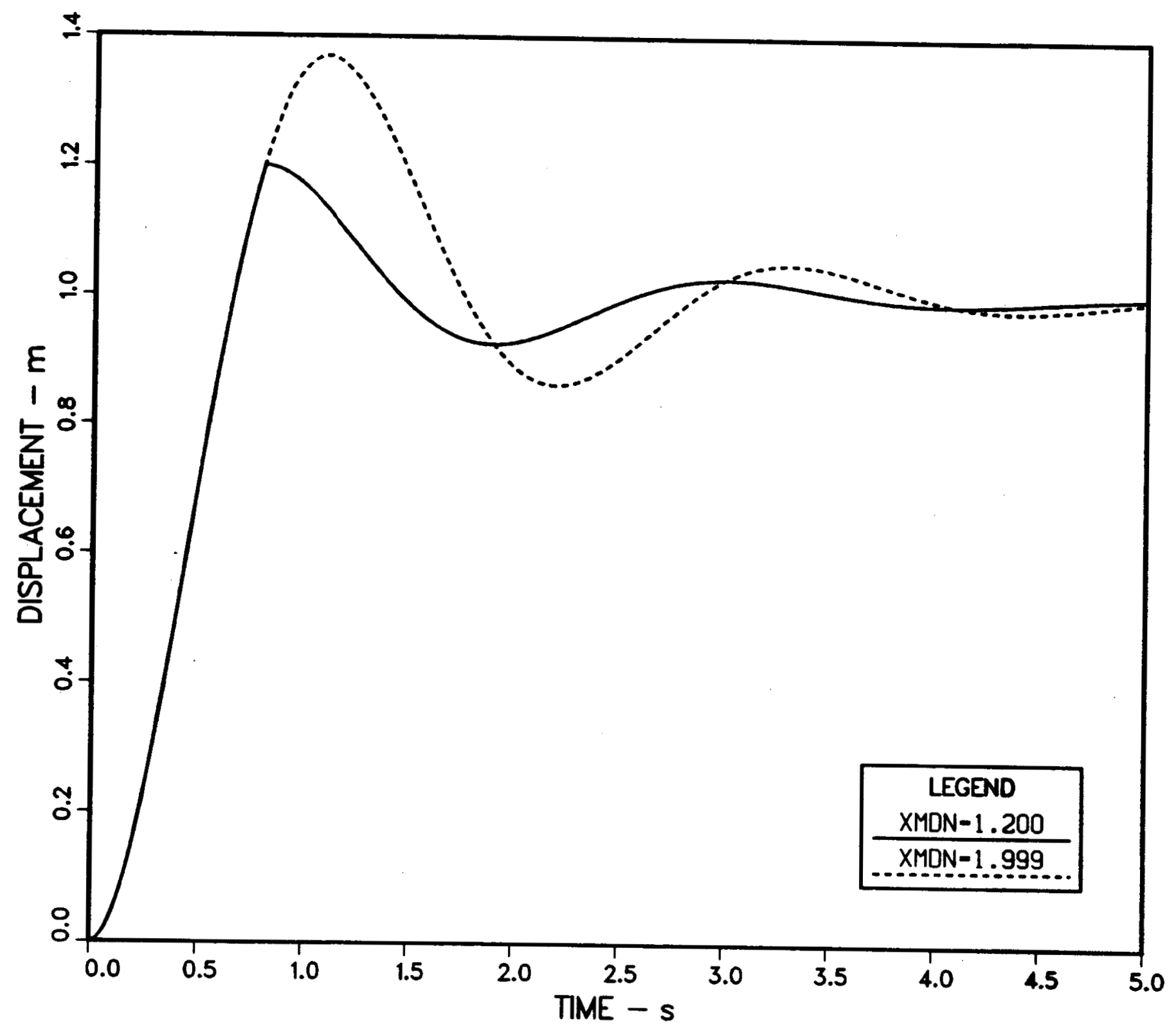

FIGURE 32. THE EFFECT OF POSITIONING THE DOWNSTREAM MECHANICAL STOP (XMDN) ON UNDERDAMPED PISTON MOTION 


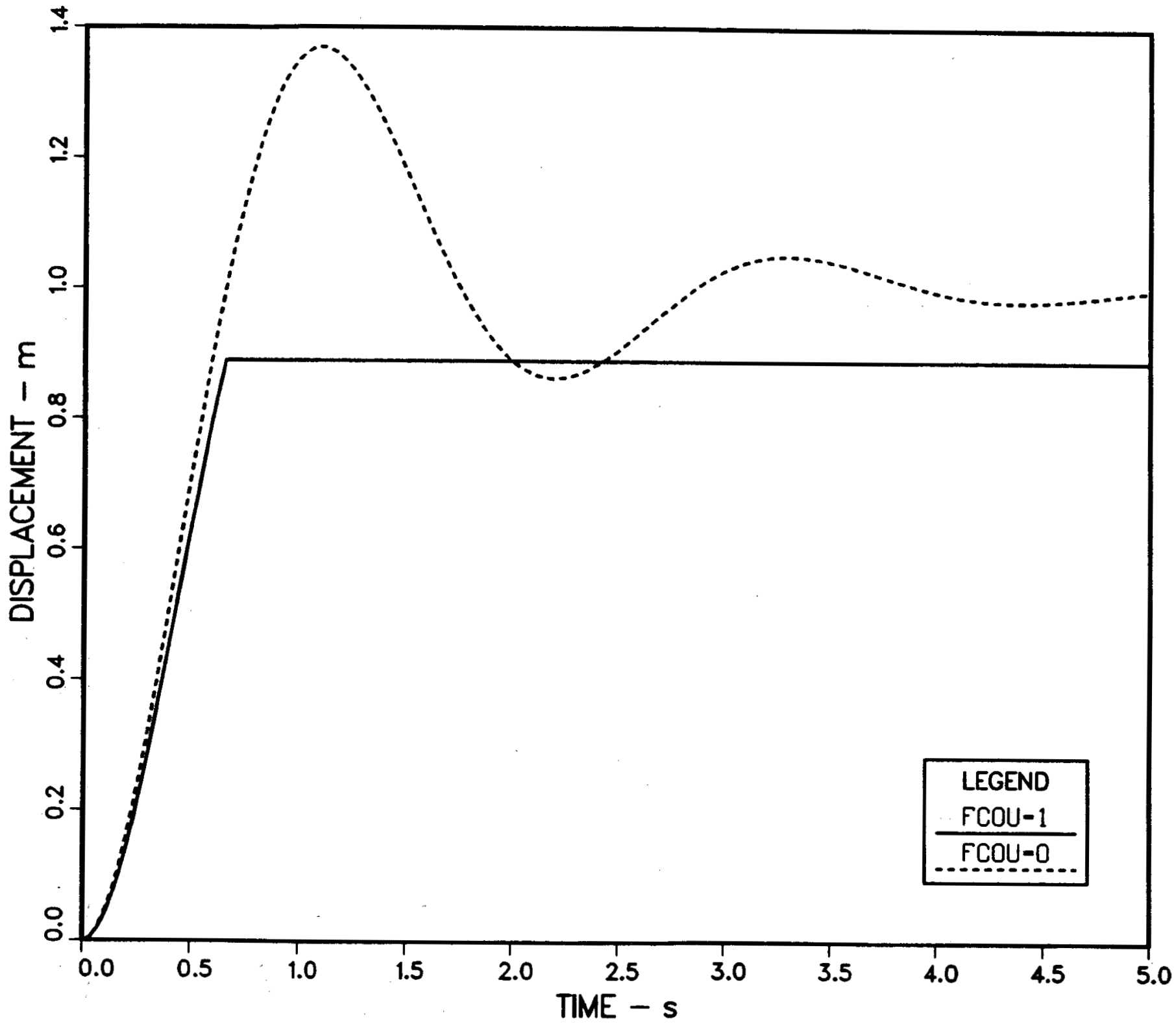

FIGURE 33. THE EFFECT OF COULOMB FRICTION (FCOU) ON UNDERDAMPED PISTON MOTION 


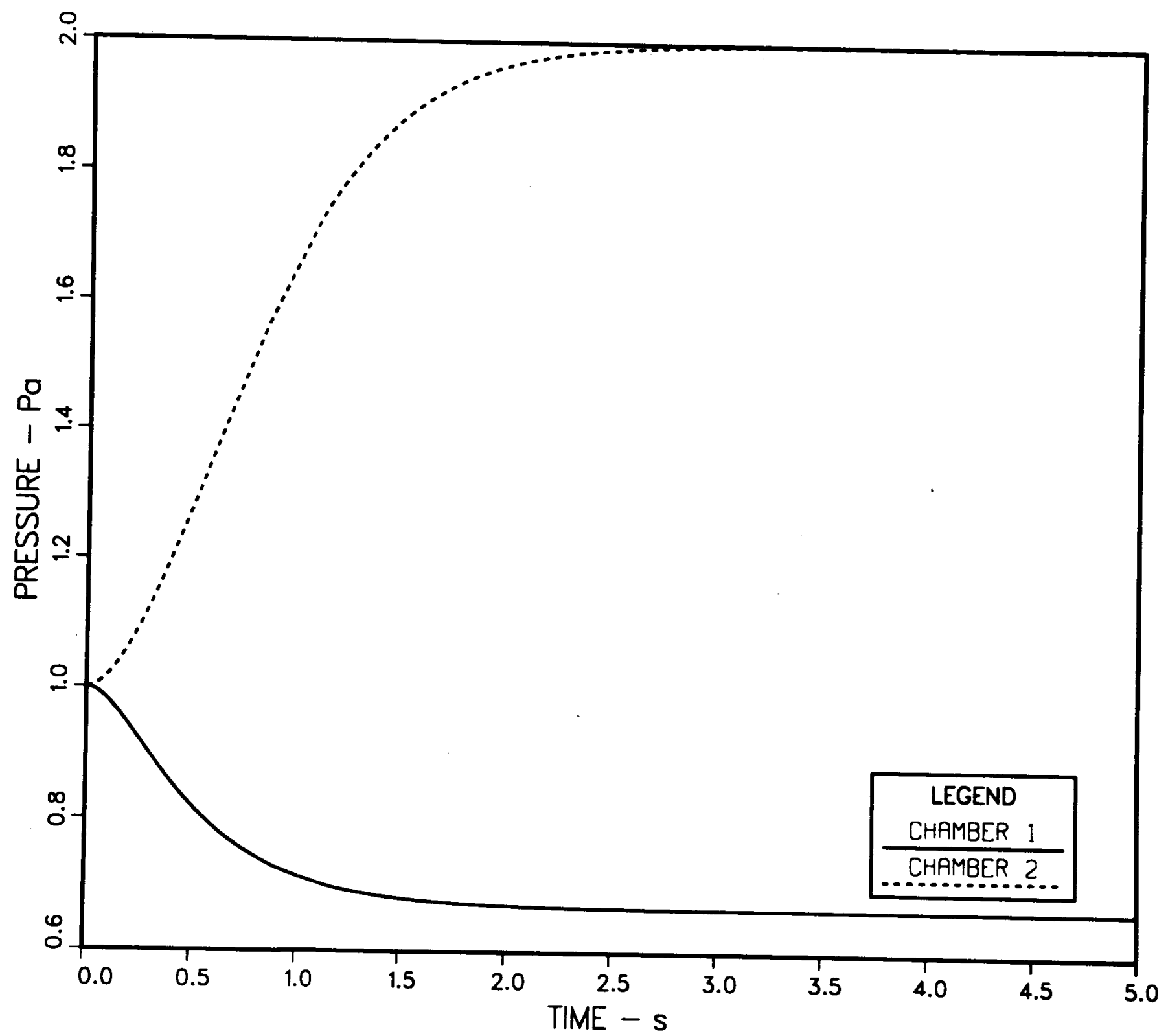

FIGURE 34. UPSTREAM AND DOWNSTREAM PRESSURE HISTORIES FOR CRITICALLY DAMPED PISTON MOTION 


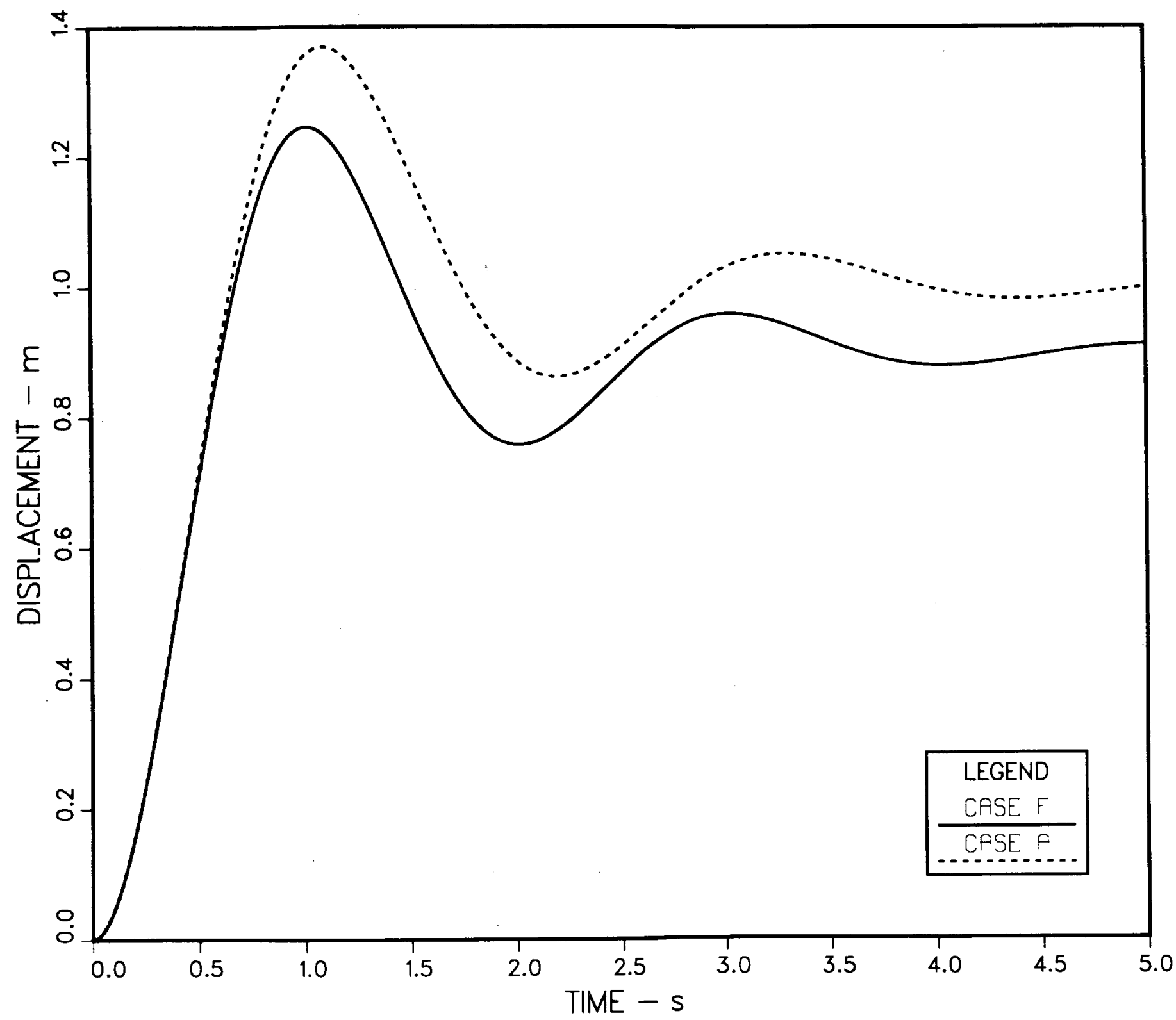

FIGURE 35. INFLUENCE OF GAS PRESSURES ON UNDERDAMPED PISTON MOTION 
When the gas pressures are allowed to influence the piston motion, the effect is similar - to introducing an additional nonlinear spring force into the problem. The piston motion continues to have an "underdamped" appearance, but the oscillations occur around a new equilibrium point. Close examination reveals that the frequency of the piston oscillations is no longer constant with time, as was the case for the simple linear spring problem solved in part $\mathbf{A}$. 


\section{EXAMPLE 7 - GAS TRANSFER IN A SYSTEM HAVING A FLOW BRANCH}

\section{Introduction}

The example problem presented in this section represents one in a class of problems most frequently solved using TOPAZ. It involves the nearly "quasi-steady" flow of a real gas mixture through a system having significant frictional pressure losses and vessel heat transfer. This particular example, illustrates how to assemble TOPAZ CHAMBERs, PIPEs, and JOINTs to model a system composed of two high pressure gas reservoirs connected to a single receiver via a flow branch. The system of interest is shown in Figure 36a. Although the system contains a single flow branch, the modeling technique discussed here can be easily extended to simulate systems of any complexity (e.g. systems having branches extending off of branches, tree-like configurations, loops, etc.).

Unlike the examples presented in the previous sections, this problem is quite complex and possesses no analytical solution. Hence only the computational results will be presented.

\section{Problem Statement}

Consider the two-reservoir/single-receiver system shown in Figure 36a. At time zero, reservoir $1(100 \mathrm{cc})$ contains pure deuterium at $100 \times 10^{5} \mathrm{~Pa}$, and reservoir $2(200 \mathrm{cc}$ ) contains pure hydrogen at $200 \times 10^{5} \mathrm{~Pa}$. The receiver $(1000 \mathrm{cc})$ and the interconnecting piping downstream of the reservoir valves initially contains pure helium at $1 \mathrm{~Pa}$. Each pipe is $100 \mathrm{~cm}$ in length and $.2 \mathrm{~cm}$ in ID. The volume of the plumbing in the vicinity of the flow branch is roughly equivalent to that of a spherical chamber having a diameter equal to twice that of the piping (i.e., $0.4 \mathrm{~cm}$ ). The orifice upstream of the receiver is $1 \mathrm{~cm}$ in length and has an ID of $.05 \mathrm{~cm}$. The valve downstream of reservoir 1 opens at time zero, and the valve downstream of reservoir 2 opens $.5 \mathrm{~s}$ later. Each valve requires $.005 \mathrm{~s}$ to open. Assume that the initial containment wall temperature and initial gas temperatures are $295 \mathrm{~K}$ (default). Determine the time history of the following quantities:

1. Reservoir and receiver pressures

2. Mass of hydrogen, helium, and deuterium in the receiver

\section{Discussion}

A mesh generation diagram and corresponding TOPAZ input file for this problem are shown in Figure $36 \mathrm{~b}$ and 37 respectively. The initially closed valves provide the natural boundaries for defining the three initial condition REGIONs. REGION 1 (pure deuterium) 


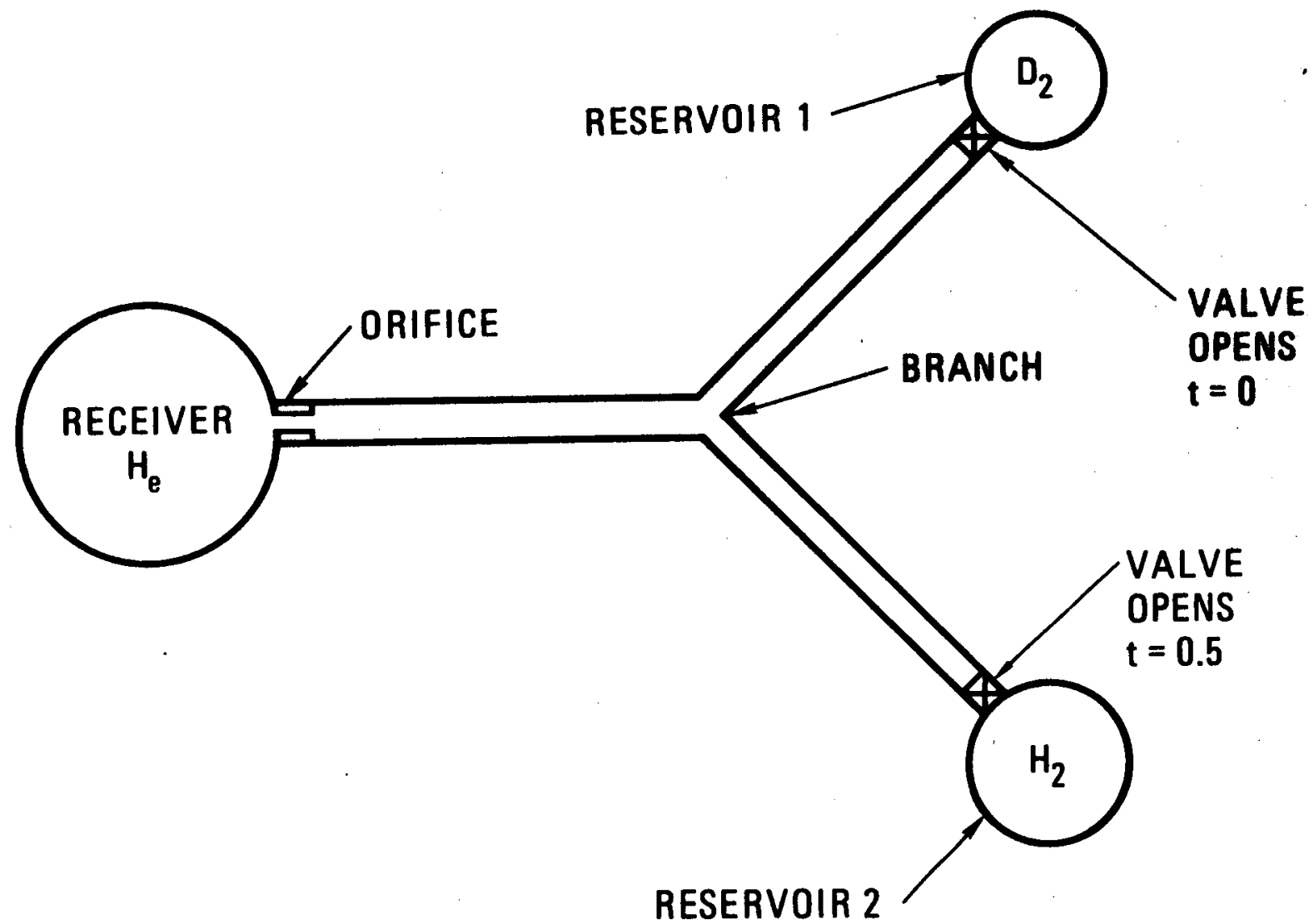

FIGURE 36a. SCHEMATIC FOR EXAMPLE 7

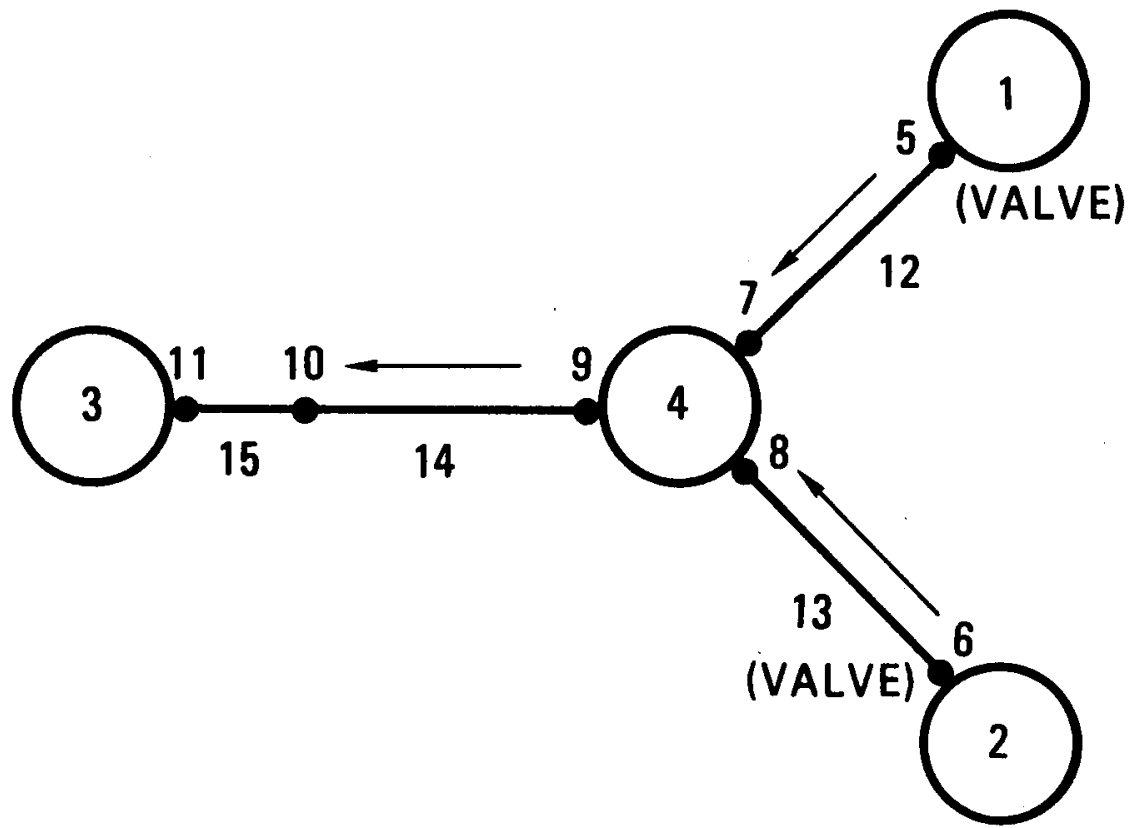

FIGURE 36b. MESH GENERATION DIAGRAM FOR EXAMPLE 7 
NOTE: TOPAZ input data for EXAMPLE 7 NOTE: Simulation of a branched flow.

CHAMBER ( $F$ irst reservoir) $=1$

VOLUME $=100 . E-6$

INITIAL CONDITIONS $=1$

CHAMBER (Second reservoir) $=2$ VOLUME $=200 . E-6$

INITIAL CONDITIONS $=2$

CHAMBER (Receiver) $=3$

VOLUME $=1000 . E-6$

INITIAL CONDITIONS $=3$

CHAMBER (Branch volume) $=4$

DI AME TER $=.004$

INI TIAL CONDITIONS=3

JoIN (Valve at first reservolr) $=5$

UPSTREAM $=1$

DOWNSTREAM $=12$

TOPEN $=0$.

DTOPEN $=.005$

JOINT (valve at second reservoir) $=6$

UPSTREAM $=2$

DOWNSTREAM $=13$

TOPEN $=.5$

DTOPEN $=.005$

JOINT $=7$

UPST $=12$

JOINT $=8$

UPST $=13$

DOWN $=4$

JOINT $=9$

UPST $=4$

- $D O W N=14$

JOINT $=10$

UPST $=14$

DOWN $=15$

JOINT $=11$

$\begin{aligned} \text { UPST } & =15 \\ \text { DOWN } & =3\end{aligned}$

PIPE (P ipe from first reservolr) $=12$

DIAMETER $=.002$

LENGTH $=.1$

NUMBER OF $C E$ 'S $=5$

INITIAL CONDITIONS $=1$
PIPE (Pipe from second reservoir) $=13$

INITIAL CONDITIONS $=1$

NUMBER OF $C E \cdot S=5$

LENGTH $=.1$

DI AME TER $=.002$

PIPE (P Ipe to receiver) $=14$

LENGTH $=.1$

DI AMETER $=.002$

NUMBER OF CE'S

INITIAL CONDITIONS $=1$

PIPE (Receiver or if ice) $=15$

LENGTH $=.0$

DI AME TER $=.0005$

NUMB $=2$

INITIAL CONDITIONS $=1$

REGION (First reservoir initial conditions) = PRESSURE $=100 . E 5$

GAS $1=0$

GAS2 $=1$

GAS5 $=0$

MIXTURE $=4$

REGION (Second reservoir initial conditions) =2 PRESSURE $=200$. E5

GAS $1=1$.

GAS2 $=0$

GAS5 $=0$.

MIXTURE $=4$

REGION (Receiver and piping initial conditions) $=3$

PRESSURE $=1 . E 5$

GAS $1=0$

AS2 $=0$

GAS5 $=1$.

MIXTURE $=4$

EXECUT ION $=1$

TSTOP $=10$.

DTMA JOR $=1$

DTMINOR $=.01$

EDIT $=6$

EFLAG (Receiver hydrogen mass inventory) $=3,5$

EFLAG (Recelver deuterium mass inventory) $=3,6$

EFLAG (Receiver helfum mass inventory) $=3.9$

EFLAG (First reservoir pressure) $=1.2$

EFLAG (5econd reservoir pressure) $=2,2$

EFLAG (Recelver Pressure) =3,2 
and REGION 2 (pure hydrogen) include reservoirs 1 and 2 respectively. REGION 3 (pure helium) includes the receiver and piping. Note that the minor directives GAS1, GAS2, and GAS3 (hydrogen, deuterium, and helium for MIXTURE=4) are specified for all three REGIONs, even though each REGION initially contains a single species. This action insures that continuity of all three species will be conserved over the entire network. This is necessary since it is physically possible to have all three species in any part of the system after the two valves are opened.

In this problem, each pipe has been divided into $5 \mathrm{CE}$ 's and the receiver orifice has been assigned 2 CE's. Subdividing the flow path in this way is somewhat arbitrary. In solving an actual problem, users are urged to begin with coarse meshes such as this and then increase the number of CE's to insure that the solution is not influenced by the number of CE's used (i.e., the finite difference discretization).

The minor edits have been selected to provide printouts of the quantities of interest, namely the masses of hydrogen, deuterium, and helium in the receiver and the pressures in the two reservoirs and receiver. Information obtained during these minor edits was later used to generate the plots shown in Figures 38 and 39.

Figure 38 shows the pressure history in the two reservoirs and receiver. When the first valve is opened at time zero, the deuterium gas from the first reservoir transfers down the pipe to the branch where it divides, the bulk of the flow going to the receiver. The pressure in the first reservoir drops quickly until the second valve is opened. At that point the first reservoir is repressurized to a peak pressure equal to the falling reservoir 2 pressure. From that point on, the two reservoirs decay in pressure at the same rate. The pressure in the receiver displays a "double hump" appearance. The first hump (between zero and $.5 \mathrm{~s}$ ) is caused by the deuterium transfer from the first reservoir. After $.5 \mathrm{~s}$ the slope of the receiver pressurization curve changes (causing the second hump) reflecting the increased transfer from both reservoirs. The gas entering the receiver after $.5 \mathrm{~s}$ is a mixture of both deuterium and hydrogen. Pressure equilibrium in the system is achieved after 4.0: $\mathrm{s}$.

Figure 39 shows the mass of hydrogen, deuterium and helium in the receiver as a function of time. The mass of helium in the receiver remains relatively constant with time. Only a trace of helium enters the receiver during the transfer. This is a result of "flushing" the lines during the initial transfer of deuterium and hydrogen to the receiver. The receiver is completely void of hydrogen until $.5 \mathrm{~s}$ when the second reservoir is vented. The curve for the deuterium inventory shows a rapid increase from time zero until .5 s. At that point the brief repressurization of the first (deuterium) reservoir actually interupts the flow of deuterium. This is evident by the "notch" in the curve at .5 s. From that point on deuterium continues to enter the receiver, but at a rate slower than the initial rate. The slower rate is due to the fact that the gas exiting the first reservoir is no longer pure deuterium but a mixture of deuterium and hydrogen.

As mentioned previously, pressure equilibrium between the reservoirs and receiver was achieved at approximately $4.0 \mathrm{~s}$ (see Figure 38). However, the slope of the deuterium and hydrogen mass curves in Figure 39 indicate that these two gases continue to transfer 


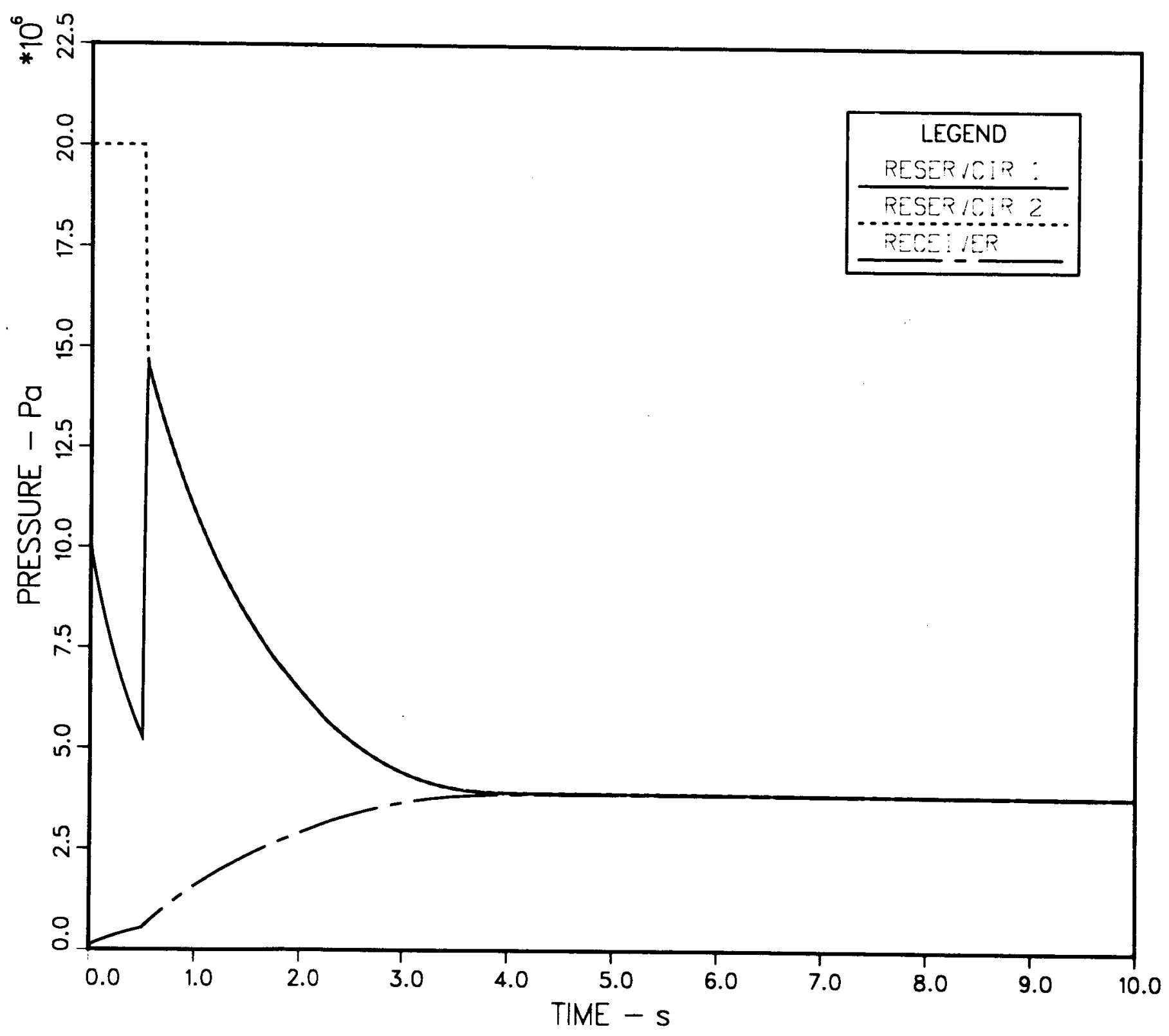

$\stackrel{\infty}{\varpi}$

FIGURE 38. RESERVOIR AND RECEIVER PRESSURE HISTORIES 


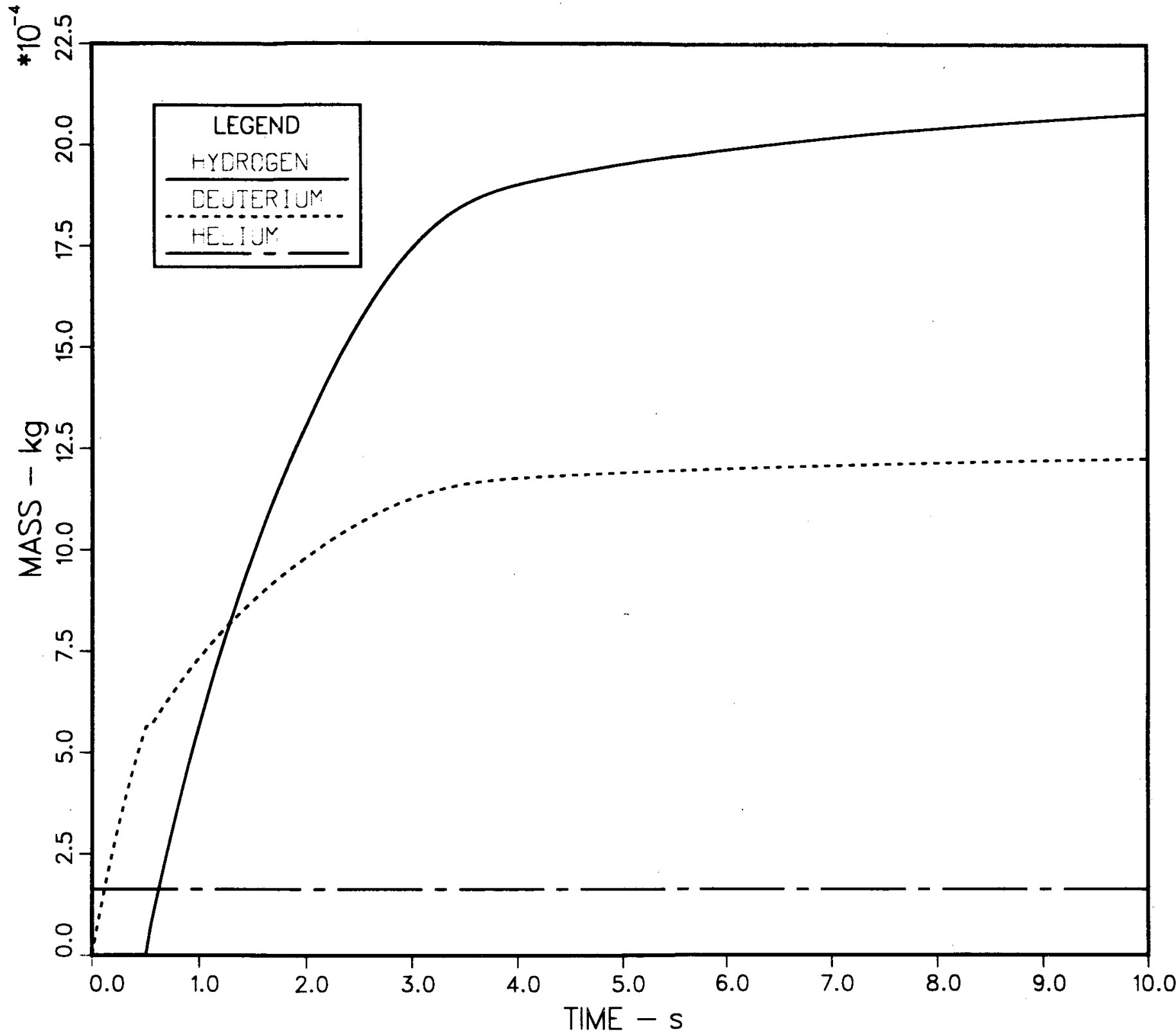

FIGURE 39. HYDROGEN, DEUTERIUM, AND HELIUM INVENTORY IN THE RECEIVER 
after pressure equilibrium. Close examination of the minor edits in the TOPAZ output file shows, for example, that the amount of hydrogen in the receiver has increased 9.4 percent between 4.0 and $10.0 \mathrm{~s}$. The mechanism for gas transfer during this period of time is frequently refered to as "thermal pumping" (see e.g. the discussion in Appendix C of reference 5). During the pressure driven part of the transfer, the gas in the reservoirs cool due to expansion, and the gas in the receiver heats up due to compression and stagnation. After pressure equilibrium is achieved heat transfer with the suroundings causes a reheating and expansion of the reservoir gases and a cooling and contraction of the receiver gas. Hence the flow becomes thermally driven. Such flows generally occur for systems such as this one, in which the reservoirs and receivers have volumes within the same order of magnitude.

In thermally driven flows, TOPAZ calculations can only be as accurate as the vessel heat transfer correlations which are used in the computations. Unfortunately, the only reliable vessel heat transfer correlations presently available are those for vessels undergoing a simple uninterupted blowdown. Hence, TOPAZ (or any similar code) predictions for transient thermally pumped flows must be regarded with a certain amount of uncertainty. This situation will persist until more accurate vessel heat transfer correlations are developed. 


\section{EXAMPLE 8 - PREDICTING PRESSURE TRANSDUCER RESPONSE}

\section{Introduction}

The example problem discussed in this section is designed to demonstrate the usefulness of TOPAZ as an aid in designing gas transfer experiments and tests. In this section the code is used to simulate a simple gas transfer network fitted with a pressure transducer. The objective is twofold:

1. To determine if the transducer plumbing introduces time lags into the measurement system.

2. To determine how transducer plumbing can be altered to prevent transducer damage during testing.

Since TOPAZ is a transient code, it is ideally suited to modeling the "dynamic" as well as quasi-steady features of compressible flow through piping networks. In order to assess the influence of pressure transducer plumbing (e.g. transducer line diameter, length, orificing, baffle volume, etc.) one need only include the plumbing as part of the simulation.

In designing a test, the experimentalist is often prevented from placing a pressure transducer at the precise location where the measurement is desired. Because of packaging constraints, safety, etc. it may be necessary to use, for example, several meters of transducer tubing in making the measurement. Furthermore, the construction of the transducer may require that a small clearance volume ( 1 or $2 \mathrm{cc}$ ) be provide at the transducer location. The addition of such plumbing may introduce significant time lags, effectively reducing the frequency response of the measurement system. In those situations where it is important to measure the transient pressure (e.g. the magnitude and duration of a transient pressure spike), a TOPAZ simulation can be used to compare the pressure history in the transducer chamber to the pressure history at the desired measurement point. Lags introduced by the transducer plumbing should be immediately apparent (thus achieving Objective 1 above).

Often, the objective of the pressure measurement is to accurately determine the steady state pressure in a system after the transfer has taken place. Accuracy may require the use of a pressure transducer with a relatively narrow measurement range. Over-pressuring such a tranducer with a large dynamic pressure spike may affect the accuracy of the measurement or even damage the transducer. In such situations the TOPAZ simulation may be useful in determining what transducer line modifications need to be made to damp out potentially damaging dynamic pressure spikes (thus achieving Objective 2 above). 


\section{Problem Statement}

Consider the gas transfer system shown in Figure 40a. A 100 cc reservoir initially containing helium at $10 \mathrm{MPa}$ is connected to a $1000 \mathrm{cc}$ receiver via a pipe $200 \mathrm{~cm}$ in length and $.2 \mathrm{~cm}$ in diameter. The plumbing downstream of the reservoir initially contains helium at $.1 \mathrm{MPa}$. The orifice at the receiver is $1 \mathrm{~cm}$ long and $.1 \mathrm{~cm}$ in diameter. The valve just downstream of the reservoir is opened at time zero and has an opening time of $.005 \mathrm{~s}$. It is desired to measure the pressure at midpoint of the transfer line where a transducer port $1 \mathrm{~cm}$ in length and $.4 \mathrm{~cm}$ in diameter has been provided. It is proposed that the transducer be placed at the end of a transducer line $100 \mathrm{~cm}$ in length and $.2 \mathrm{~cm}$ in diameter. The transducer is placed in an orificed volume of $5 \mathrm{cc}$. Initially it is proposed that the transducer orifice be $1 \mathrm{~cm}$ in length and $0.05 \mathrm{~cm}$ in diameter. The transfer takes place at $295 \mathrm{~K}$.

A. Will the frequency response of the measurement system be adequate to follow the flow transient?

B. What transducer orifice diameter would be required to protect a transducer having a range of 0 to $2 \mathrm{MPa}$.

\section{Discussion}

A TOPAZ mesh generation diagram for this problem appears in Figure 40b. The corresponding input file is given in Figure 41. As is frequently the case, the initially closed valve provides the natural boundary for specifying initial conditions. In this case there are two REGIONs, REGION 1 representing the high pressure ambient temperature helium in the reservoir, and REGION 2 representing the low pressure ambient temperature helium in the remainder of the network. PIPEs having $5 \mathrm{CE}$ 's have been used to simulated the long runs of tubing, while the orifices have been simulated with 1 CE PIPEs. The orifices could have been simulated using a cylindrical CHAMBER with an HFLAG $=3$ to provide the desired forced convection tube flow heat transfer. This was, in fact, done to simulate the transducer port at the midpoint of the reservoir-receiver line. The only difference between a single CE PIPE and a cylindrical CHAMBER having the same length and diameter is that the CHAMBER permits connection with more than two JOINTs and does not allow for the specification of a friction factor ( $f=0$ is assumed). Including or neglecting tube wall friction for the orifices and transducer port will have a negligible influence on the results since most of the frictional losses occur in the long runs of piping.

This problem consists of two parts. In the first part, part $A$, the objective is to determine if the pressure measured in the transducer chamber (CHAMBER 3) is sufficiently close to the pressure at the midpoint of the transfer line (CHAMBER 2). Figure 42 contains a comparison of the two computed pressures. The line pressure spikes rapidly to $10 \mathrm{MPa}$ as the valve is opened and then falls off more slowly as the reservoir gas is transfered. The measured pressure, i.e. that computed for the transducer chamber (CHAMBER 3), rises more slowly to approximately $7 \mathrm{MPa}$ where it meets and begins to follow the falling line pressure curve. The curves indicate that the transducer will correctly monitor the 


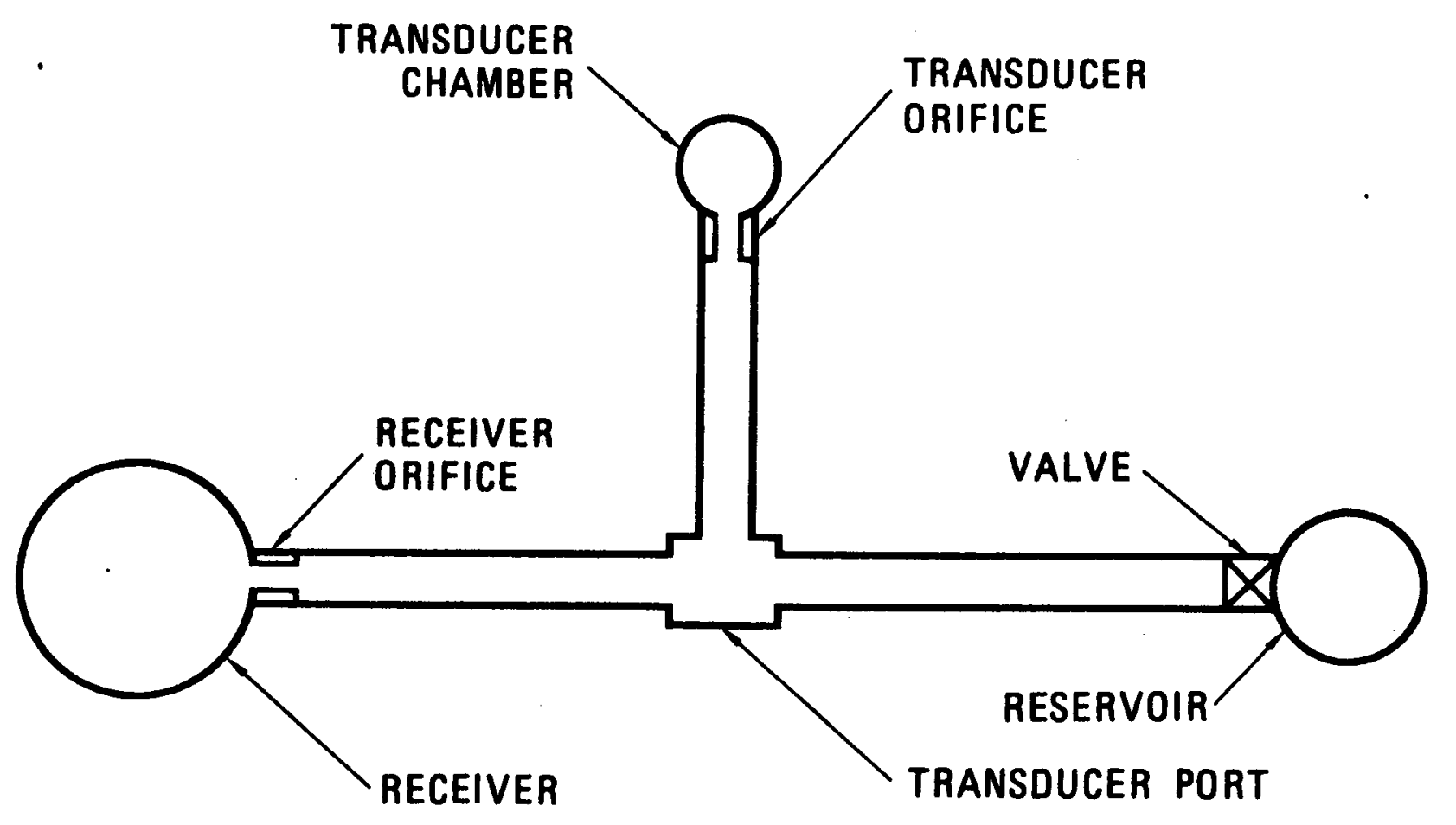

FIGURE 40a. SCHEMATIC FOR EXAMPLE 8

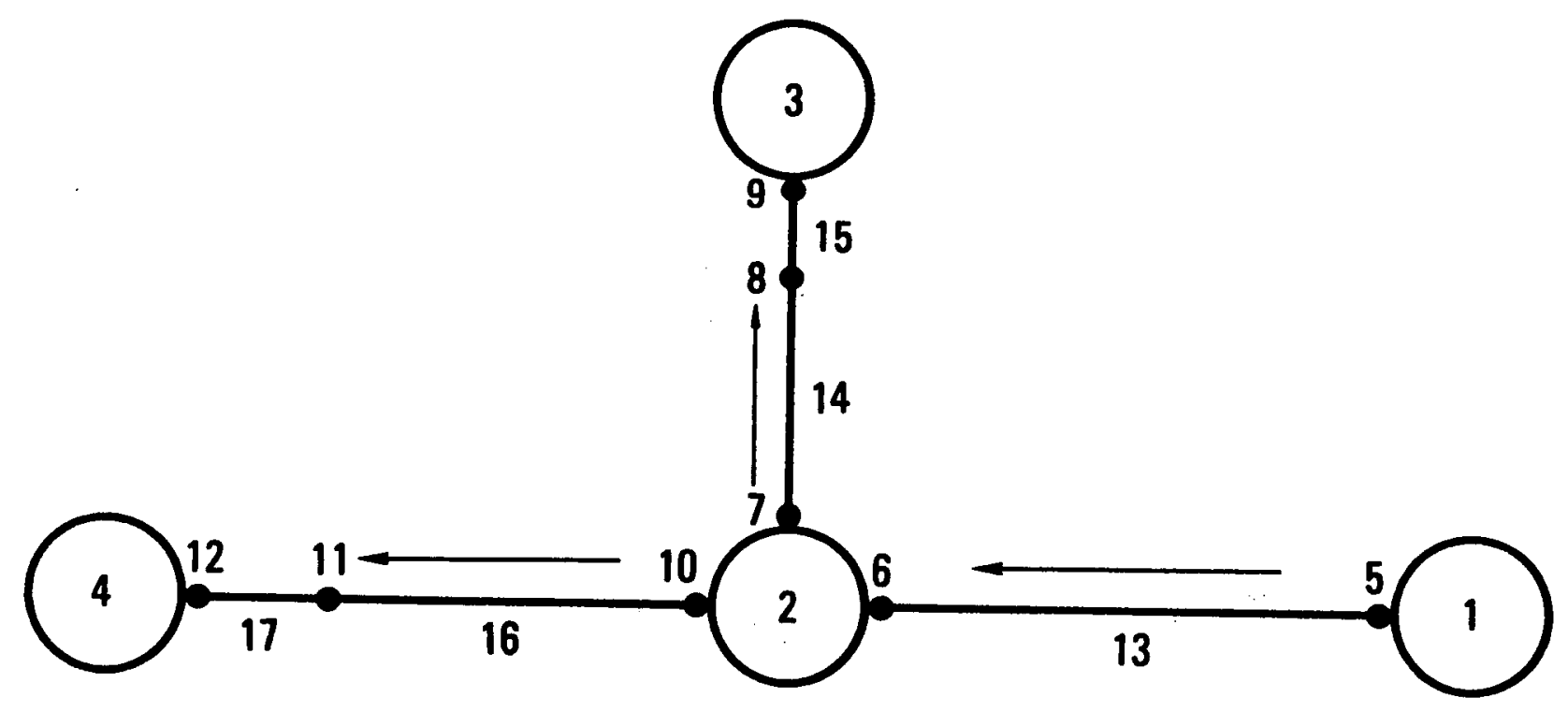

FIGURE 40b. MESH GENERATION DIAGRAM FOR EXAMPLE 8 
NOTE: TOPAZ input data for EXAMPLE 8 NOTE: Pressure transducer response.

CHAMEER (Reservoir) $=1$

VOLUME $=100 . E-6$

INITIAL CONDITIONS $=1$

CHAMBER ( $L$ ine pressure por $t$ ) $=2$

DI.AMETER $=.004$

LENGTH $=.01$

HFLAG $=3$

INITIAL CONDITIONS $=2$

CHAMBER (Transducer chamber) $=3$

VOLUME $=5 . E-6$

INITIAL CONDITIONS $=2$

CHAMBER (Rece iver) $=4$

VOLUME $=1000 \cdot E-6$

INITIAL CONDITIONS $=2$

JOINT (VaIve) $=5$

UPST $=1$

DOWN $=13$

TOPEN $=0$

DTOPEN $=.005$

JOINT $=6$

UPST $=13$

DOWN $=2$

JOINT $=7$

UPST $=2$

DOWN $=14$
JOINT $=8$

UPST $=14$

DOWN $=15$

JOINT $=9$

UPST $=15$

OTNT $=10$

UPST $=2$

DOWN $=16$

JOINT $=11$

UPST $=16$

DOWN $=1$.

DONT $=12$

UPST $=17$

UPST $=17$
DOWN $=4$
PIPE (Pipe from reservoir) $=13$

LENGTH $=.1$

DI $\triangle M E T E R=.002$

NUMBER OF $C E ' S=5$

INIT I AL CONDITIONS $=2$

PIPE (Transducer $p$ ipe) $=14$

LENGTH $\%$.

METER $=.002$

NUMPER OF $C E \cdot S=5$

INI TIAL CONDITIONS $=2$

PIPE (Transducer or if ice) $=15$

LENGTH $=.01$

DI AME TER $=.0005$

NUMBER OF $C E$ ' $S=1$

INITIAL CONDITIONS $=2$

PIPE (To rece iver) $=16$

L.ENGTH $=.1$

DI AME TER $=.002$

NUMBER OF $C E^{\prime} S=5$

INITIAL CONDITIONS $=2$

PIPE (Rece iver or if ice) $=17$

LENGTH $=.01$

DI AME TER $=.001$

NUMBER OF $C E^{\prime} S=1$

INITIAL CONDITIONS $=2$

REGION (Reservoir initial conditions) $=1$

PRESSURE $=100 . E 5$

GASS $=1$.

$M I X T U R E=4$

REGION (Receiver, I ine, and transducer initial conditions) $=2$ PRE SSURE $=1 . E 5$

GAS5 $=1$

MIXTURE $=4$

EXECUTION $=1$

TSTOP $=8$

DTMINOR $=.001$

EDIT $=4$

EFLAG (Line pressure) $=2,2$

(rensucer pressure) $=3,2$

(Reservoir pressure) $=1,2$

EFLAG (Receiver pressure) $=4,2$

FIGURE 41. TOPAZ INPUT FILE FOR EXAMPLE 8 


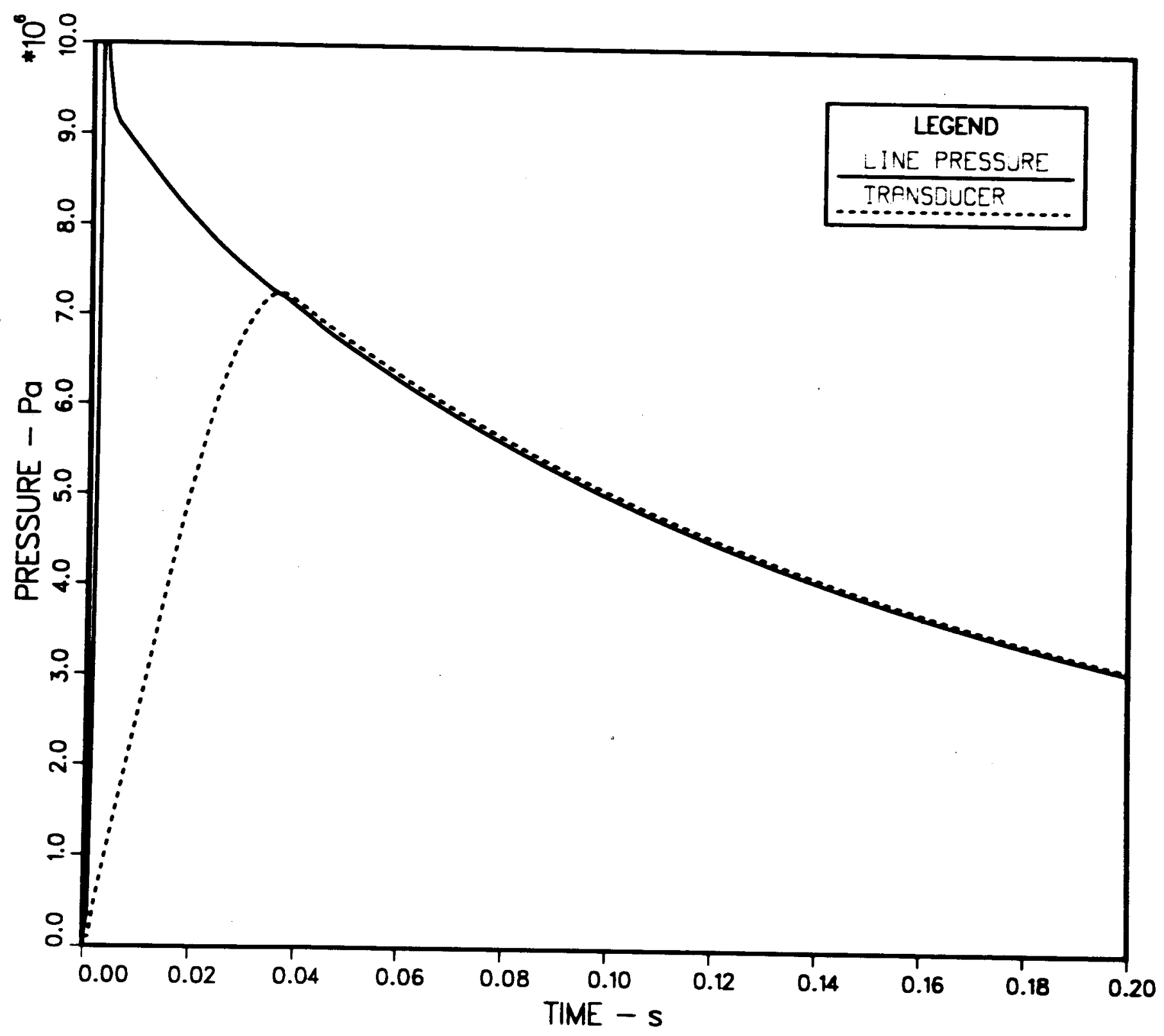

FIGURE 42. COMPARISON OF LINE PRESSURE AND TRANSDUCER PRESSURE 
line pressure for times greater than $.05 \mathrm{~s}$. However, the response time of the measurement system (transducer line, orifice, and volume) is too slow to sense pressure transients having frequencies on the order of the initial pressure spike.

In part $B$ the objective is to determine what orifice diameter will effectively damp out the initial pressure spike to a value less than $2 \mathrm{MPa}$, thereby protecting a narrow range ( 0 to $2 \mathrm{MPa}$ ) pressure transducer. Figure 43 contains plots of the pressure history in the transducer chamber for various transducer orifice sizes. The plots indicate that an orifice having a diameter greater than or equal to $.0002 \mathrm{~m}$ will expose the transducer to pressures exceeding $3 \mathrm{MPa}$. Reducing the orifice to a diameter of $.0001 \mathrm{~m}$, however, protects the transducer. Such a measurement system would, of course, be inadequate for recording the transient character of the transfer, but would be sufficient for recording the final network pressure. Similar transducer damping can be investigated by lengthening the transducer line (PIPE 14) or increasing the volume of the transducer chamber (CHAMBER 3).

TOPAZ can be an extremely useful tool in assessing pressure transducer response. Users should, however, keep in mind the "quasi-steady" nature of the friction factor correlations and to a lesser extent the heat transfer correlations. For extremely rapid transients the flow may fail to exhibit quasi-steady behavior. To the extent that this is true, the code predictions may be inaccurate. It is believed that such inaccuracies are second order in nature, compared to time lags induced by flow restrictions at orifices and volume compressiblity effects. These later effects should be well replicated by TOPAZ regardless of the speed of the transfer. 


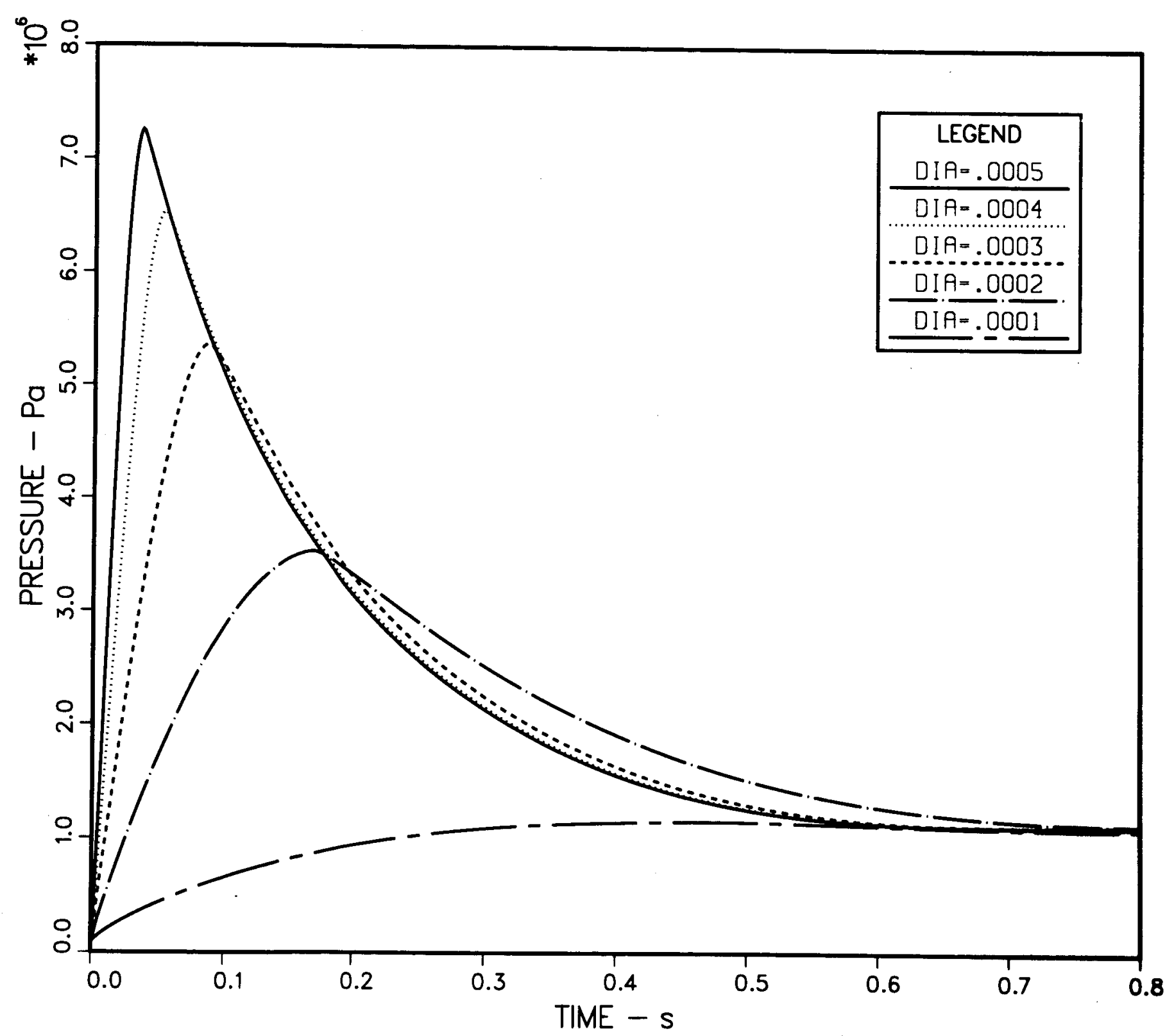

FIGURE 43. PRESSURE TRANSDUCER RESPONSE FOR VARIOUS ORIFICE DIAMETERS 



\section{EXAMPLE 9 - CALCULATION WITH A BLADDER AND USER SPECIFIED FORM LOSSES}

\section{Introduction}

The network simulated in this example is shown in Figure 44a. A reservoir initially containing a high pressure mixture of hydrogen and helium is connected to a receiver via a long pipe. A complex flow component is plumbed into the system midway between the reservoir and receiver. The first objective of this example is to illustrate how laboratory flow data for such components can be included in TOPAZ simulations.

At time zero the valve downstream of the reservoir is opened allowing the hydrogenhelium mixture to flow to the receiver volume. One wall of the receiver volume is a deformable rolling bladder which displaces whenever the pressure difference across it exceeds a given "roll pressure". Downstream of the bladder is a compression chamber containing pure helium. The second objective of the example is to illustrate how the PISTON directives can be used to simulate the rolling bladder.

Although the flow is known to be from the reservoir to the receiver, this example will arbitrarily adopt a flow sign convention which assumes "positive" flow to be from the receiver to the reservoir. The third objective of this example is to demonstrate that assignment of sign conventions along a flow path is arbitrary and in no way affects the calculations.

Before proceeding with the problem statement, a few words are appropriate regarding the TOPAZ momentum element equation, particularly as it applies to quasi-steady, low Mach number flows (i.e. nearly incompressible) through "high form loss" flow components. Here we refer to high-form-loss flow components as components having pressure losses on the order of the pipe friction pressure drops in the flow path.

The TOPAZ momentum balance for steady flow through an arbitrary momentum element $(M)$ is given by:

$$
0=\left(P+\rho v^{2}\right)_{u}-\left(P+\rho v^{2}\right)_{d}-\left(\frac{f L \rho v^{2}}{4 D}\right)_{u}-\left(\frac{f L \rho v^{2}}{4 D}\right)_{d}-\frac{K \rho v^{2}}{2}
$$

The $u$ and $d$ subscripted quantities refer to the upstream and downstream continuityenergy (CE) elements respectively. The unsubscripted quantities refer to the $M$ element itself. The last term in the equation is the form loss term and the quantity $K$ is a constant form loss factor. If one neglects the friction terms (or incorporates the terms into the form loss term), and assumes incompressible flow, equation (10) becomes: 


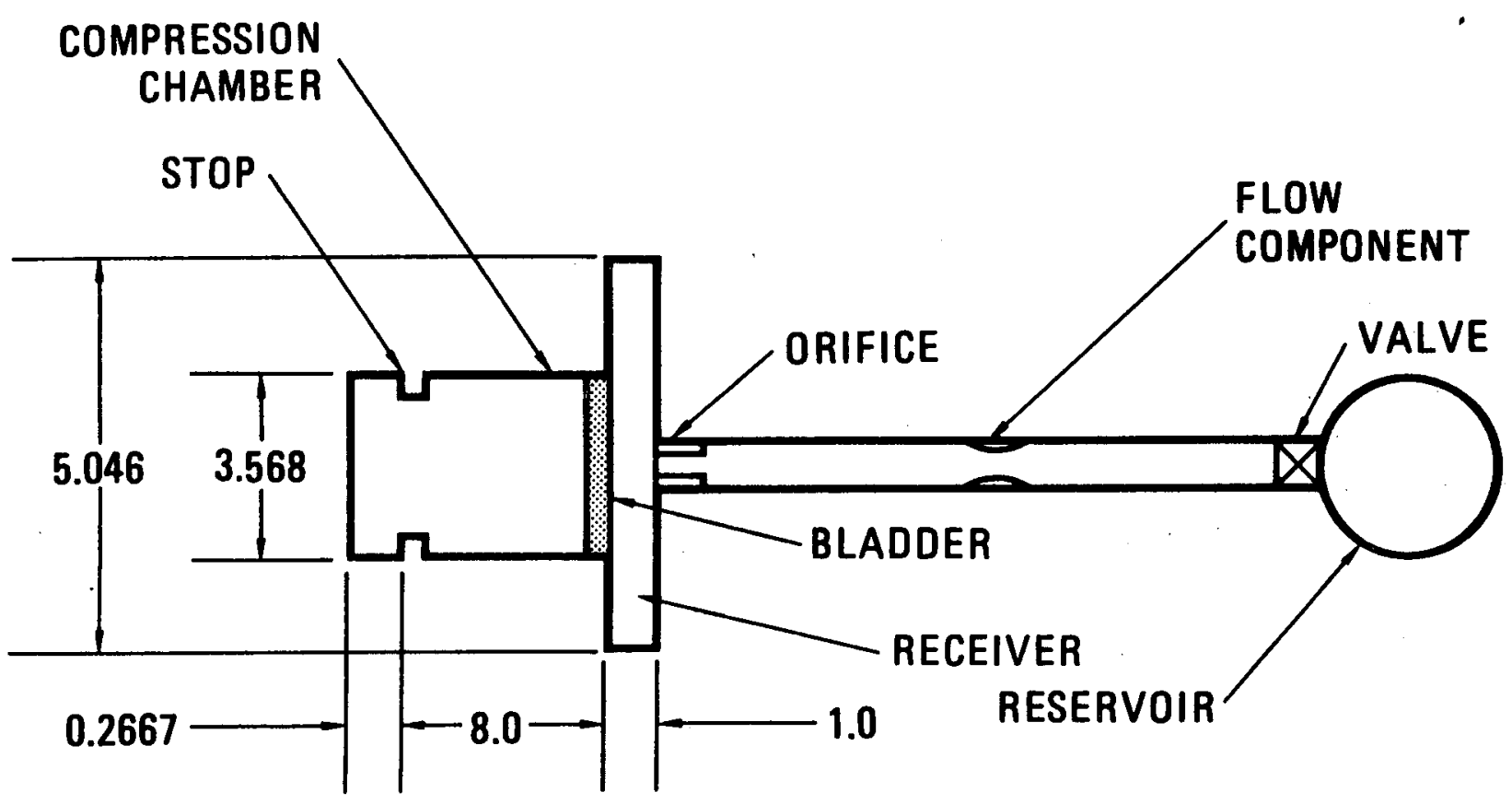

NOTE: DIMENSIONS ARE IN CM

FIGURE 44a. SCHEMATIC FOR EXAMPLE 9

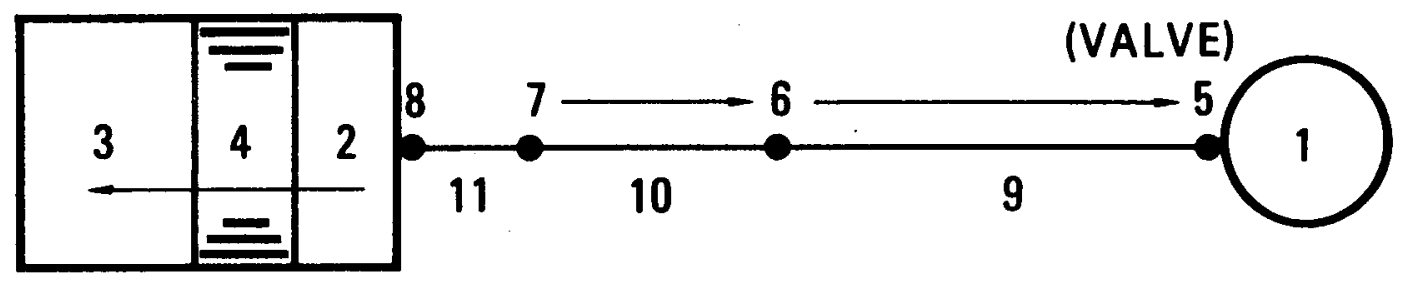

FIGURE 44b. MESH GENERATION DIAGRAM FOR EXAMPLE 9 


$$
\frac{K \rho v^{2}}{2}=P_{u}-P_{d}
$$

The velocity, density, and cross-sectional flow area for the $M$ element (or in this case the flow component) are related by the following expression:

$$
\dot{m}=\rho A v
$$

When equation (12) is substituted into (11), one obtains the the following simple equation relating the mass flow rate through the flow component to the pressure drop across it.

$$
\dot{m}^{2}=\frac{\rho A^{2}\left(P_{u}-P_{D}\right)}{K}
$$

Often the relationship between the mass flow rate squared and pressure drop is nearly linear for incompressible flow, hence a constant value for $K$ may be assumed. References [14] and [15] provide estimates of form loss coefficients for a number of complex flow components such as pipe bends, abrupt area changes, gate valves, etc. When handbook values for $K$ are unavailable, experimental measurements of flow rate and pressure drop must be made. Once such data is obtained, equation (13) can be used to calculate the appropriate $K$.

Usually the direction of flow through the component has an influence on $K$. It is for this reason that TOPAZ users are given the option of supplying a reverse flow value of $K$ (RLOSS directive) as well as a forward flow value of $K$ (FLOSS directive).

Users may also model components having form loss coefficients which are arbitrary functions of system variables such as pressure drop, flow rate, Mach number, Reynolds number etc., but such modeling currently requires the programing of a FORTRAN subroutine and a recompilation of the code. Users interested in such modeling should consult the author.

\section{Problem Statement}

Consider the network shown in Figure 44a. The reservoir has a volume of $100 \mathrm{cc}$ and initially contains an equal molar mixture of hydrogen and helium. The valve opens at time zero and has an opening time of $.005 \mathrm{~s}$. The flow component shown has a reference flow ID of $.1 \mathrm{~cm}$ and form loss factor of 30 regardless of flow direction. The pipes upstream and downstream of the flow component each have an ID of $.2 \mathrm{~cm}$ and length of $1 \mathrm{~m}$. The relative interior wall roughness for these pipes is .002 . The orifice at the receiver is $1 \mathrm{~cm}$ long with an ID of $.02 \mathrm{~cm}$. The receiver, bladder, and compression chamber have the dimensions shown. The bladder "rolls" whenever the differential pressure across it exceeds 
$1 \mathrm{MPa}$. Assume a mass of $1 \mathrm{~kg}$ and a viscous damping factor of $1 \mathrm{~N}-\mathrm{s} / \mathrm{m}$ for the bladder. The initial temperature of the system is $300 \mathrm{~K}$ and all the plumbing downstream of the receiver initially contains helium at $.1 \mathrm{MPa}$. Assume isothermal (infinite) heat transfer in the receiver and compression chamber and determine the time history of the following quantities:

A. The reservoir, receiver, and compression chamber pressure histories.

B. The bladder displacement.

\section{Discussion}

The mesh generation diagram for this example is shown in Figure $44 \mathrm{~b}$. The corresponding TOPAZ input file is presented in Figure 45. Three initial condition REGIONs were used in the input file. REGION 1 (reservoir) and REGION 2 (receiver and flow path) are separated from each other at time zero by the valve downstream of the reservoir. Note that the GAS1 and GAS5 directives have been specified for these REGIONs because of the need to conserve and track both hydrogen and helium. REGION 3 (helium compression chamber) is permanently separated from REGION 2 by the bladder. Since it is physically impossible for hydrogen to enter the compression chamber, there is no need to include the GAS1 directive in REGION 3. The GAS1 directive could have been included for REGION 3 without introducing errors. However, the computational time would increase because of the increased number of dependent variables and equations in the model.

The PISTON directives shown in Figure 45 illustrate how to model the bladder. Mechanical stops have been specified at $X=0$ and $X=8 \mathrm{~cm}$. The FORC directive was used to insure that a pressure difference of $1 \mathrm{MPa}$ would be required to "roll the bladder". The $1000 \mathrm{~N}$ force was computed by multiplying the required roll pressure by the cross-sectional bladder area. The negative sign insures the force always opposes the driving pressure difference. The FSTA and FSTO directives are used to maintain the force on the bladder for the duration of the problem.

This problem illustrates an important point regarding the cross-sectional areas of PISTONs and the adjacent upstream and downstream CHAMBERs. Users are not required to specify identical cross-sectional areas for these components. In this case the crosssectional area for the upstream CHAMBER (receiver) is substantially greater than the PISTON area. Furthermore, the CHAMBERs adjacent to PISTONs need not be cylindrical. In this problem the receiver and compression chamber could have been simulated as spheres instead of cylinders providing the appropriate volumes were used. Regardless of the CHAMBER geometry specified, the volume swept out by a PISTON is always the product of the PISTON cross-sectional area and the displacement.

The specification of the UPST and DOWN directives for all JOINTs indicate that the assumed direction for "positive" flow is from the receiver to the reservoir. As mentioned earlier this assignment was made arbitrarily. An examination of the output file for this TOPAZ calculation (not shown here) reveals that all printed velocities for momentum 
NOTE: TOPAZ input data for EXAMPLE 9.

CHAMBER (Reservoir) $=1$

VOLUME $=100 . E-6$

INITIAL CONDITIONS $=1$

CHAMBER (RECEIVEr) $=2$

DIAMETER $=5.046 E-2$

LENGTH $=1 . E-2$

HFLAG (I sothermal) $=2$

INITIAL CONDITIONS $=2$

CHAMBER (COmpresston chamber) $=3$

CHAMBER TCOMT

LENGTH $=8,2667 E-2$

HFLAG (I sotherma ) $=2$

PISTON (B ladder) $=4$

MASS $=1$

CVIS $=1$.

FORCE $=-1000$

FSTART $=0$.

FSTOP $=1$. E 10

$A R E A=10 . E-4$

UPSTREAM CHAMBER $=2$

DOWNSTREAM CHAMBER $=3$

$X M U P=0$

$X M D N=8 \cdot E-2$

JOINT (Vaive at reservoir) $=5$

UPST $=9$

TOPEN $=0$

DTOPEN $=.005$

JOINT (Flow Component with form loss) $=6$ UPST $=10$

DOWN $=9$

DIAMETER AT THE SMALLEST FLOW CROSS-SECTION $=.001$

FLOSS (Form loss for $f$ low from receiver to reservoir) $=30$.

RLOSS (Form loss for flow from reservoir to receiver) $=30$.

JOINT $=7$

UPST $=11$

DOWN $=10$

JOINT $=8$

UPST $=2$

DOWN $=11$

LENGTH $=1$.

DI AMETER $=.002$

FDATA (TUDe wall relative roughness) $=.001$

NUMBER OF CHAMBERS $=5$

INITIAL CONDITIONS=2
PIPE $=10$

LENGTH $=1$.

DIAMETER $=.002$

FDATA (Tube wall relative roughness) $=.001$

NUMBER OF CHAMBERS $=5$

INITIAL CONDITIONS $=2$

PIPE (Receiver or if ice) $=11$

LENGTH $=.01$

DIAMETER $=.0002$

NUMBER OF CHAMBERS $=1$

INITIAL CONDITIONS $=2$

REGION (He-H2 mixture in reservoir) $=1$

PRESSURE $=10 . E 6$

TEMPERATURE $=300$

TWALL $=300$

MIXTURE $=4$

GAS1 $(\mathrm{H} 2)=.5$

GAS5 $(\mathrm{He})=.5$

REGION (He backf +11$)=2$

PRESSURE $=.1 E 6$

TEMPERATURE $=300$.

TWALL $=300$

MIXTURE $=4$

GAS1 $(H 2)=0$

REGION (COmpression gas) $=3$

PRESSURE

TEMPERATURE $=300$.

TWALL $=300$.

MIXTURE $=4$

GAS $1(H 2)=1$

EXECUTION=

$T S T O P=8$.

DTMAJUR $=1$.

DTMINOR $=.01$

EDI $T=6$

EFLAG (Reservoir pressure) $=1,2$

EFLAG (Receiver pressure) $=2,2$

EFLAG (Pressure in compression chamber) $=3,2$

EFLAG ( $B$ ladder displacement) $=4,1$

EFLAG (Receiver $\mathrm{H} 2$ mass) $=2,5$

EFLAG (Receiver He mass) $=2,9$

FIGURE 45. TOPAZ INPUT FILE FOR EXAMPLE 9 
elements along the flow path are negative. This is to be expected since the flow in this problem proceeds from the receiver to the reservoir. Although the flow path sign convention has no influence on the computations, users must be aware of the convention when interpreting the output file.

TOPAZ plotted output for this example problem is presented in Figures 46 through 49. Figure 46 shows the pressure histories in the reservoir, receiver and helium compression chamber. The pressure in the reservoir drops almost instantaneously to $9.2 \mathrm{MPa}$ as the valve is opened. This rapid drop is a result of pressurizing the $6.3 \mathrm{cc}$ flow path volume. Reservoir decompression then proceeds at a slower rate governed by the choking at the receiver orifice. The receiver pressurization curve shows a steep rise over the first $0.19 \mathrm{~s}$ of transfer. At that point the pressure difference across the bladder exceeds the roll pressure thus permitting the bladder to move and the receiver volume to grow. The growth in the receiver volume slows the pressurization. The receiver and reservoir are in pressure equilibrium after $8 \mathrm{~s}$. Pressurization of the helium compression chamber occurs as the bladder begins to roll. Note that while the bladder is in motion the pressure difference across it is very close to the roll pressure of $1 \mathrm{MPa}$. The pressure difference across the bladder can exceed the roll pressure if the bladder mass (and hence its inertia) or viscous damping is increased significantly. The receiver and compression chamber pressure continue to rise in parallel until the bladder reaches the mechanical stop at $X=8 \mathrm{~cm}$. At that point no further pressurization of the helium compression chamber can take place.

The displacement history of the bladder is shown in Figure 47. As indicated by the pressure curves, bladder motion begins at $0.19 \mathrm{~s}$. The motion continues until $5.4 \mathrm{~s}$ when the bladder gradually reaches the stop.

Figure 48 shows the flow component Mach number as a function of time. The Mach number rises rapidly to 0.2 as the valve is opened. However, for most of the event the Mach number never exceeds 0.01 indicating that flow through the component is essentially incompressible. Generally compressibility effects become important when the Mach number exceeds 0.3. In those cases when the reference cross-sectional area (usually the minimum area for the component) is small, obtaining high Mach number flow or even flow choking $(\mathrm{Ma}=1)$ is always a possibility. In such cases, the assumption of a constant $K$ could lead to errors. In the present example, the reference area for the flow component is a factor of four less than the adjacent piping. However, the high Mach number portion of the flow is confined to the end of the flow path where the receiver orifice causes the flow to choke. Hence the flow through the high-form-loss flow component remains nearly incompressible as indicated by Figure 48.

The present example was rerun with different minor edit variables so that the pressure difference $P_{u}-P_{d}$ for the flow component could be plotted against the velocity head term $0.5 \rho v^{2}$ over the entire flow history. This plot is shown in Figure 49. Note that some hysteresis in the pressure-velocity head relationship occurs over the flow history. This hysteresis is caused primarily by the unsteady effects of flow inertia. The upper curve results during early times when the pressure difference across the flow component reaches its maximum. This is the flow acceleration portion of the transfer. The lower curve is 


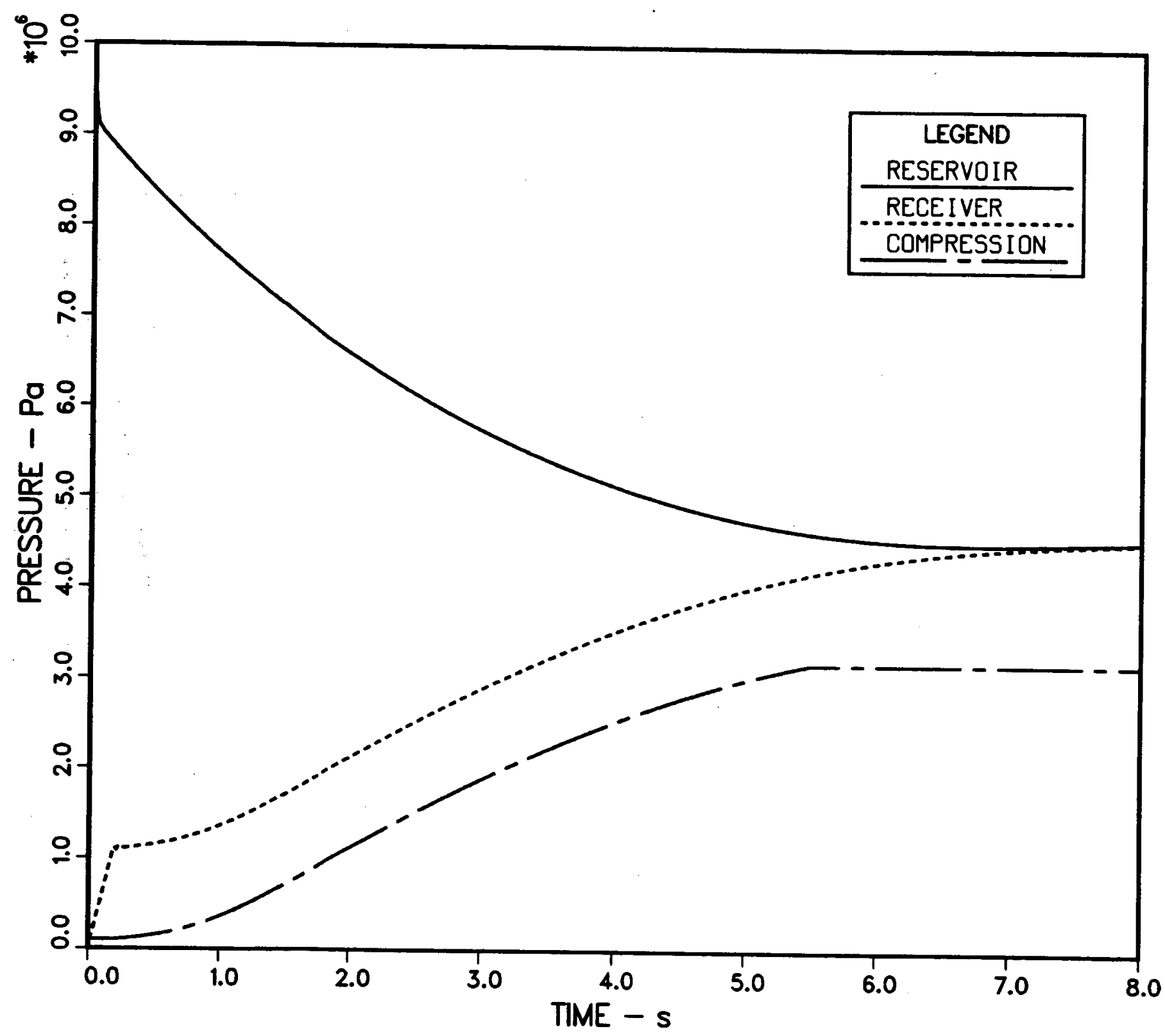

它

FIGURE 46. PRESSURE HISTORIES FOR EXAMPLE 9 


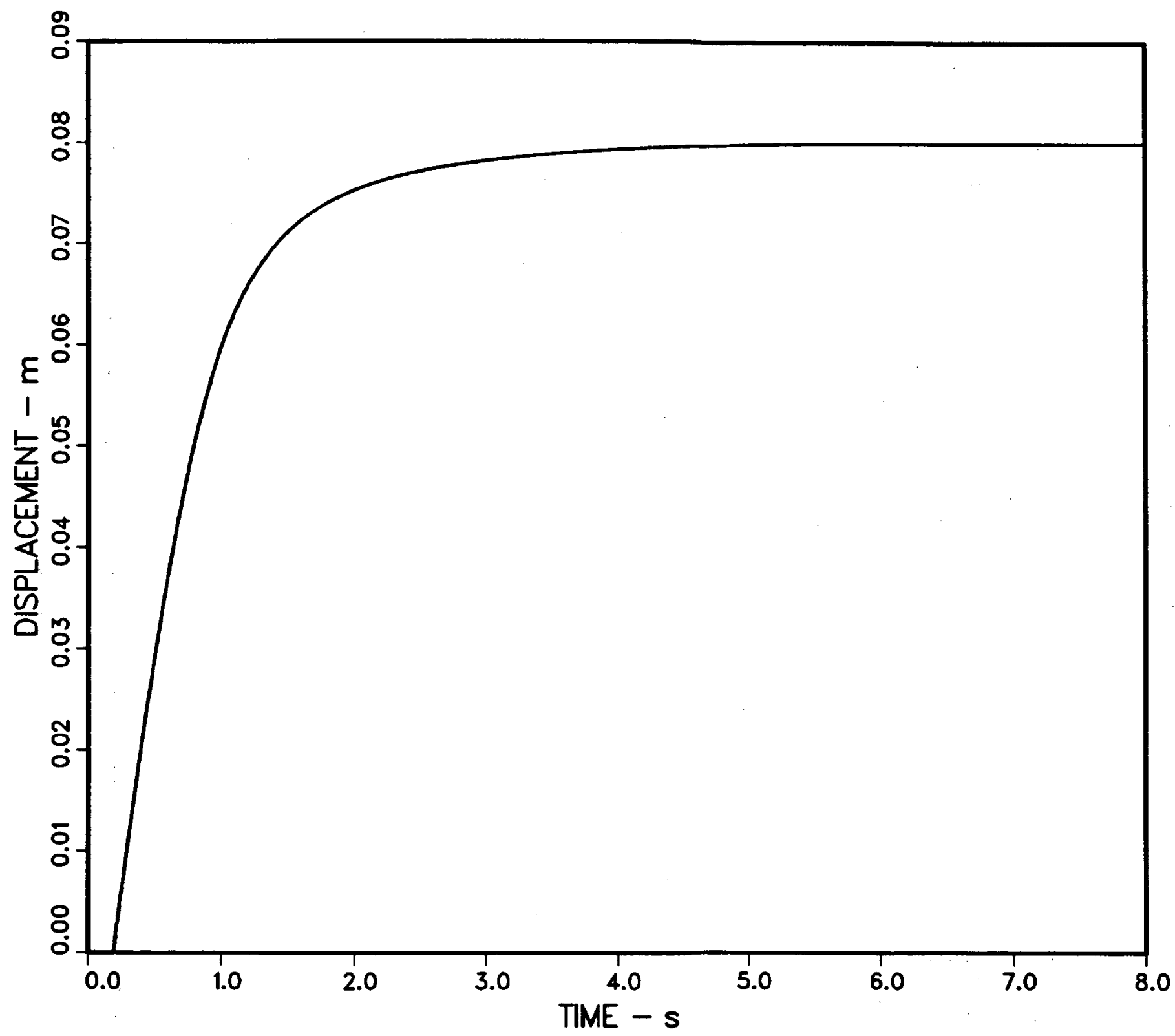

FIGURE 47. BLADDER DISPLACEMENT FOR EXAMPLE 9 


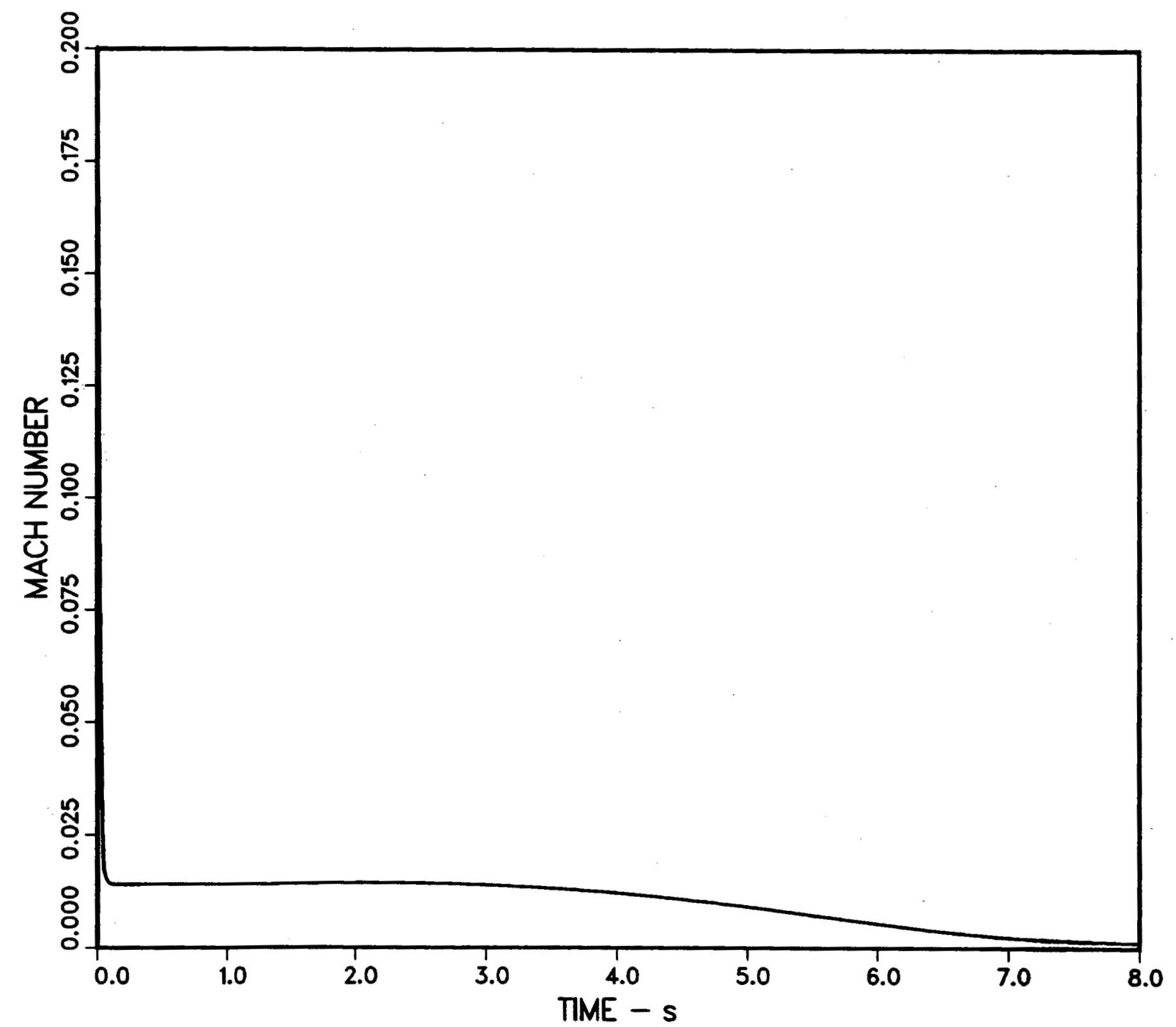

옹

FIGURE 48. FLOW COMPONENT MACH NUMBER VS. TIME 


$$
\triangle
$$


the deceleration portion of the transfer which accounts for nearly all of the transfer time. It should come as no surprise that a straight line drawn between the acceleration and deceleration curves has a slope of 30 , the value of the form loss coefficient for the flow component. 


\section{CONCLUDING REMARKS}

It is hoped that the nine example problems presented in sections II through $\mathbf{X}$ have provided potential TOPAZ users with an additional understanding of how to model complex gas flows through piping networks. Every effort was made to select examples which demonstrate the wide variety of problems that can be simulated with the code. Whenever possible, problems were selected for which analytical solutions presently exist, thus providing some measure of code validation.

Readers are reminded that the TOPAZ input files presented here represent only one way of modeling the examples. Component numbering, arrangement of the directives in the input file, etc. are in many cases arbitrary provided the simple rules outlined in the TOPAZ Users Manual [5] are followed.

TOPAZ provides a means of analyzing complex gas transfers systems with minimal knowledge of compressible flow, finite differences, and implicit numerical methods. Nevertheless, appropriate use of the code often depends on the user's understanding of the code's modeling limitations. It is hoped that the discussions provided in this document have served to acquaint potential TOPAZ users with an understanding of these limitations as well as an appreciation of the code's power. 


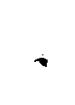




\section{REFERENCES}

1. W. S. Winters, "TOPAZ - A Computer Code for Modeling Heat Transfer and Fluid Flow in Arbitrary Networks of Pipes, Flow Branches, and Vessels," SAND83-8253, Sandia National Laboratories, Livermore, CA, January 1984.

2. W. S. Winters, "DRAC - User Friendly Computer Code for Modeling Transient Thermohydraulic Phenomena in Solar Receiver Tubing," SAND82-8744, Sandia National Laboratories, Livermore, CA, January 1983.

3. W. S. Winters and M. P. Kanouff, "Implementation of Empirical Total Pressure Loss Data into the DUCTFLO and TOPAZ Gas Transfer Codes," SAND84-8246, Sandia National Laboratories, Livermore, CA, November 1984.

4. L. R. Petzold, "A Description of DASSL: A Differential/Algebraic System Solver," SAND82-8637, Sandia National Laboratories, Livermore, CA, September 1982.

5. W. S. Winters, "TOPAZ - The Transient One-Dimensional Pipe Flow Analyzer: User's Manual," SAND85-8215, Sandia National Laboratories, Livermore, CA, July 1985.

6. P. J. Roache, "Computational Fluid Dynamics" Hermosa Publishers, Albuquerque, NM, p. 237, 1976.

7. D. R. Chenoweth, "Gas-Transfer Analysis Section F- -Approximate Unchoked Solutions for Arbitrary $V_{\infty} / V_{0}$ ", SAND74-8216, Sandia National Laboratories, Livermore, CA, November 1974.

8. S. Paolucci, "On the Filtering of Sound from the Navier-Stokes Equations," SAND828257, Sandia National Laboratories, CA, December 1982.

9. J. Kestin and J. S. Glass, "The Rapid Discharge of Gases from Vessels," Aircraft Engineering, 23, p. 300, 1951.

10. W. S. Winters, "Nonequilibrium Blowdown in Long Pipes," Ph.D. Thesis, The University of Michigan, Ann Arbor, MI, 1978.

11. R. D. Richtmyer and K. W. Morton, Difference Methods for Initial Value Problems, John Wiley \& Sons, New York, 1967.

12. A. H. Shapiro, The Dynamics and Thermodynamics of Compressible Fluid Flow, 1, John Wiley \& Sons, New York, 1953. 
13. H. L. Horison and J. G. Bollenger, Introduction to Automatic Controls, International Textbook Co., Scranton, PA, 1969.

14. Flow of Fluids, Technical Paper No. 410, Crane Co., 300 Park Avenue, New York, NY, 10022, 1980.

15. R. D. Belevins, Applied Fluid Dynamics Handbook, Van Nostrand Reinhold Company Inc., New York, NY, 1984. 
Los Alamos National Laboratory (5)

P. O. Box 1663

Los Alamos, NM 87544

Attn: J. Hopkins

E. H. Plassman

Bert Banks WX-5

D. J. Cagliostro, K-555

G. L. Clark B-265

Monsanto Research Corporation (4)

Mound Laboratory

P. O. Box 32

Miamisburg, OH 45343

Attn: Ken C. Phipps, SW233

W. R. Woods, Jr., SW202

W. W. Thomasson

D. Hobrock

Rockwell International

Rocky Flats Plant

Golden, CO 80401

Attn: James K. Roberts, Bldg. 750

E. I. Dupont De Nemours and Company, Inc. (3)

Savannah River Plant

Document Transfer Station 703-A

Aiken, SC 29808

Attn: Thomas M. Monahon Bldg. $234 \mathrm{H}$

Karl Angermann, Bldg. 773A

James J. Henteges, Bldg. $704 \mathrm{H}$

University of Utah

Dept. of Mechanical \& Industrial Engineering

Mechanical Eng. Bldg. (MEB) 3008

Salt Lake City, UT 84112

Attn: Prof. R. F. Boehm

R. T. Langland, LLNL, L-90

A. B. Copeland, LLNL, L-122

G. L. Goudreau, LLNL, L-122

S. J. Sackett, LLNL, L-122

A. B. Shapiro, LLNL, L-122

W. D. Harvey, LLNL, L-125

W. H. Hubbell, LLNL, L125 
G. T. Mannell, LLNL, L-125

D. R. Selway, LLNL, L-125

G. M. Thomas, LLNL, L-125

L. R. Petzold, LLNL, L-316

B. R. Bowman, LLNL, L-390

W. J. Comfort III, LLNL, L-390

J. L. Minkler, LLNL, L-452

C. S. Landram, LLNL, L-470

W. A. Sebrell, 0311

J. P. Van Devender, 1200; Attn: M. B. Cowan, 1220

J. E. Powell, 1230

W. C. Luth, 1540

J. W. Nunziato, 1510

G. G. Weigand, 1511

J. C. Cummings, 1512

D. W. Larson, 1513

S. M. Kempka, 1513

J. C. Crawford, 5100; Attn: C. C. Burks, 5110

W. E. Alzheimer, 5120

K. D. Hardin, 5150

G. R. Otey, 5160

V. L. Dugan, 6200; Attn: R. K. Traeger, 6240

B. W. Marshall, 6250

A. W. Snyder, 6400; Attn: J. W. Hickman, 6410

J. V. Walker, 6420

D. A. Dahlgren, 6444; Attn: L. D. Buxton, 6444

R. K. Byers, 6444

L. Kmetyk, 6444

D. M. Olson, $7500 ;$ Attn: T. B. Lane, 7530

R. S. Claassen, 8000; Attn: D. L. Hartley, 8300

E. E. Ives, 8100; Attn: J. D. Gilson, 8130

C. T. Yokomizo, 8132

J. D. Wright, 8150

J. E. Marion, 8151

D. J. Bohrer, 8160

J. S. Kraabel, 8132

A. S. Rivenes, 8162 ; Attn: B. D. Pontsler, 8162

S. White, 8162

W. G. Wilson, 8163 ; Attn: D. Beyer, 8163

K. E. Carbiener, 8163

A. N. Blackwell, 8200; Attn:R. D. Cozine, 8250

P. E. Brewer, 8260

R. C. Dougherty, 8270

W. D. Wilson, 8230; Attn: J. S. Binkley, 8233 
'C. W. Robinson, 8240; Attn: G. A. Benedetti, 8241

M. L. Callabresi, 8242

C. M. Hartwig, 8244

M. R. Birnbaum, 8243

C. E. Hackett, 8244

D. R. Chenoweth, 8244

S. K. Griffiths, 8244

M. P. Kanouff, 8244

B. A. Meyer, 8244

R. J. Kee, 8245

G. H. Evans, 8245

W. L. Hermina, 8245

W. G. Houf, 8245

C. A. LaJeunesse, 8245

A. E. Lutz, 8245

W. E. Mason, 8245

S. Paolucci, 8245

W. S. Winters, $8245(40)$

P. L. Mattern, 8350; Attn: S. C. Johnston, 8351

M. Lapp, 8352

R. E. Palmer, 8354

W. J. McLean, 8360; Attn: D. Hardesty, 8361

T. Bramlette, 8362

M. Dyer, 8362

B. R. Sanders, 8363

R. C. Wayne, $8400 ;$ Attn: L. D. Bertholf, 8430

D. J. Havlik, 8431; Attn: M. A brams, 8431

H. Hanser, 8440; Attn: P. Gildea, 8443

A. J. West, 8441

A. R. Willis, 8444

L. W. Derickson, 8441

B. L. Haroldson, 8441

W. R. Hoover, 8442

E. T. Cull, 8445

R. L. Rinne, 8470; Attn: A. C. Skinrood, 8471

P. K. Falcone, 8471

J. C. Swearengen, 8742

M. E. John, 8478

R. J. Gallagher, 8474

Publications Division, for TIC (30)

Publications Division 8265/Technical Library Processes Division, 3141

Technical Library Processes Division, 3141 (3)

P. W. Dean, 8024-2, for Central Technical Files (3) 
